

\section{Propositions}

1. There is no general net yield enhancing effect of an increased level of soil organic matter.

(this thesis)

2. Ecological mechanisms observed in greenhouse experiments are often not relevant in field scenarios.

(this thesis)

3. Diederik Stapel's contribution to science would have been smaller if he had carried out his research honestly.

4. Understanding of ecosystem services would benefit more from hiring philosophers rather than hiring more ecologists.

5. As all variation in nature is continuous, true categorical variables do not exist.

6. A strict use of indicators has a negative effect on reaching the underlying goals.

7. Personalization of information leads to more polarization.

8. There is no relationship between societal benefits and financial profits.

\section{Propositions belonging to the thesis}

'It depends: effects of soil organic matter in aboveground-belowground interactions in agro-ecosystems'

Stijn van Gils

Wageningen, 13 September 2017.

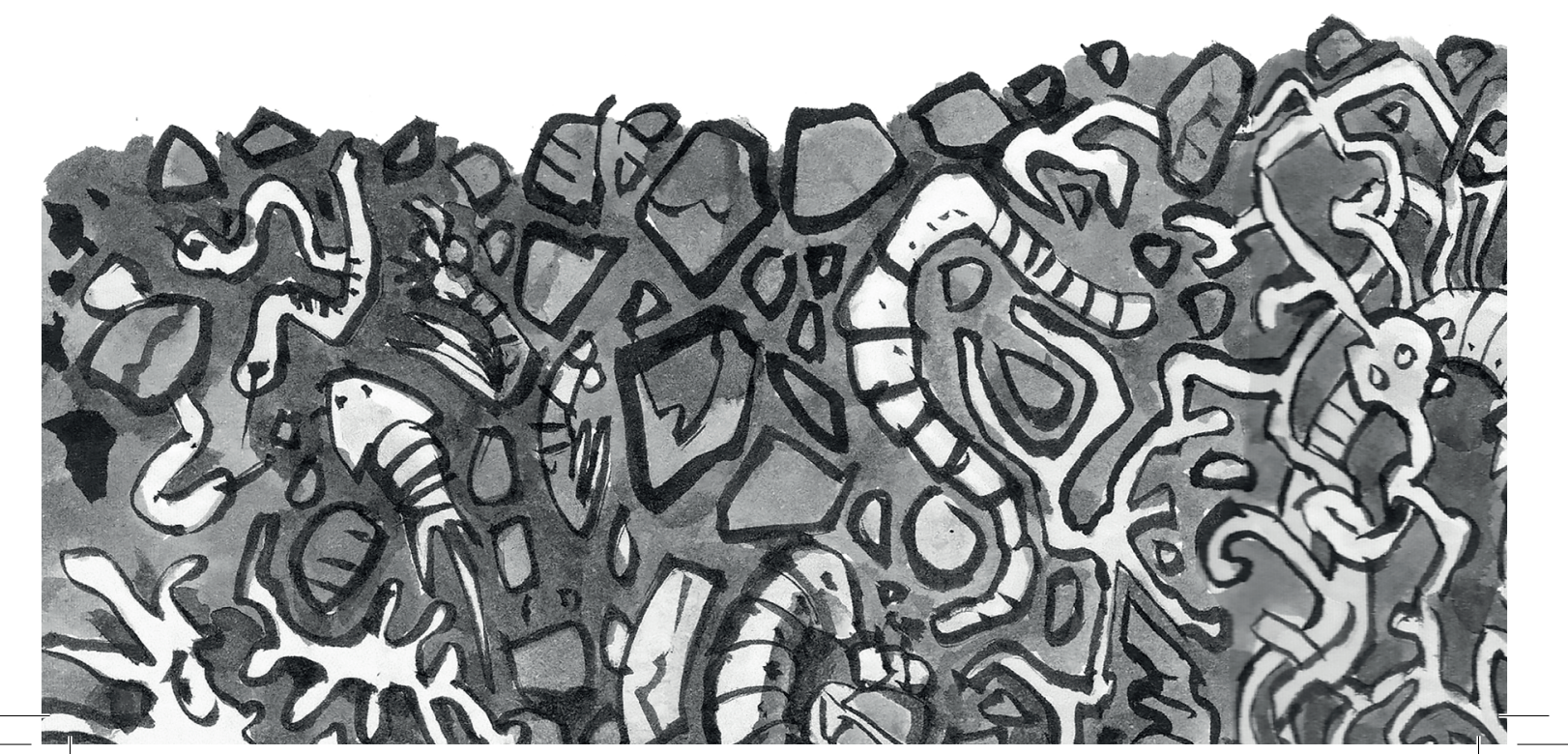


It depends:

effects of soil organic matter in aboveground-

belowground interactions in agro-ecosystems 


\section{Thesis committee}

\section{Promotor}

Prof. Dr W.H. van der Putten

Special Professor Functional Biodiversity

Wageningen University \& Research

And Netherlands Institute of Ecology

Promotor

Prof. Dr D. Kleijn

Professor Plant Ecology and Nature Conservation

Plant Ecology and Nature Conservation Group

Wageningen University \& Research

\section{Other members}

Prof. Dr. MK van Ittersum

Prof. Dr JJA van Loon

Dr. MM Pulleman

Prof. Dr HG Smith

This research was conducted under the auspices of the C.T. de Wit Graduate School for Production Ecology \& Resource Conservation (PE\&RC) 


\title{
It depends: effects of soil organic matter in aboveground- belowground interactions in agro-ecosystems
}

\section{Stijn Herman van Gils}

\author{
Thesis \\ submitted in fulfilment of the requirements for the degree of doctor \\ at Wageningen University \\ by the authority of the Rector Magnificus \\ Prof. Dr M.J. Kropff, \\ in the presence of the \\ Thesis Committee appointed by the Academic Board \\ to be defended in public \\ on Wednesday 13 September 2017 \\ at 4 p.m. in the Aula.
}




\section{Stijn Herman van Gils}

It depends: effects of soil organic matter in aboveground-belowground interactions in agro-ecosystems 178 pages.

$\mathrm{PhD}$ thesis, Wageningen University, Wageningen, NL (2017)

With references, with summaries in Dutch and English

ISBN: 978-94-6343-652-6

DOI: $10.18174 / 420734$ 


\section{Content}

Abstract 8

Chapter 1. General introduction 9

Chapter 2. Soil pathogen-aphid interactions under differences in soil organic matter and mineral fertilizer.....

Chapter 3. Drought and soil organic matter modify fertilization effects on aphid performance in wheat

Chapter 4. Soil organic matter effects on nutrient provisioning, pest suppression, and crop yield 57

Chapter 5. Can above-ground ecosystem services compensate for reduced fertilizer input and soil organic matter in annual crops?.

Chapter 6. Soil biotic and abiotic properties during transition from conventional to organic arable farming and potential consequences for plant and aphid performance.

Chapter 7. General discussion and synthesis

References 142

Summary 156

Nederlandstalige samenvatting. 160

Acknowledgements 164

Affiliation of co-authors. 171

Curriculum vitae 173

PE\&RC Training and Education Statement 174 


\section{Abstract}

Over the last decades agricultural production increased drastically due to the use of external inputs.

However, the use of external inputs has high environmental costs and may negatively influence ecosystem processes such as pollination and pest control that underpin agricultural production. Soil organic matter has been proposed as a potential alternative to external inputs as it relates to multiple yield promoting ecosystem processes. The aim of my thesis is to assess whether and how soil organic matter content alters the effect of some ecosystem processes and external inputs on crop yield. I examined whether soil organic matter alters biomass of wheat and oilseed rape under fertilizer supply. Other biotic and abiotic factors that operate at different spatial and temporal scales are also included in some of these experiments. I found that under controlled conditions soil organic matter may reduce the positive effect of mineral fertilizer supply on crop biomass. The reduction changed with the presence or absence of a pathogenic root fungus, but not with drought stress. Moreover, soil organic matter enhances performance of aphids under controlled greenhouse conditions, but the enhancement was less than fertilizer supply. None of these controlled experiments, however, showed that soil organic matter can be an alternative to mineral fertilizer supply. Under field conditions soil organic matter did not strongly affect plant nutrient availability or performances of aphid and its natural enemies. The relation between soil organic matter and plant biomass in a greenhouse experiment did not change with organic management or the duration of it, neither did it change with pollinator visitation rate, an ecosystem process that is managed on the landscape scale. These results suggest that soil organic matter may relate to ecosystem services that influence crop yield, whereas these relations might not be significant under field conditions. Collectively, all these results suggest that the relation between soil organic matter content and ecosystem processes that benefit crop yield is highly context dependent. I propose future research may focus on (1) the quality of soil organic matter rather than the content per se and (2) the relation between soil organic matter content and crop yield under realistic conditions in a longer term. 
Chapter 1

General introduction

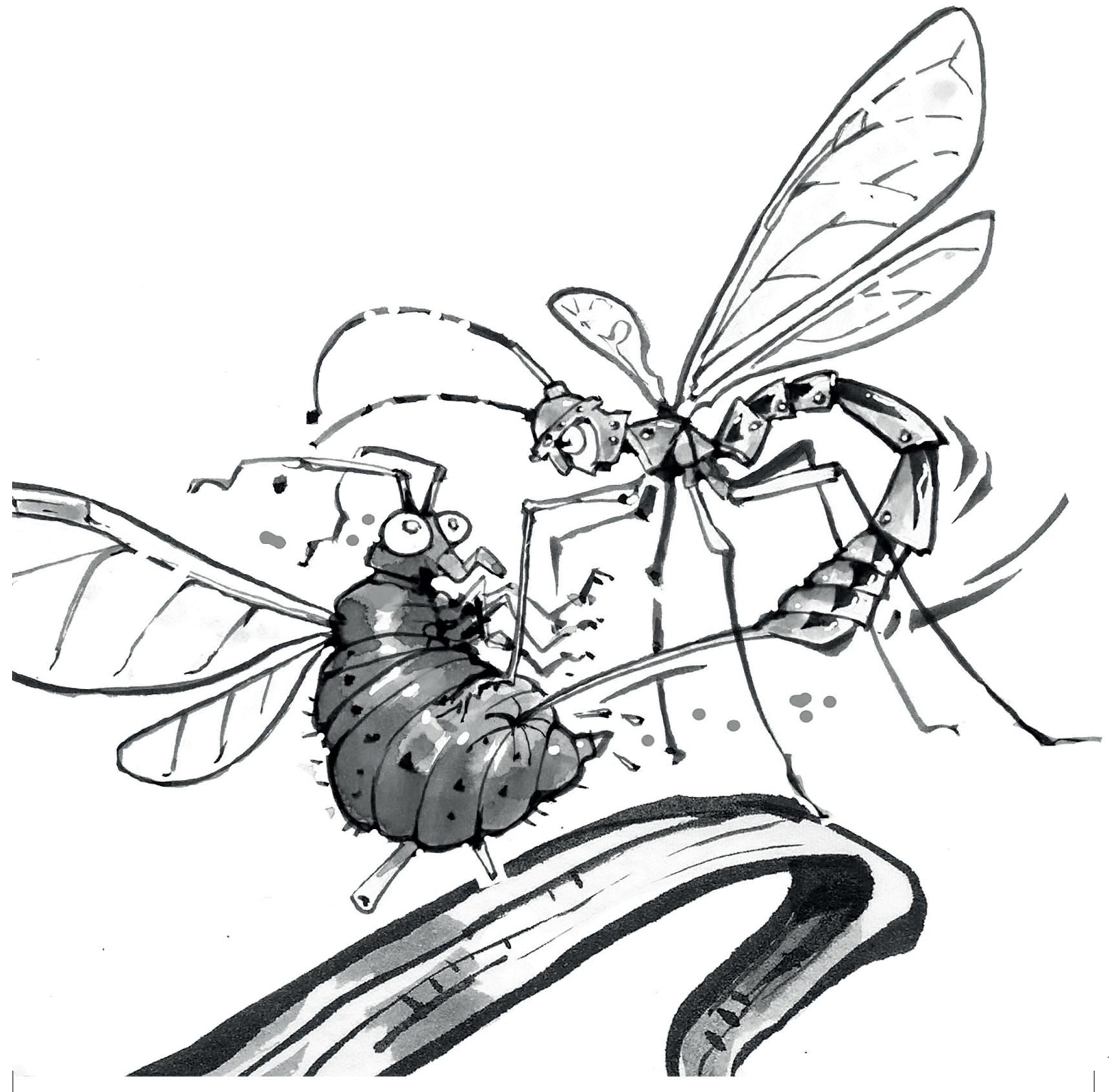




\section{Chapter 1}

Over the last decades the agricultural production in the world had been rising dramatically. During this so called 'green revolution', use of nitrogen fertilization and pesticides increased, leading to a substantial increase in food security for millions of people, but at high environmental costs (Tilman et al. 2001). For example, land use intensification let to a decline in populations of various farmland birds (Wretenberg et al. 2006), a decrease in pollinator abundance (Garibaldi et al. 2011) and a decrease in soil biodiversity (Tsiafouli et al. 2015). In addition, land use intensification and associated biodiversity loss are often linked to declines in ecosystem services that benefit agricultural production, such as insect pollination (Garibaldi et al. 2011), pest control (Rusch et al. 2010; Veres et al. 2013) and long-term nutrient cycling (de Vries et al. 2013).

Roughly, land use intensification is therefore linked to an increase in food production, since external inputs such as mineral fertilizer (also named synthetic- or artificial fertilizer) supply lead to higher yields. In addition, land use intensification also has negative influences on ecosystem services that do enhance productivity, implying that land use intensification causes both positive and negative effects on crop production. In this thesis, I unravel how multiple ecosystem services affect crop yield in conjunction, under different elements of land use intensification, including fertilizer supply.

\section{Redesign of the food system}

Predictions show that future agricultural production will not meet the needs of the growing human population by 2050 (Ray et al. 2013) and that the crop production of some important crops will even decline in the future due to climate change (Lobell, Schlenker \& Costa-Roberts 2011). Moreover, a global study in multiple countries, showed that in almost $40 \%$ of the studied area wheat yields are already no longer improving (Ray et al. 2012). However, it has been concluded that there is a potential to further increase food production if it is possible to create a win-win situation: intensifying agriculture to increase food production, while not interfering or even positively influencing ecosystem services (Bommarco, Kleijn \& Potts 2013). For an effective redesign of the food system, a reconsideration of all factors that affect productivity may be needed (Garnett et al. 2013). Such a reconsideration would include both the use of technical advantages as well as the use of natural processes and combinations between these two (de Haan, Sukkel \& Stilma 2010). 
Crop plants would most likely be key in any reconsideration of the food system, as the world's food system is steered by plants that provide feed for life stock and food for humans. These plants are influenced by multiple factors that occur aboveground or belowground. Aboveground factors that influence yield are for instance insect pollination and herbivory from aboveground organisms (Losey \& Vaughan 2006; Garibaldi et al. 2013). Belowground factors that influence yield are for instance water holding capacity, nutrient provision, soil structure and herbivory from belowground organisms (Bardgett \& van der Putten 2014). To increase agricultural production one could manipulate the plant's response to aboveground and belowground factors, for instance by selecting another crop variety that is more drought resistant (Huang, Pray \& Rozelle 2002). Another way to enhance production is by altering yield influencing factors directly, for instance by enhancing soil structure or indirectly, for instance by enhancing natural enemy populations to reduce the pest abundance (Veres et al. 2013). These yield influencing factors can be managed belowground - such as pest control provided by natural belowground enemies via altered soil conditions (Korthals et al. 2014) - as well as aboveground - such as enhancing pollinator abundance to improve the visitation rate by pollinators (Steffan-Dewenter \& Tscharntke 1999).

\section{Optimizing multiple aboveground and belowground factors}

Farming implies the optimization of these different aboveground and belowground factors in order to improve yield. Although improvements still could be made and existing knowledge is often not implemented, it is relatively well known how these different aboveground and belowground factors could be enhanced in order to increase yield (Bommarco, Kleijn \& Potts 2013). Belowground, for instance, it is known that micro-organisms such as the plant beneficial arbuscular mycorrhiza and a diverse and abundant soil microbial community and subsequently lower pathogen abundance could improve yield (Garbeva, van Veen \& van Elsas 2004; Bender \& van der Heijden 2015). It is also known that these organisms could be enhanced by for instance the use of organic manure (Gryndler et al. 2006). Aboveground, more semi-natural habitat in the surrounding of croplands promotes populations of natural enemies of pests and thereby indirectly yield (Thies \& Tscharntke 1999; Rusch 


\section{Chapter 1}

et al. 2013). An increase in semi-natural habitat also enhances pollinator abundance and thereby also indirectly yield (Kennedy et al. 2013).

Whereas there is understanding on how different individual factors increase yield, it is not well studied how aboveground and belowground factors may interact with each other, potentially altering the net effect on yield. Roughly, it is expected that such interactions are important (Bennett, Peterson \& Gordon 2009) and few empirical studies also prove that this is the case. For instance, Lundin et al. (2013) found that under higher levels of natural enemies of pests, the effect of pollination increases. To optimize aboveground and belowground factors that influence yield, it is necessary to have a substantially deeper understanding on the interactions among these factors on yield (Bommarco, Kleijn \& Potts 2013).

\section{Soil organic matter as key component}

A key component in the optimization of aboveground and belowground yield influencing factors is soil organic matter (SOM) (Bommarco, Kleijn \& Potts 2013). An increase of the SOM content could potentially replace the supply mineral fertilizers, at least partially (Brady et al. 2015). Apart from its effect on the ecosystem service nutrient provision, SOM also relates to other ecosystem services and properties, such as carbon sequestration, soil structure, water holding capacity, and pest suppression (Hendrix, Coleman \& Crossley 1992; Scheu 2001; Lal 2004b). Enhancing the SOM content can therefore be seen as a way to enhance multiple ecosystem services at once.

Soil organic matter refers to all organic materials in a soil that are at least partially decomposed. It can for instance be enhanced by the application of organic manure or compost, or by measures to retain the existing SOM in the soil (Stockfisch, Forstreuter \& Ehlers 1999; Kaiser, Ellerbrock \& Gerke 2007). As approximately $50 \%$ of the materials in SOM are carbon, the term SOM and soil organic carbon (SOC) are often intermixed; even though not carbon but other components, such as nitrogen, phosphorous and potassium are the driver for the ecosystem service nutrient provision (Fageria 2012). Some functions of SOC are related to its property: a higher SOM content implies a higher a carbon stock and thus more carbon sequestration (Lal 2004b); a higher SOC content changes the soil structure 
and thereby increases the water holding capacity (Fageria 2012). Other aspects of SOM, however, relate especially to de decomposition of SOM, such as the decomposition of soil organic matter to plant available nutrients (Janzen 2006).

\section{Aboveground-belowground interactions}

\section{Aboveground and belowground factors are interlinked via plants}

It is commonly acknowledged that aboveground and belowground factors are interlinked, mediated by a plant that occurs both in an aboveground and a belowground environment (van der Putten, Vet \& Harvey 2001). In various studies it has been shown that events that happen belowground may lead to a chemical reaction in the whole plant, subsequently leading to an altered performance of organisms that interact aboveground with the plant. Likewise, also aboveground factors may lead to a chemical reaction in the plant,that affects belowground tissues, subsequently affecting organisms that interact belowground with the plant. Over the last decades, the evidence for interactions between the aboveground and the belowground environment had been growing substantially (Wardle et al. 2004). It has been stated that aboveground-belowground interactions could boost crop production at low costs, however, it is not well studied how these aboveground-belowground interactions could be management in practice (Orrell \& Bennett 2013).

\section{Effects of abiotic belowground factors on aboveground processes}

Aboveground organisms could be affected by belowground abiotic factors. For instance, nutrients or water provided by the belowground system are generally taken up by the whole plant leading to an altered chemical composition aboveground, which subsequently leads to an altered performance of aboveground organisms (Garratt, Wright \& Leather 2011). Soil nutrient management may alter the temporal availability of nutrients and subsequently the chemical composition of the plant. This could subsequently lead to a differential response of aboveground herbivores (Hasken \& Poehling 1995). Soil structure management may also alter the water holding capacity of the soil, thereby influencing aboveground plant tissue chemistry and the performance of aboveground insects (Tariq et al. 2012). 


\section{Chapter 1}

It is expected that SOM content affects aboveground-belowground interactions. Under high SOM content, plants may be exposed to lower water stress than under a low SOM content, as SOM increases the water holding capacity of the soil (Hudson 1994). Water stress in plants can, subsequently, limit the performance of insects such as aphids (Huberty \& Denno 2004), while it may accelerate the performance of other herbivores (Fuhrer 2003). Mineral fertilizer, moreover, could substantially enhance the performance of insect herbivores (Butler, Garratt \& Leather 2012). Under a higher SOM content, however, nutrients from mineral fertilizer might be releases at a different temporal dynamics, potentially leading to an altered fertilizer effect on aboveground herbivores (Hasken \& Poehling 1995). It is therefore expected that abiotic factors, such as water availability and nutrient management will have different effects on plants and aphids under a different SOM content, but this is not well studied.

\section{Effects of biotic belowground factors on aboveground processes}

Much work on aboveground-belowground interactions has been focusing on the effect of belowground organisms on aboveground organisms. It is now widely acknowledged that interactions between plants and belowground organisms may lead to a systemic reaction in the whole plant which includes aboveground tissues, subsequently followed by an altered performance of aboveground organisms (Van Geem et al. 2015). These aboveground-belowground interactions could be induced by various groups of organism, such as herbivorous insects (Soler et al. 2005), nematodes (Wondafrash, Van Dam \& Tytgat 2013), mycorrhizal fungi (Kempel et al. 2010), and whole soil communities (Kos et al. 2015). The induction of the plant by a belowground organism or community may lead not only to an altered performance of aboveground antagonists, such as herbivores, but may also affect higher tropic levels such as parasitoids (Bezemer et al. 2005) and mutualists such as pollinators (Poveda et al. 2003). These aboveground-belowground interactions, may even occur in a next generation of the focal plant (Kostenko et al. 2012).

Plants defend themselves against belowground pathogens by the use of constitutive and induced defence and by physical structures, such as spines, as well as chemical matters of defence (Fortuna et al. 2014). Induced chemical defences are partially regulated via the Jasmonic acid (JA) and Salicylic 
acid (SA) signalling pathway (de Vos et al. 2005). Necrotrophic pathogens and leaf chewing herbivores are generally defended by the JA pathway, whereas biotrophic pathogens and phloem feeding herbivores are usually defended via the SA pathway (Moran \& Thompson 2001; Glazebrook 2005). Both pathways, moreover, operate in a crosstalk with each other, meaning that an enhancement of JA, for instance induced by a necrotrophic pathogen, often leads to a suppression of SA, for instance benefitting phloem feeders, and vice versa (Felton \& Korth 2000). In addition to the defence pathway, a belowground pathogen may also change the nutrient composition of the plant and thereby indirectly aboveground herbivores (Barbosa, Krischik \& Jones 1991).

\section{Effects of SOM and biotic belowground factors on aboveground processes}

Nutrient management, for instance by enhancing SOM content or by the supply of mineral fertilizer could affect the performance of belowground pathogens (Wall et al. 1994). An increase in SOM content, moreover, is linked to an increase in the total abundance of belowground organisms (Fierer et al. 2009). Many of these organisms emit volatile organic compounds, potentially hindering the growth of soil pathogens (Garbeva, van Veen \& van Elsas 2004). Soil conditions, such as fertilizer supply and SOM management, could therefore not only alter the performance of plants and their aboveground herbivores directly, but also indirectly via effect on belowground pathogens. It is largely unknown how SOM content alters the interaction between soil pathogens and aboveground herbivores.

\section{Effects of SOM under field conditions}

Under field conditions, soil conditions such as SOM, are influencing the performance of aboveground and belowground pathogens in more ways than under controlled conditions. Besides the previously described effect of SOM on belowground pathogens via volatile organic compounds, and the effect of SOM on nutrient dynamics and thereby pest performance, SOM content may also affect aboveground herbivores via the decomposition pathway. A higher SOM content leads to more decomposition activity. Species involved in the decomposition of SOM are predated by some generalist predators. These general predators, moreover, also partially feed on insect pests, such as aphids (Birkhofer et al. 2011). As the detrital food chain contains more energy than the herbivore system, a relatively small 


\section{Chapter 1}

change in the detrital food chain can have relatively large consequences for the herbivore food chain (Scheu 2001).

Whereas relatively much is known about potential mechanisms explaining pest suppression, little is known how important pest suppression from SOM under field conditions is on yield. It is also not well known how important these effects of pest suppression are, compared to nutrient effects of SOM and fertilization that also contribute to yield. Often it is assumed that effects of multiple components that contribute to yield are additive (Seppelt et al. 2011), but available literature does not support that claim (Bartomeus, Gagic \& Bommarco 2015). Experiments under realistic conditions, could help to understand the relative importance of pests, enemies of those pests and nutrient provision for agricultural production (van Grunsven \& Liefting 2015).

\section{Scales}

Spatial

Aboveground-belowground interactions do take place at different scales, as belowground processes are usually determined on a much finer scale than aboveground processes, which has implications for the management strategies of aboveground-belowground interactions (Tamburini et al. 2016). Soil management mainly takes place on the field itself; ploughing or supply of mineral fertilizer, for instance, mainly affect soil structure and nutrient availability on a specific location in the field itself. Due to technological advantages, soil management can be more and more targeted to a specific location, subsequently enhancing yield (Gebbers \& Adamchuk 2010). Aboveground processes, however, are mainly managed outside the focal arable field. Bees and hoverflies are, for instance, largely influenced by the landscape around the field (Kennedy et al. 2013). Semi-natural habitats such as flower strips in the surroundings of a crop can enhance the number of pollinators on a crop (Scheper et al. 2015). The abundance of natural enemies of pests, moreover, is also enhanced by the abundance of semi natural habitat (Veres et al. 2013). An investment in the amount of semi-natural habitat nearby a crop, could therefore lead to a synergistic effect between pest control and pollination on crop yield (Otieno et al. 2011; Boreux et al. 2013; Woodcock et al. 2014). 
The management of wild pollinators is mainly seen as a landscape scale intervention that goes beyond the management of an individual farm (Tscharntke et al. 2005b). The SOM content and mineral fertilizer supply, however, may also have an effect on aboveground mutualists such as pollinators. Under higher nutrient availability, either from SOM or fertilizer, plants produce more flowers and potentially also emit more volatile organic compounds (Lau \& Stephenson 1993; Klatt et al. 2013). A higher number of flowers or more volatile organic compounds, subsequently, attract more pollinators such as bees and hoverflies (Makino, Ohashi \& Sakai 2007), suggesting that management of soil conditions potentially change the effect of pollinators (Marini et al. 2015). To obtain the highest benefit from pollination, influences of landscapes might be considered in conjunction with the effects of management of the soil. It is, however, empirically not well studied whether fine scale soil management affects the effect of aboveground processes such as pollination (Tamburini et al. 2016).

\section{Temporal}

Relatively little is known on the time scale under which soil management has in influence on aboveground organisms. As some fundamental aspects of the soil may be affected by a management change - such as a conversion from conventional to organic agriculture - it is to be expected that shifts in the soil community also take place in a gradual time frame (Marriott \& Wander 2006). Recently, Morriën et al. (2017) found that after restoration of natural grasslands the trophic interactions in the soil are shifting towards a fungal dominated network in a time frame of several decades. It is, however, understudied how long it takes before a soil community is converted from a conventional type towards an organic type.

Organic arable management implies a management free of mineral fertilizers and pesticides (van Diepeningen et al. 2006). Instead, organic famers depend on organic inputs such as manure and compost as well as natural ways to manage pests. This type of management is known to have an effect on the soil. Organically managed soils generally have more SOM, more microbial diversity and substantially lower yield (Maeder et al. 2002; Syswerda et al. 2011). A more diverse microbial community, however, may also relate to higher yield of higher quality (Bender \& van der Heijden 2015). How fast SOM accumulates and how a soil community develops over time since conversion to 


\section{Chapter 1}

organic agriculture is unknown. Likewise it is also unknown how higher SOM content and a higher microbial diversity influences yield and aboveground organisms in organic systems over a longer time frame.

\section{Research objective and thesis outline}

In this thesis I try to unravel how multiple aboveground and belowground ecosystem services affect crop yield in conjunction. More specifically, I studied whether and how SOM alters the effect of ecosystem services and external inputs on crop yield. I studied whether it is possible to partially replace yield promoting external inputs that trade-off with yield promoting ecosystem services, by optimizing soil and landscape conditions (Bommarco, Kleijn \& Potts 2013). It is therefore implicitly a study of interactions among ecosystem services, ecosystem properties, and external inputs on crop yield. The approach I used is new; although farming implies the optimization of ecosystem services and other crop growth promoting factors, interactions among ecosystem services are often not taken into consideration (Bennett, Peterson \& Gordon 2009).

I performed my research under the context of the existing agricultural practices in Europe or under the context of experimental (greenhouse) conditions aimed to mimic agricultural conditions in Europe. I made use of several approaches, being a correlative field approach, a field experiment, a semi-field experiment and a greenhouse experiment. For all my experiments I made use of two different crop species: wheat (Triticum aestivum) oilseed rape (Brassica napus, also known as canola).

In Chapter 2 I studied how biotic and abiotic factors in combination affect the interaction between Triticum aestivum and Sitobion avenae. For this greenhouse experiment, I used the necrotrophic root fungus Rhizotonia solani under high land low SOM content conditions and with and without mineral fertilizer supply. I measured how these factors influenced plant quality, biomass and aphids.

In Chapter 3 I studied how abiotic soil conditions may affect the interaction between Triticum aestivum and the aphid Sitobion avenae. For this greenhouse experiment, I tested how two levels of SOM content, fertilizer supply and drought affected the performance of plants and aphids. This study 
mimics how enhancement of soil organic matter affects wheat growth under a drought climate change scenario.

For Chapter 4 I studied how SOM content and fertilizer supply affected yield of Triticum aestivum under field conditions. In addition, I tested how these soil conditions related to mineralization potential and abundance of aphids (mainly Sitobion avenae) and its natural predators. This field experiment was performed in paired fields with high and low SOM content across four different countries.

In Chapter 5 I studied how seed production of the partially insect pollinated crop Brassica napus is influenced by processed that occur directly around the plant and on landscape scale. For this semi-field experiment I grew plants under high and low SOM content and with and without mineral fertilizer supply. Subsequently, I placed these plants in landscapes that formed a gradient in pollinator visitation rate and, independently, in pest pressure. I tested how these variables affected seed weight in conjunction and thus whether soil conditions alter the yield influencing effect of pollinator visitation rate.

In Chapter 6 I investigated how the effect of management - being organic or conventional farming on crop growth changes over time. For this greenhouse experiment I collected soils from conventionally farmed fields and from fields that were for a shorter or longer period of time converted into organic agriculture. I tested whether duration of organic farming affected biomass of Triticum aestivum and the interactions between this focal plant and the aphid Sitobion avenae.

Finally, in Chapter 7 I place my results in a wider context and I draw general conclusions from my overall $\mathrm{PhD}$ project. 
Chapter 1

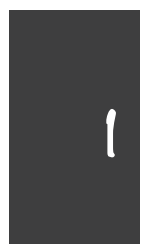




\section{Chapter 2}

\section{Soil pathogen-aphid interactions under differences in soil organic matter and mineral fertilizer}

Stijn van Gils*, Giovanni Tamburini*, Lorenzo Marini, Arjen Biere, Maaike van Agtmaal, Olaf Tyc,

Martine Kos, David Kleijn and Wim H. van der Putten

*Authors contributed equally to this study.

Published in:

PLoS ONE (2017)

DOI: 10.1371/journal.pone.0179695

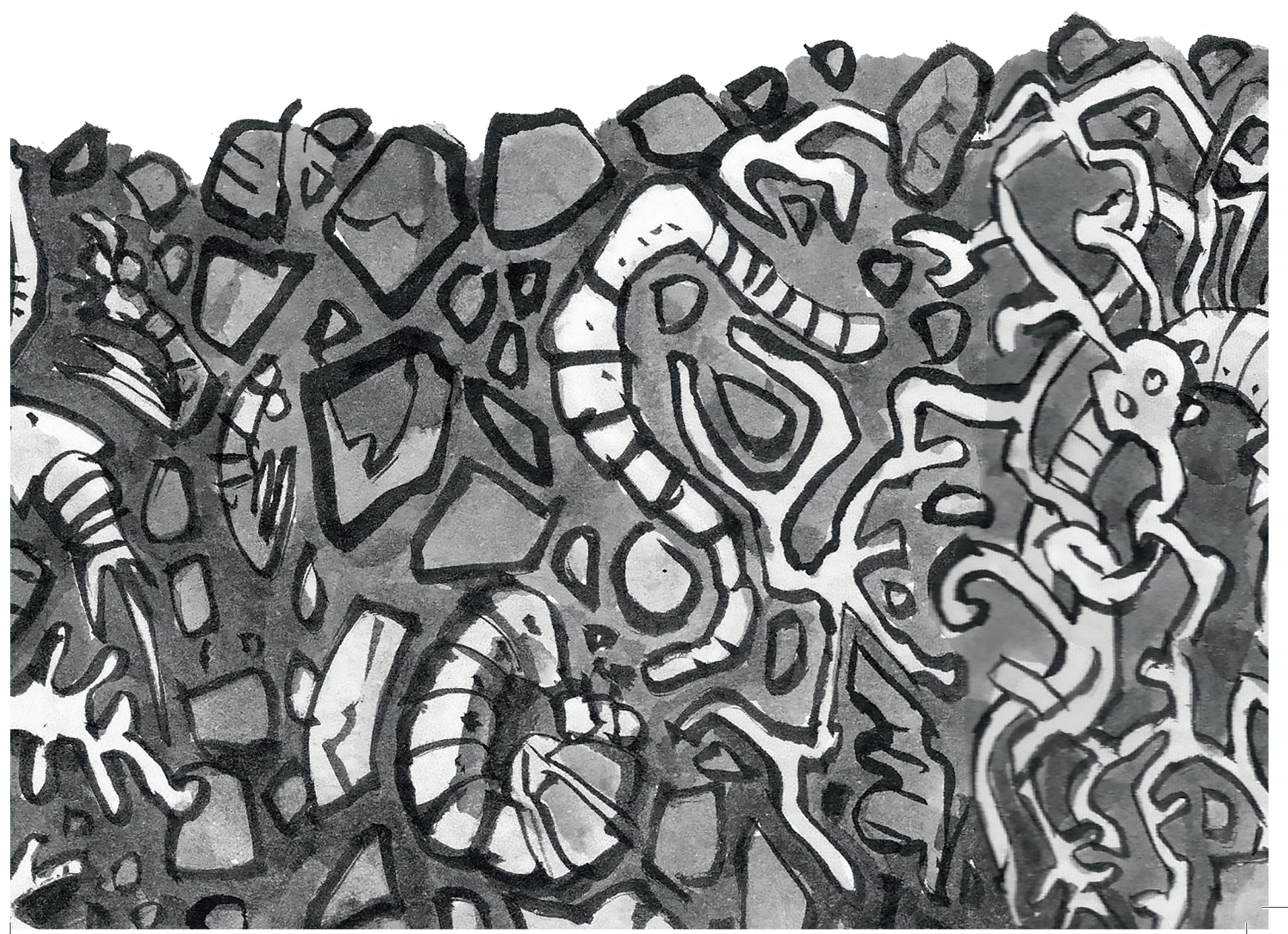




\section{Chapter 2}

\section{Abstract}

There is increasing evidence showing that microbes can influence plant-insect interactions. In addition, various studies have shown that aboveground pathogens can alter the interactions between plants and insects. However, little is known about the role of soil-borne pathogens in plant-insect interactions. It is also not known how environmental conditions, that steer the performance of soilborne pathogens, might influence these microbe-plant-insect interactions. Here, we studied effects of the soil-borne pathogen Rhizoctonia solani on aphids (Sitobion avenae) using wheat (Triticum aestivum) as a host. In a greenhouse experiment, we tested how different levels of soil organic matter (SOM) and fertilizer addition influence the interactions between plants and aphids. To examine the influence of the existing soil microbiome on the pathogen effects, we used both unsterilized field soil and sterilized field soil. In unsterilized soil with low SOM content, $R$. solani addition had a negative effect on aphid biomass, whereas it enhanced aphid biomass in soil with high SOM content. In sterilized soil, however, aphid biomass was enhanced by R. solani addition and by high SOM content. Plant biomass was enhanced by fertilizer addition, but only when SOM content was low, or in the absence of $R$. solani. We conclude that belowground pathogens influence aphid performance and that the effect of soil pathogens on aphids can be more positive in the absence of a soil microbiome. This implies that experiments studying the effect of pathogens under sterile conditions might not represent realistic interactions. Moreover, pathogen-plant-aphid interactions can be more positive for aphids under high SOM conditions. We recommend that soil conditions should be taken into account in the study of microbe-plant-insect interactions.

\section{Introduction}

The importance of aboveground-belowground invertebrate interactions in plant defence has been well acknowledged (van der Putten, Vet \& Harvey 2001; Bezemer \& Van Dam 2005; Johnson et al. 2012; Tscharntke et al. 2012). Belowground herbivory on plant roots may induce resistance or susceptibility in plant tissues to aboveground herbivores, as well as influence interactions with organisms at higher trophic levels (Bezemer et al. 2005). Aboveground-aboveground interactions between microbes and insects mediated by the plant have also been well acknowledged (de Vos et al. 2005). However, only recently, interest in plant-mediated above-belowground interactions involving microbes and insects 
has emerged (Biere \& Bennett 2013), mainly focusing on plant-mediated interactions between aboveground insects and belowground symbiotic mutualists, such as arbuscular mycorrhizal fungi (Jung et al. 2012; Song et al. 2013; Gilbert \& Johnson 2015) and plant growth promoting rhizobacteria (Pineda et al. 2013b; Pangesti et al. 2015). Few studies have considered interactions between belowground pathogenic microbes and aboveground herbivores (Biere \& Goverse 2016). Plantmicrobe-insect interactions also depend on environmental conditions such as soil fertility (Garratt, Wright \& Leather 2011), but these effects are not well studied. Here we examine how soil organic matter (SOM) and mineral fertilizer influence interactions among a pathogenic soil fungus, a crop plant, and an aboveground aphid.

In natural ecosystems, as well as in agro-ecosystems, most plant species are attacked by numerous herbivores and pathogens that simultaneously subtract energy and nutrients from the plant (Kessler \& Baldwin 2002). Plants defend against enemies with an array of constitutive or induced, direct and indirect defences, including the induction of chemical defence compounds (Karban \& Baldwin 1997). Plant defences against necrotrophic pathogens (Glazebrook 2005) and chewing insects are predominantly regulated via the jasmonic acid (JA) signal transduction pathway (Bodenhausen \& Reymond 2007), whereas the salicylic acid (SA) pathway is triggered by biotrophic pathogenic fungi (Makandar et al. 2012) and phloem feeding herbivores, such as aphids (Moran \& Thompson 2001; Mohase \& van der Westhuizen 2002). The JA and SA pathways can interact via antagonistic crosstalk (Felton \& Korth 2000; Robert-Seilaniantz, Grant \& Jones 2011), meaning that induction of JA signalling can lead to a decrease in SA mediated defences and vice versa (Thaler, Humphrey \& Whiteman 2012). It has therefore been suggested that infection with a necrotrophic pathogenic soil fungus such as Rhizoctonia solani, would most likely result in an increased performance of aphids such as Sitobion avenae (Lazebnik et al. 2014). However, there seems to be no general support for this suggestion (Lazebnik et al. 2014), perhaps because pathogens may also affect plant nutrient uptake directly or via competition with other soil organisms leading to differences in the chemical composition of the plant that are not related to the JA-SA crosstalk (Carvalho et al. 2012). 


\section{Chapter 2}

It has been well-established that aphids are affected by soil fertility, which influences plant growth and chemistry including secondary metabolites and, consequently, quantity and quality of food for aphids (Gershenzon 1984; Altieri \& Nicholls 2003). Soil fertility can be enhanced by adding mineral fertilizer, but SOM also influences soil fertility. Effects of mineral fertilizer and SOM on plants may differ in various aspects, for example because of the rate at which nutrients become available (Pimentel et al. 2005). Mineral fertilizers may become available more quickly than nutrients from SOM, which first need to be mineralized by the soil microbiome (Hendrix, Coleman \& Crossley 1992), resulting in a lower carbon to nitrogen $(\mathrm{C}: \mathrm{N})$ ratio of plants growing with mineral fertilizer. A low $\mathrm{C}: \mathrm{N}$ ratio enhances the quality of phloem sap for phloem-feeding herbivores, such as aphids (Nowak \& Komor 2010). Variation in SOM content may likewise affect plant quality for aphids (Zhang et al. 2012), however, considering the rate at which nutrients become available, SOM is expected to have weaker effects on the $\mathrm{C}: \mathrm{N}$ ratio than mineral fertilizer supply. It is therefore expected that aphids will not respond as strongly to enhanced SOM content as to mineral fertilizer supply. Interestingly, experimental studies have provided mixed support for this expectation; some studies find support (Hasken \& Poehling 1995) whereas Garratt, Wright and Leather (2010) found no significant overall effect in a meta-analysis.

Fertility management practices, including practices to enhance SOM content, can influence soil organisms including soil-borne pathogens such as $R$. solani, which have a weaker negative impact on plant biomass when plants are well supplied with nitrogen (Wall et al. 1994). Subsequently, any change in the relative abundance of organisms in the soil microbiome may alter the systemic induction of plant defences (Mazzola 2002) and, therefore, aphid performance. Also abiotic stress situations can alter microbe-plant-insect interactions (Pineda et al. 2013a). Indeed, it has been shown that specific effects of mineral fertilizer on aphid performance largely depend on the composition of the soil community (Kos et al. 2015). Also SOM- and fertilizer-induced changes in soil biota (Zhong et al. 2009) may indirectly affect aphid performance by changing the magnitude or direction of plantmediated interactions between soil-borne pathogens and aphids. This could be due either to shifts in the abundance of decomposer organisms that alter the nutritional status of plants, which may alter 
plant induced defence responses to soil-borne pathogens, or to shifts in the abundance of antagonists of the soil-borne pathogens (Philippot et al. 2013).

In the present study we experimentally exposed spring wheat (Triticum aestivum) plants, an important crop species, to aphids (S. avenae), an important pest species, to two levels of SOM, two levels of mineral fertilizer, and with or without the addition of the soil borne fungal pathogen $R$. solani. We tested the following hypotheses: (1) Enhanced SOM content and higher mineral fertilizer supply decrease the effect of $R$. solani on aphid biomass and its negative effect on plant biomass. (2) Mineral fertilizer supply reduces plant $\mathrm{C}: \mathrm{N}$ ratio more than an increase in SOM content, so that aphid biomass will be higher under enhanced mineral fertilizer supply than under enhanced SOM content. (3) Addition of $R$. solani affects aphid biomass strongest when the pathogen is inoculated to sterilized soils, which lack a soil microbiome that may control the fungus.

\section{Materials and Methods}

Study design

We grew spring wheat (Triticum aestivum) under exposure to grain aphids (Sitobion avenae) in unsterilized and sterilized soil. Plants growing in unsterilized soil were exposed to all combinations of two levels of soil organic matter (SOM) content, high and low mineral fertilizer supply and presence or absence of the fungus Rhizoctonia solani. Each combination was replicated 14 times, bringing the total to $2 \times 2 \times 2 \times 14=112$ experimental units. Plants growing in sterilized soil were exposed to all combinations of two levels of SOM content and presence or absence of $R$. solani (i.e. we had no fertilization treatment, as sterilization already leads to a nutrient flush). Each combination was replicated 8 times, bringing the total to $2 \times 2 \times 8=32$ units. All treatments from both sterilized and unsterilized soil were fully randomized in one greenhouse. We studied main and interaction effects on aphid performance (S. avenae) and the biomass and C:N ratio of its host plant spring wheat ( $T$. aestivum).

\section{Treatments}

We placed six pairs of seeds of T. aestivum (var. Tybalt) in four-litre pots (diameter $\sim 20 \mathrm{~cm}$ ) filled with soil consisting of $1.7 \%$ (Low) or $3.1 \%$ (High) SOM content. Soil was obtained from a soil health 


\section{Chapter 2}

experiment from a loamy fine sand area in the South East of the Netherlands $\left(51^{\circ} 32^{\prime} 26.0^{\prime \prime} \mathrm{N}\right.$; $5^{\circ} 51^{\prime} 13.0^{\prime \prime E}$, see Korthals et al. 2014 for a full description of this experiment). To study the effect of SOM on aphid performance, independent of all other physical, chemical and biological properties of the soil that might affect yield and aphid performance, we obtained the two SOM treatments by mixing different proportions of two soil layers that differed in SOM but that originated from the same area. We used a concrete mixer for mixing the soils. The two soil layers were the top layer, $0-20 \mathrm{~cm}$ (3.4\% SOM) and the $\mathrm{C}$ horizon ( $100 \mathrm{~cm}$ depth) that hardly contained any SOM. The high SOM treatment was obtained by mixing the $\mathrm{C}$ horizon with the top layer in a 1:9 mixture, whereas the low SOM treatment was obtained using a mixture of 1:1. For the sterilized soil treatments we sterilized the soils twice during 20 minutes ( 40 minutes total) at $121^{\circ} \mathrm{C}$ using an autoclave.

After germination we removed the smaller of the two plants in a pair to get six plants per pot. One day after sowing, the high fertilizer supply treatment plants received $60 \%$ of the total fertilizer supplied during the experiment. The remaining $40 \%$ of fertilizer was provided at tiller development. In total we supplied 0.3 gram N.pot ${ }^{-1}$, which corresponds with an average nitrogen supply for spring wheat of around $130 \mathrm{~kg} \mathrm{~N} \cdot \mathrm{aa}^{-1}$. Nitrogen was supplied in a dissolved form of $\mathrm{NO}_{3}{ }^{-}$, (mainly $\left.\mathrm{Ca}\left(\mathrm{NO}_{3}\right)_{2}\right)$, enriched with half a litre $1 / 2$ Hoagland solution that also contains other macro and micro nutrients (see Hewitt 1966 for composition of the solution). All other plants, including all plants growing in the sterilized soil, received fertilizer at the low supply rate. These plants received $10 \%$ of this solution complemented with tap water to add equal volumes of water to every pot. In addition plants received ample water; on average $300 \mathrm{ml}$ per pot per week.

Six days later, at tiller development, we inoculated half the pots with two $5 \mathrm{~mm}$ plugs of the fungus $R$. solani (AG-8) (Fiddaman \& Rossall 1993), which had grown for one week on Petri dishes with $1 / 5^{\text {th }}$ Potato Dextrose Agar (PDA; $29 \mathrm{gL}^{-1}$ Oxoid CM 139). Pots were inoculated at rooting depth, around 4 $\mathrm{cm}$ depth, at both sides of the pot and plugs were always taken from two randomly selected agar plates to avoid any bias from a potential plate effect.

Three weeks after tiller development, each pot was covered by a gauze net (mesh size around $150 \mu \mathrm{m}$ ) and infested with six aphids per pot. A single adult apterous aphid was carefully placed with a fine 
brush on the biggest leaf of each of the six plants. Seven weeks after tiller development (hence four weeks after aphid infestation), aphids were carefully removed using a brush, put in a tube and weighted to obtain the aphid fresh weight (mg). Eight weeks after tiller development, plants were at that time at flowering stage, aboveground plant biomass - shoots and spikes - were harvested, oven dried at $70^{\circ} \mathrm{C}$ for $48 \mathrm{~h}$ and weighted. Subsequently we obtained the C:N ratio of the plant shoots, because most of the aphids fed on the shoots. To obtain C:N ratio, shoot plant material was homogenized and grinded to a fine powder and oven dried again for $24 \mathrm{~h}$ at $70^{\circ} \mathrm{C}$ to estimate carbon (C) and nitrogen $(\mathrm{N})$ concentration. Prior to analysis tin cups were filled with 3-6 mg of sample powder and analysed using combustion-reduction with an element analyser (Thermo flash EA 1112, Thermo Fisher Scientific Inc., Waltham, USA).

Analyses

To test hypotheses 1 and 2 we analysed data from the plants growing in unsterilized soil using a type 3 ANOVA. We ran separate models for the three response variables, aboveground plant biomass (shoots and spikes), fresh aphid biomass and plant quality (C:N ratio) and used SOM, fertilizer supply level and $R$. solani addition and all possible interactions as explanatory variables. We tested whether residuals followed a normal distribution, using Shapiro-Wilk tests. Residuals of the data on aphid biomass and C:N ratio were not normally distributed and the data were therefore $\sqrt{ }(\ln +1)$ and $\sqrt{ }$ transformed, respectively. We checked whether variances were equal using a Bartlett's test. Afterwards, we ran a Tukey Honest Significant Difference (HSD) contrast test as a post hoc to see which combinations were significantly different from each other. Moreover, we looked how aboveground plant biomass, fresh aphid biomass, and C:N ratio were correlated to each, other using Pearson Correlations.

To test hypothesis 3 , we combined the data from sterilized and unsterilized pots, the latter not receiving mineral fertilizer. Since sample sizes were not equal (i.e. we had fewer pots per combination for the sterilized soil), we performed this analysis using a linear model. We tested whether SOM and soil sterilization had an effect on aboveground plant biomass and aphid biomass. Also here, we tested whether residuals followed a normal distribution, using Shapiro-Wilk tests, resulting in $\sqrt{ }(\ln +1)$ transformation of the data. All analyses were performed with R 3.2.2 (R Core Team). 


\section{Chapter 2}

\section{Results}

Effect of mineral fertilizer supply and SOM on plant- and aphid biomass and plant C:N ratio Fertilizer supply had a positive effect on aboveground plant biomass, but only under low SOM conditions, whereas higher SOM content had only a positive effect on plant biomass under low mineral fertilizer supply (Fig 2.1a). There was more aphid biomass on plants growing under high SOM content and if more mineral fertilizer was supplied (Fig 2.1b). However, the effect of fertilizer supply changed with high SOM content (Table 2.1); under high SOM content the positive effect of fertilizer supply on aphid biomass was bigger (Fig 2.1b). Fertilizer supply was the only factor influencing shoot C:N ratio (Table 2.1). Fertilizer supply reduced C:N ratio by $60 \%$ compared to unfertilized soil, whereas the SOM content had no effect on leaf C:N ratio (Fig 2.2). Plant biomass was neither related to leaf $\mathrm{C}$ : $\mathrm{N}$ ratio $(\mathrm{r}=-0.01, \mathrm{P}=0.90)$, nor to aphid biomass ( $\mathrm{r}=-0.00, \mathrm{P}=0.99)$, but leaf $\mathrm{C}: \mathrm{N}$ ratio was negatively related to aphid biomass $(\mathrm{r}=0.76, \mathrm{P}<0.0001)$. 

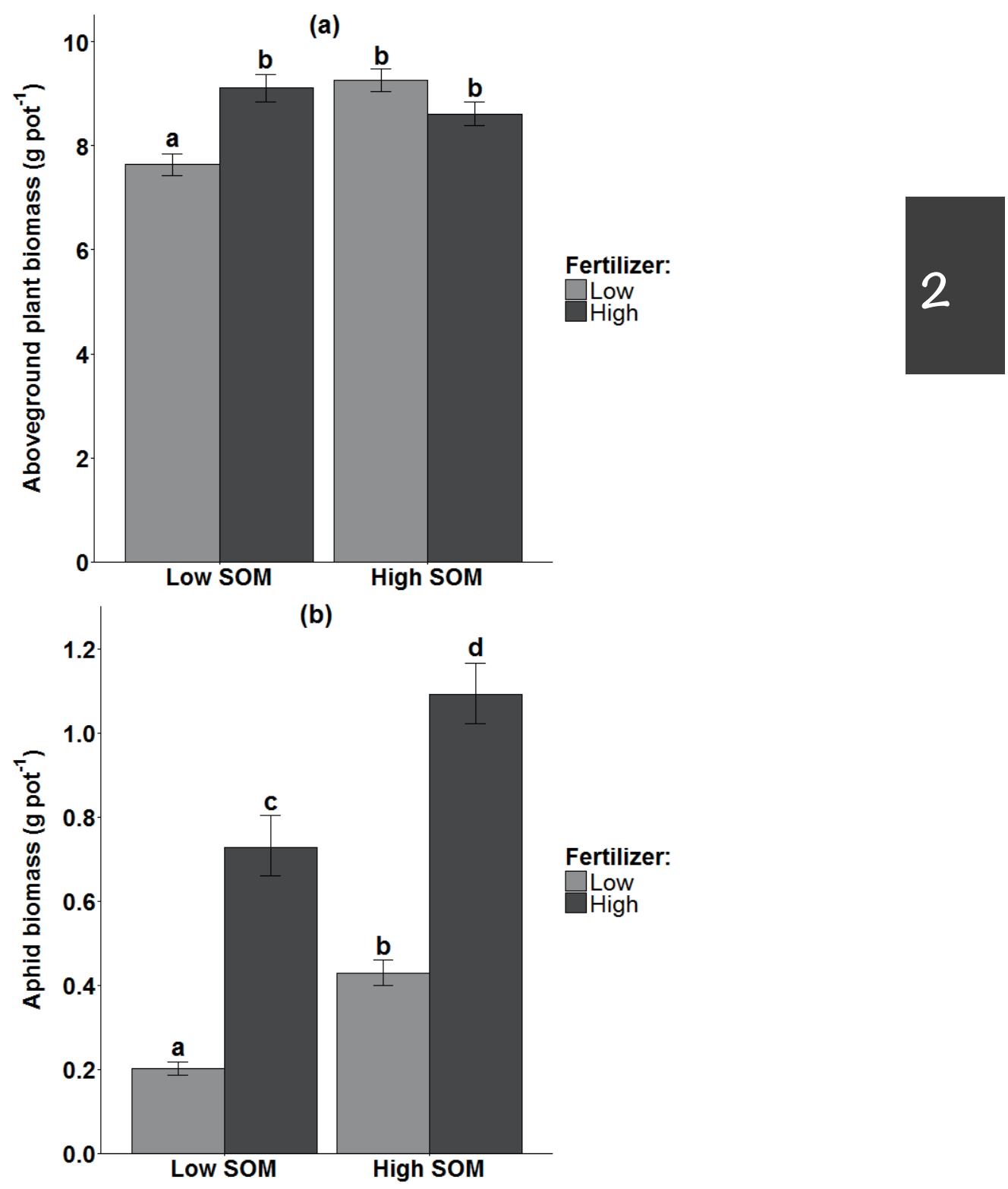

Fig 2.1. Effects of soil organic matter (SOM) content (low, high) and mineral fertilizer supply (low, high) on plant- and aphid biomass on unsterilized soil. a) Plant biomass of Triticum aestivum. b) Aphid biomass of Sitobion avenae. Error bars represent standard errors. Significant differences are indicated by different letters (Tukey Honest Significant Difference contrast test). 
Chapter 2
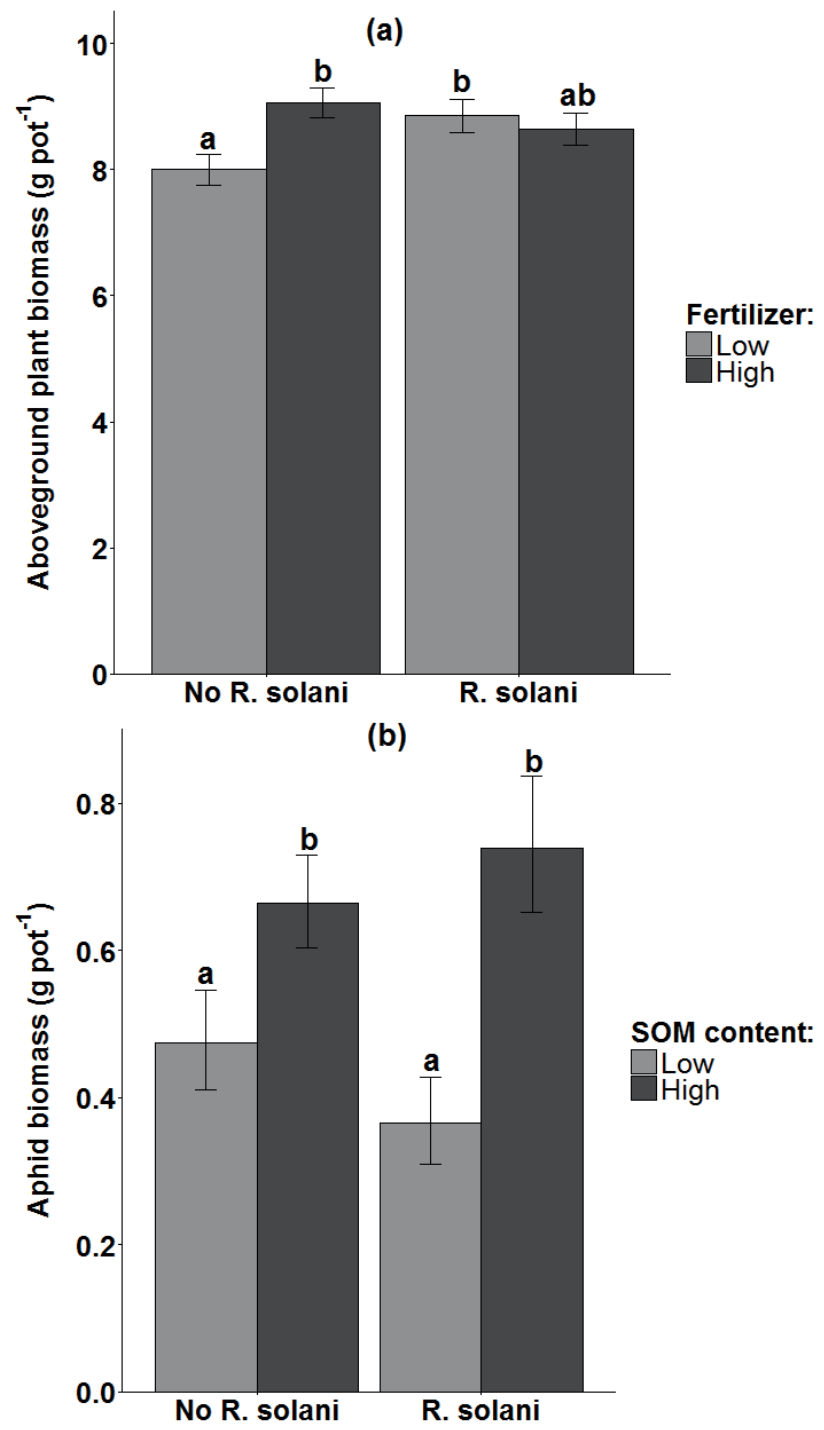

Fig 2.2. Effects of Rhizoctonia solani addition on plant- and aphid biomass under different soil conditions on unsterilized soil. a) Aboveground plant biomass of Triticum aestivum explained by $R$. solani addition and mineral fertilizer supply (low, high). b) Aphid biomass of Sitobion avenae explained by $R$. solani addition and soil organic matter (SOM) content (low, high). Error bars represent standard errors. Significant differences are indicated by different letters (Tukey Honest Significant Difference contrast test). 
Effect of adding $R$. solani on plant-and aphid biomass under different soil conditions

The addition of Rhizoctonia solani affected both plant and aphid biomass in unsterilized soils, but the effects were different depending on the soil conditions soil organic matter (SOM) content and fertilizer supply (Table 2.1). Under low mineral fertilizer supply, $R$. solani did not affect plant biomass, whereas under fertilized conditions $R$. solani cancelled the positive effect of mineral fertilizer supply on yield (Table 1, Fig 2.3a). The effect of adding R. solani on aphid biomass, depended on SOM content (Table 2.1). In soils with low SOM content $R$. solani addition tended to decrease aphid biomass, whereas it tended to increase aphid biomass in soil with high SOM content (Fig 2.3b), resulting in a significant interaction between SOM and $R$. solani addition (Table 2.1). The combination of $R$. solani addition and mineral fertilizer supply did not result in a significant interaction, although the trend was similar to the interaction between SOM content and R. solani addition (Table 2.1). 
Chapter 2

Table 2.1. ANOVA models explaining aboveground dried plant biomass (stem and flower biomass) of wheat (Triticum aestivum), fresh aphid biomass (Sitobion avenae, $\sqrt{ }(\mathrm{ln}+1)$ transformed), and plant $\mathrm{C}: \mathrm{N}$ ratio $(\sqrt{ }$ transformed) by soil organic matter (SOM) content, fertilizer supply, Rhizoctonia solani addition and all possible interactions. All analyses were done on unsterilized soil. Significant $(P<0.05)$ effects are highlighted in bold, $N=104$.

Plant biomass Aphid biomass

$\mathrm{C}: \mathrm{N}$ ratio plant

F

P

F

P

F

P

\begin{tabular}{|c|c|c|c|c|c|c|}
\hline \multicolumn{7}{|l|}{ Main effects } \\
\hline $\mathrm{SOM}$ & 0.03 & 0.8674 & 1.09 & 0.2990 & 0.02 & 0.8747 \\
\hline Fertilizer & 0.54 & 0.4626 & 22.75 & 0.0000 & 142.94 & 0.0000 \\
\hline R. solani & 4.91 & 0.0290 & 4.82 & 0.0305 & 0.44 & 0.5067 \\
\hline \multicolumn{7}{|l|}{ Interactions } \\
\hline SOM:Fertilizer & 5.06 & 0.0268 & 3.96 & 0.0495 & 0.00 & 0.9768 \\
\hline SOM:R. solani & 3.26 & 0.0743 & 7.49 & 0.0074 & 0.21 & 0.6497 \\
\hline Fertilizer:R.solani & 8.40 & 0.0047 & 3.75 & 0.0559 & 0.31 & 0.5786 \\
\hline SOM:Fertilizer:R.solani & 1.64 & 0.2038 & 2.72 & 0.1021 & 2.50 & 0.1172 \\
\hline
\end{tabular}


Soil conditions alter soil pathogen-aphid interactions
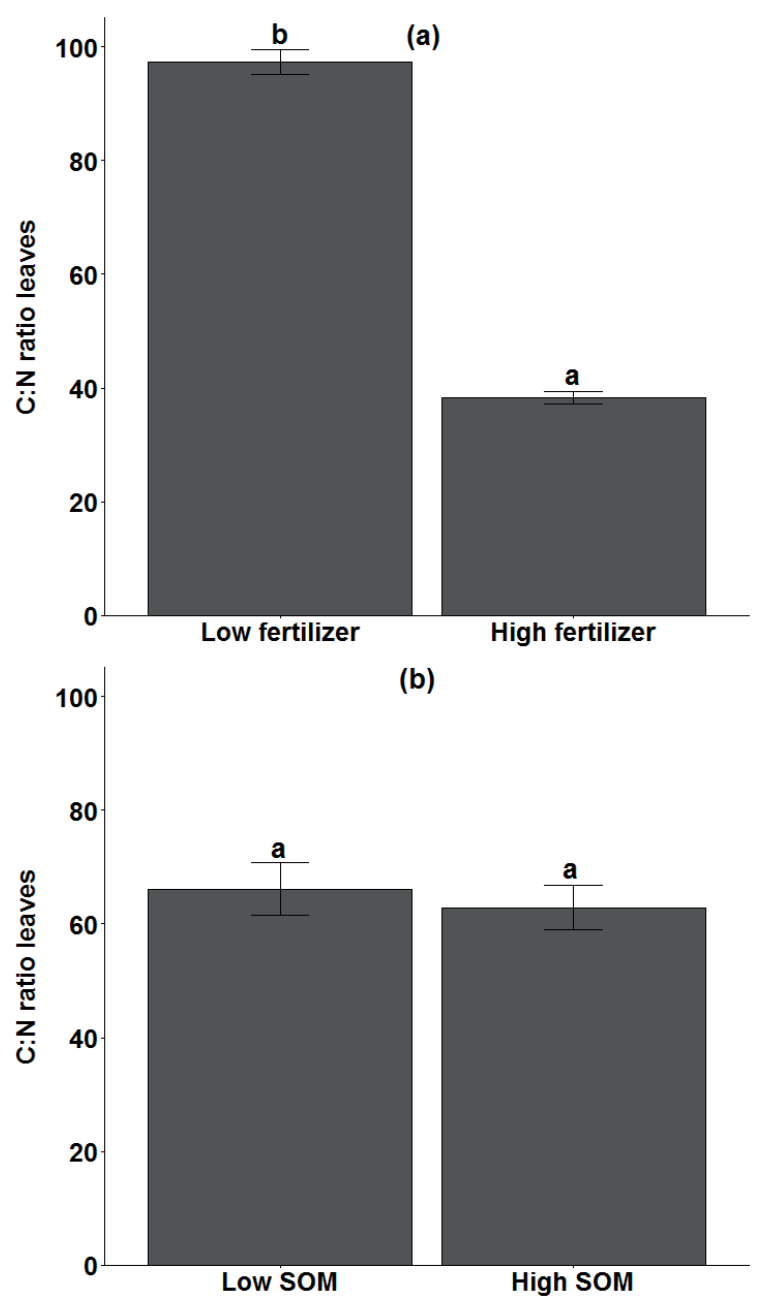

Fig 2.3. Effects of mineral fertilizer supply (low, high) and soil organic matter (SOM) content (low, high) on C:N ratio of Triticum aestivum leaves in unsterilized soil. a) $\mathrm{C}: \mathrm{N}$ ratio explained by mineral fertilizer supply. b) C:N ratio explained by SOM content. Error bars represent standard errors. Significant differences are indicated by different letters (Tukey Honest Significant Difference contrast test). 


\section{Chapter 2}

Effects of R. solani under sterilized and unsterilized soil conditions

The effect of $R$. solani addition on plant biomass changed with soil sterilization ( $\mathrm{F}=6.97, \mathrm{P}=0.01$, $\mathrm{N}=88$ ). In non-sterilized soil, $R$. solani addition increased plant biomass, whereas it tended to decrease plant biomass under sterilized conditions (Fig 2.4a). The effects of $R$. solani infection on aphid biomass depended on soil sterilization (interaction: $\mathrm{t}=4.20, \mathrm{P}=0.0001, \mathrm{~N}=88$, Fig $2.4 \mathrm{~b}$ ). In unsterilized soil, addition of $R$. solani tended to decrease aphid biomass, but in sterilized soil, addition of $R$. solani had a substantial positive effect on aphid biomass (Fig 2.4b). All effects of sterilization, SOM content and $R$. solani addition on biomass of aphids and plants and $\mathrm{C}: \mathrm{N}$ ratio of leaves are presented in Appendix S2.1. 
Soil conditions alter soil pathogen-aphid interactions

(a)

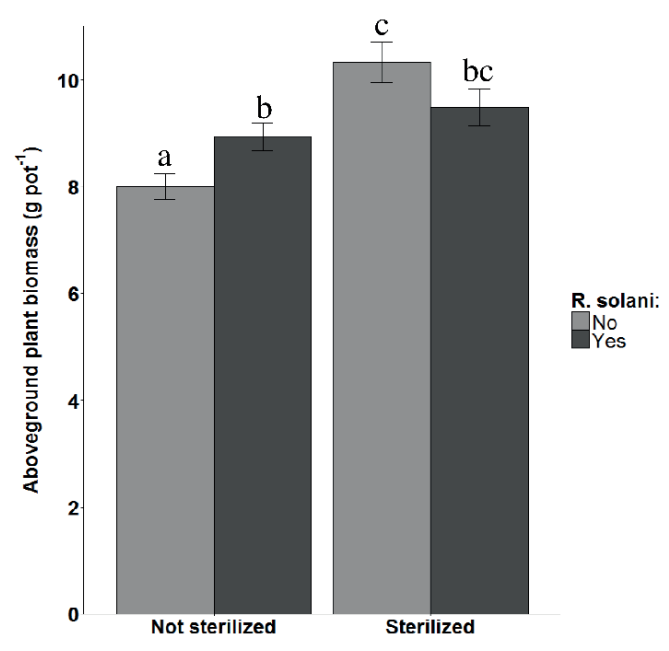

(b)

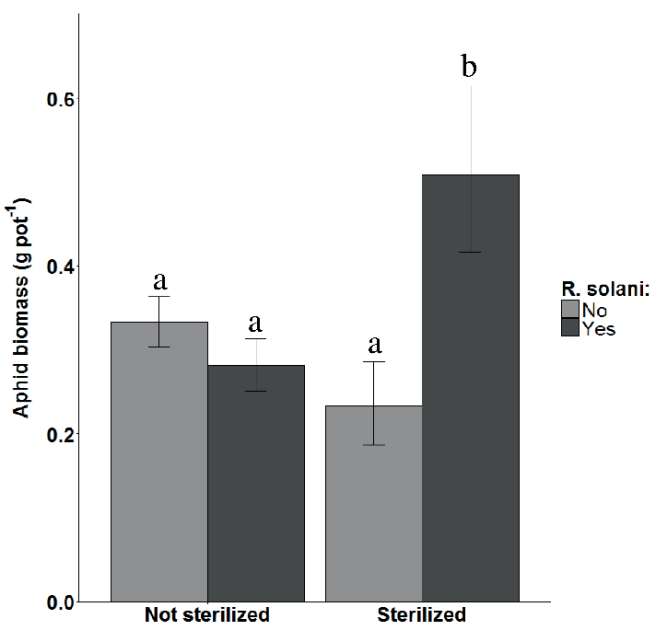

Fig 2.4. Effects of soil sterilization and Rhizoctonia solani addition on aboveground plant biomass of and fresh aphid biomass. a) Effects on aboveground plant biomass of Triticum aestivum. b) Effects on fresh aphid biomass of Sitobion avenae. Error bars represent standard errors. Significant differences are indicated by different letters (Tukey Honest Significant Difference contrast test). 


\section{Chapter 2}

\section{Discussion}

Various studies have shown that belowground organisms, such as insects (Soler et al. 2012), nematodes (Wondafrash, Van Dam \& Tytgat 2013), and mycorrhizal fungi (Gange \& West 1994; Kempel et al. 2010; Jung et al. 2012) can alter the performance of aboveground invertebrate organisms. It is also known that aboveground pathogens may alter the performance of aboveground herbivores (Lazebnik et al. 2014). However, as the effects of belowground pathogens on aboveground herbivores are not well studied (Biere \& Goverse 2016), it remains unclear whether interactions between pathogenic microbes plants and insects are local or systemic (Pieterse et al. 2013). Here, we demonstrate that a belowground pathogen may also influence aboveground plant-insect interactions and we show that effects depend on soil organic matter (SOM) content and mineral fertilizer supply.

We hypothesized that Rhizoctonia solani addition would lead to a decrease in plant biomass and an increase in aphid biomass and that enhanced SOM content and mineral fertilizer supply would reduce these effects. However, we found a pattern that opposed our hypothesis: under low SOM content $R$. solani addition tended to decrease aphid (Sitobion avenae) biomass, whereas it tended to increase aphid biomass under high SOM content. Supply of mineral fertilizer had a similar interaction effect with $R$. solani on aphid biomass, but this interaction was only marginally significant. Also in aboveground plant biomass we found a pattern opposing our hypothesis. As R. solani is known to have less negative effects on wheat growth under higher nitrogen conditions (Wall et al. 1994), we expected that SOM content or mineral fertilizer supply would negatively affect $R$. solani performance, leading to a less positive effect of $R$. solani on aphid performance. We observed, however, that $R$. solani addition led to an increase in aboveground plant biomass when the low fertilizer treatment was supplied and that there was no effect of aphids when we supplied the full mineral fertilizer treatment. This result was not expected as $R$. solani AG-8 is known to be pathogenic to wheat Triticum aestivum (Smith et al. 2003). Potentially, an R. solani infection increases immunity of the crop plant against aphids in some situations.

Our second hypothesis was that mineral fertilizer supply would reduce plant $\mathrm{C}: \mathrm{N}$ ratio more than an increase in SOM content, so that aphid biomass will be higher under enhanced mineral fertilizer 
supply than under enhanced SOM content. We expected that high SOM content would have a smaller effect on C:N ratio than mineral fertilizer supply (Nowak \& Komor 2010), leading to relatively weaker performance of aphids. Indeed, our data showed that mineral fertilizer supply strongly decreased plant $\mathrm{C}: \mathrm{N}$ ratio. High SOM content, however, increased plant biomass without affecting plant C:N ratio when no mineral fertilizer was supplied. These different responses of plant biomass production and C:N ratio to SOM and fertilizer could explain why an increase in SOM content could have a smaller positive effect on aphid biomass than mineral fertilizer supply, while the effect on plant biomass is similar. This could be explained by a competition for nutrients among micro-organisms that decompose SOM and the plant (Hasken \& Poehling 1995). However, S. avenae showed still an increase in biomass under higher SOM content. Possibly, S. avenae does not solely respond to the decrease in $\mathrm{C}: \mathrm{N}$ ratio after fertilization per se. Instead, it might respond to extra increase in plant biomass after mineral fertilizer supply, potentially explaining why $S$. avenae responds after fertilization in some studies (Aqueel et al. 2014), but not in others (Honek 1991).

We expected that addition of $R$. solani affected aphid biomass strongest when the pathogen is inoculated to sterilized soils, as these sterilized soils lack microbiome components that may control the fungus (Philippot et al. 2013). In support of this hypothesis we found that aphid biomass increased when $R$. solani was added to sterilized soil. The positive effect of $R$. solani on aphid performance is also in line with predictions from defence signalling interactions (Lazebnik et al. 2014). Necrotrophic fungi, such as $R$. solani trigger defence responses mediated by the jasmonic acid (JA) signalling pathway, which through JA-SA crosstalk can lead to a suppression of salicylic acid (SA) mediated defence (Thaler, Humphrey \& Whiteman 2012). However, we did not measure hormone levels in plants, so that this possible mechanistic explanation needs further study.

\section{Conclusions}

We conclude that the outcome of a soil pathogen-aphid interaction may depend on the SOM content as a higher SOM content leads to a more positive effect of $R$. solani on aphids. We therefore recommend that soil conditions, such as SOM content, should be taken into account in the study of microbe-plantinsect interactions. We also show that belowground pathogens influence aphid performance and that 


\section{Chapter 2}

this effect depends on the presence of a soil microbiome. We saw that, under the absence of a soil microbiome, the effect of $R$. solani on aphid biomass became more positive, implying that experiments studying the effect of soil pathogens under sterile conditions might not represent realistic outcomes of interactions. Further studies are needed to further unravel mechanisms at the plant hormone level, and to test how this knowledge can be used to understand plant exposure to combinations of belowground and aboveground natural enemies at field scale, for instance in agricultural systems.

\section{Acknowledgements}

We thank Christian Chabot, Gregor Disveld, Florentine van Noppen, and Erik Reichman for technical assistance. 


\section{S2.1. Appendix Fresh aphid biomass, aboveground plant biomass, and $\mathrm{C}: \mathrm{N}$ ratio explained by}

\section{soil sterilization, soil organic matter content and Rhizoctonia solani addition}

We tested whether soil sterilization, soil organic matter (SOM) content, Rhizoctonia solani addition and interactions among these factors affected fresh aphid biomass, aboveground dried plant biomass and $\mathrm{C}: \mathrm{N}$ ratio of the plant leaves using linear models and a generalized least square model.

Fresh aphid biomass was affected by SOM content and the interaction between soil sterilization and $R$. solani addition (see main text and Table S1). Under high SOM content aphid biomass was higher (Fig S1). Plant biomass was affected by soil sterilization, SOM content and the interaction between soil sterilization and $R$. solani addition (main text and Table S1). Aphid biomass, plant biomass was higher under high SOM content (Fig S2). The C:N ratio of the leaves was influenced by soil sterilization, SOM content, the interaction between soil sterilization and SOM content and the interaction between soil sterilization and $R$. solani addition. In sterilized soil, a higher SOM content let to a decrease in $\mathrm{C}: \mathrm{N}$ ratio, whereas a higher $\mathrm{SOM}$ content did not let to a decrease in $\mathrm{C}: \mathrm{N}$ ratio under unsterilized conditions (Fig S3a). In sterilized soils $R$. solani addition tended to increase C:N ratio, whereas it tended to decrease $\mathrm{C}: \mathrm{N}$ ratio sterilized soils (Fig $\mathrm{S} 3 \mathrm{~b}$ ). 
Chapter 2

Table S2.1. Generalized least squares model explaining fresh aphid biomass (Sitobion avenae,

$\sqrt{ }(\ln +1)$ transformed) and linear models explaining aboveground dried plant biomass (stem and flower biomass) of wheat (Triticum aestivum) and plant $\mathrm{C}: \mathrm{N}$ ratio ( $\sqrt{ }$ transformed) by soil sterilization, soil organic matter (SOM) content, Rhizoctonia solani addition and all possible interactions. Significant $(\mathrm{P}<0.05)$ effects are highlighted in bold, $\mathrm{N}=88$.

\begin{tabular}{lrrrrrr}
\hline & Aphid biomass & \multicolumn{3}{c}{ Plant biomass } & \multicolumn{3}{c}{ C:N ratio plant } \\
& $\mathrm{t}$ & $\mathrm{P}$ & $\mathrm{F}$ & $\mathrm{P}$ & $\mathrm{F}$ & $\mathrm{P}$ \\
\hline Main effects & & & & & & \\
Sterilization & -1.76 & 0.0821 & $\mathbf{3 3 . 6 5}$ & $<\mathbf{0 . 0 0 0 1}$ & $\mathbf{4 4 . 2 9}$ & $<\mathbf{0 . 0 0 0 1}$ \\
SOM & $\mathbf{- 3 . 8 0}$ & $\mathbf{0 . 0 0 0 3}$ & $\mathbf{2 8 . 6 9}$ & $<\mathbf{0 . 0 0 0 1}$ & $\mathbf{2 0 . 9 1}$ & $<\mathbf{0 . 0 0 0 1}$ \\
R. solani & -0.70 & 0.4859 & 1.73 & 0.1919 & 0.17 & 0.6829 \\
Interactions & & & & & & \\
Sterilization:SOM & 0.30 & 0.7673 & 1.53 & 0.2196 & $\mathbf{5 . 5 2}$ & $\mathbf{0 . 0 2 1 2}$ \\
Sterilization: . solani & $\mathbf{4 . 2 0}$ & $\mathbf{0 . 0 0 0 1}$ & $\mathbf{6 . 9 7}$ & $\mathbf{0 . 0 1 0 0}$ & $\mathbf{4 . 2 0}$ & $\mathbf{0 . 0 4 3 6}$ \\
SOM:R. solani & -0.32 & 0.7508 & 0.16 & 0.6882 & 1.19 & 0.2780 \\
Sterilization:SOM: $R$. & 1.45 & 0.1520 & 0.01 & 0.9120 & 1.61 & 0.2077 \\
solani & & & & & & \\
\hline
\end{tabular}


Soil conditions alter soil pathogen-aphid interactions

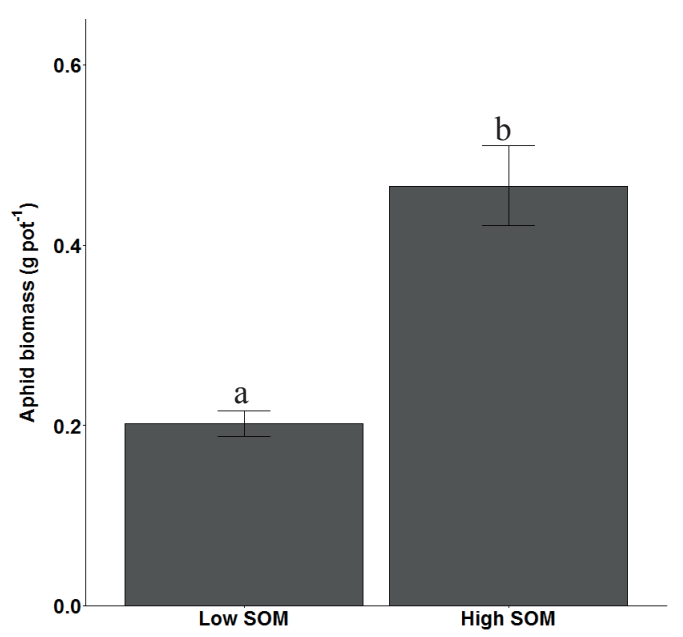

Fig S2.1. Effects of soil organic matter (SOM) content (low, high) on fresh aphid biomass in both sterilized and unsterilized soil. Significant differences are indicated by different letters (Tukey Honest Significant Difference contrast test). 
Chapter 2

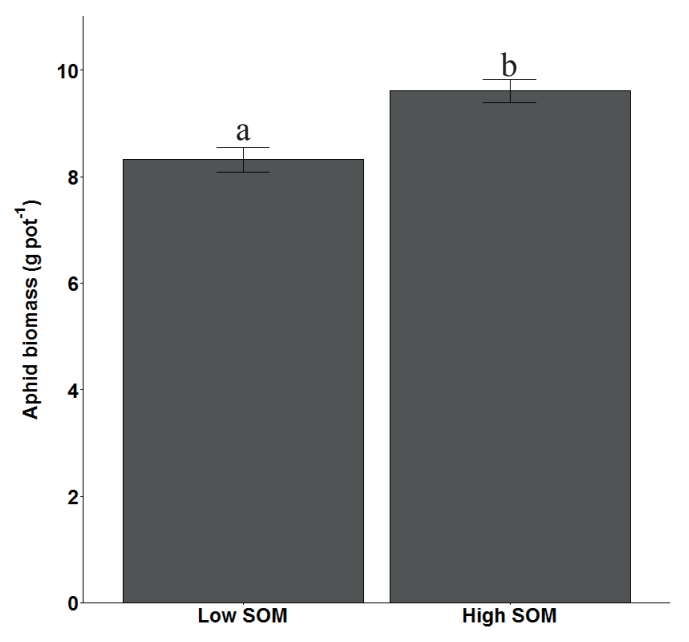

Fig S2.2. Effects of soil organic matter (SOM) content (low, high) on aboveground plant biomass in both sterilized and unsterilized soil. Significant differences are indicated by different letters (Tukey Honest Significant Difference contrast test). 
Soil conditions alter soil pathogen-aphid interactions

(a)

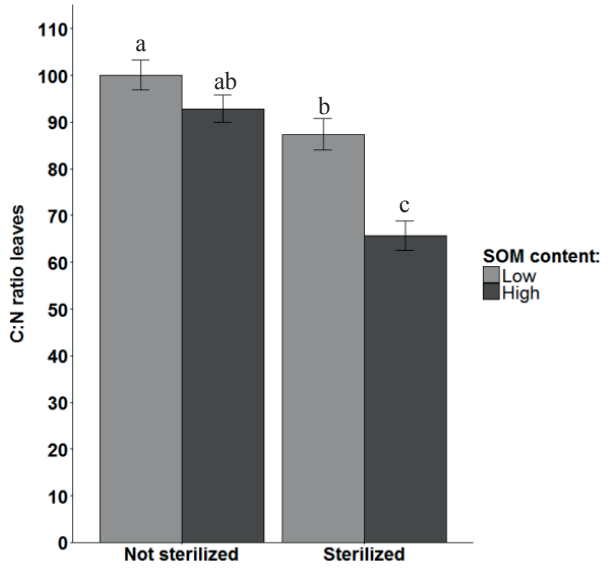

(b)

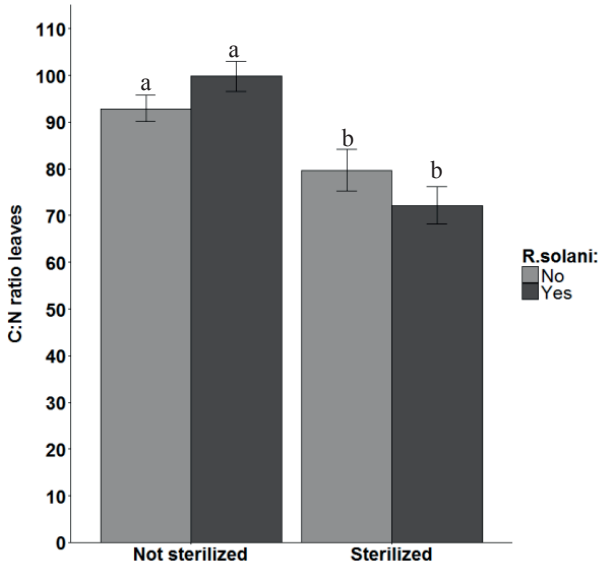

Fig S2.3. Effects of soil sterilization, soil organic matter (SOM) content (low, high) and

Rhizoctonia solani addition on C:N ratio of Triticum aestivum leaves. a) C:N ratio explained by soil sterilization and SOM content. b) C:N ratio explained by soil sterilization and $R$. solani addition. Error bars represent standard errors. Significant differences are indicated by different letters (Tukey Honest Significant Difference contrast test). 
Chapter 2

2 


\section{Chapter 3}

Drought and soil organic matter modify fertilization effects on aphid performance in wheat

Giovanni Tamburini*, Stijn van Gils*, Martine Kos, Wim van der Putten, Lorenzo Marini

*Authors contributed equally to this study.

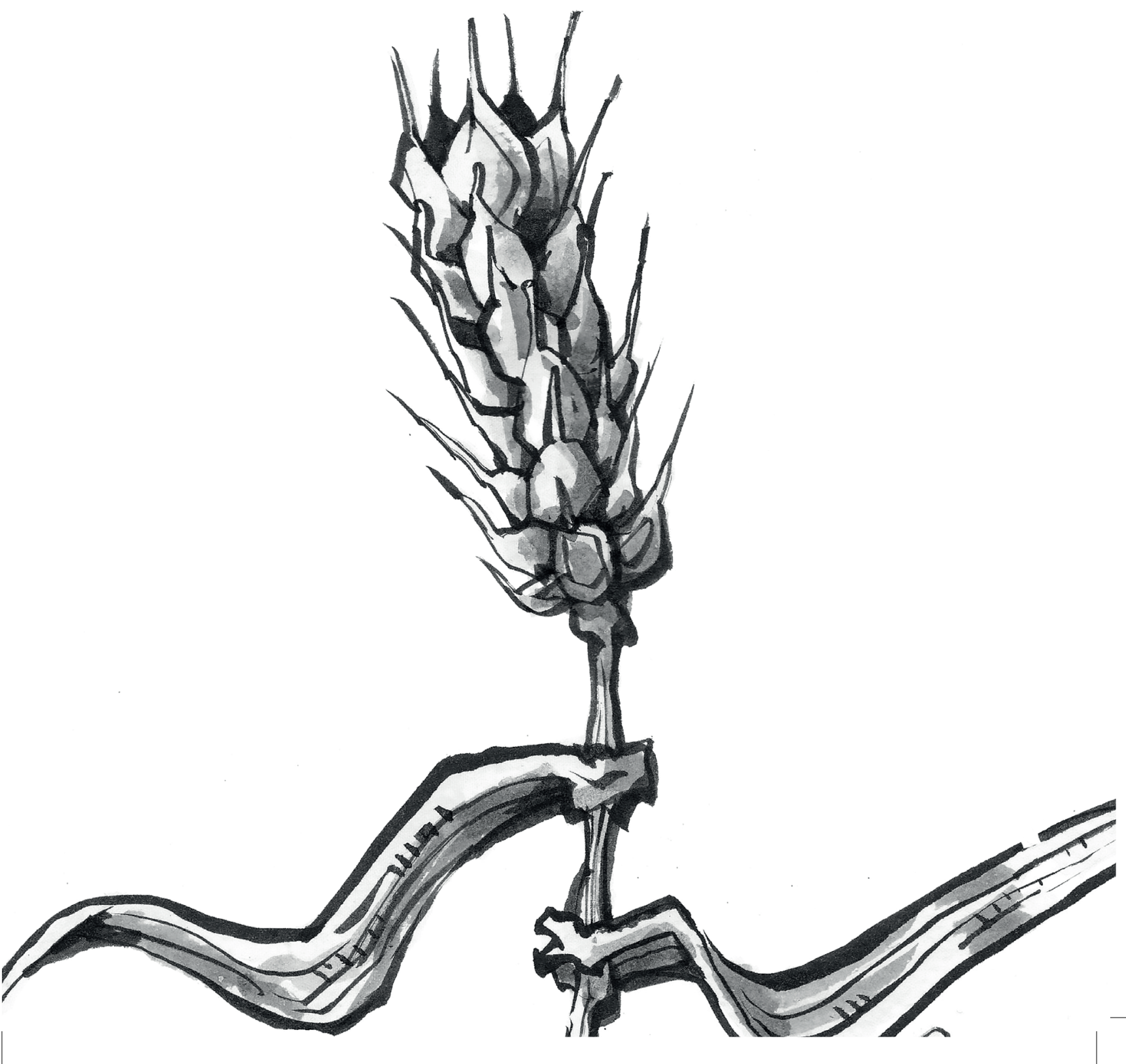




\title{
Chapter 3
}

\begin{abstract}
Agricultural intensification and climate change are expected to affect pest performance through excessive inputs of chemical fertilizers and increased probability of extreme drought events. Potential interactive effects of fertilization and water availability on aboveground pest performance may depend on the soil organic matter (SOM) content because of its effect on both nutrient availability and water holding capacity of the soil. With a greenhouse experiment, we examined the effects of nitrogen $(\mathrm{N})$ fertilization on the performance of the grain aphid (Sitobion avenae, F.), an important pest of wheat, under different conditions of SOM content and water availability. We found SOM content and water availability to influence the positive effects of $\mathrm{N}$ fertilization on aphid growth: $\mathrm{N}$ fertilization promoted higher aphid development time, fecundity and final biomass under low SOM levels and under well-watered conditions. The current practices promoting SOM and associated ecosystems services may not have negative consequence on crop protection under conventional cropping systems. Morever, although drought can have severe negative impacts on wheat production, the crop should be able to cope better with aphid attacks than under normal weather conditions.
\end{abstract}

\section{Introduction}

Insect pests represent a severe threat to food production, being responsible for an estimated yield loss of 15\% worldwide (Maxmen 2013). Agricultural intensification has been shown to alter pest dynamics through excessive inputs of nitrogen $(\mathrm{N})$ and promotion of monoculture cropping, potentially increasing herbivore pressure in several agroecosystems (Matson et al. 1997). Moreover, climate change is known to affect plant-herbivore interactions (Johnson et al. 2011) and it is expected to exacerbate pest problems in several cropping systems (Fuhrer 2003). However, the mechanisms driving pest dynamics are far from well understood (Welch \& Harwood 2014) and large knowledge gaps remain to understand the consequences of adopting different soil management strategies under a climate change scenario (Vermeulen, Campbell \& Ingram 2012).

Inorganic $\mathrm{N}$ fertilization is a widely adopted practice known to affect pest performance. $\mathrm{N}$ application rapidly modifies nutrient balance in plants enhancing $\mathrm{N}$ concentrations in plant tissues and it improves the performance of pests, particularly of sap feeding insects (Mattson 1980; Awmack \& Leather 


\section{Drought and soil organic matter modify fertilization effects on aphid}

2002). High concentration of $\mathrm{N}$ in phloem sap has been shown to increase growth rate, development time and fecundity of this herbivore guild, boosting their population growth (Nevo \& Coll 2001; Douglas 2003). Nevertheless, plant nutrient status also depends on other concomitant factors such as water availability and soil quality that are also expected to influence herbivore dynamics (Meyer 2000; Huberty \& Denno 2004). Understanding the potential interactions between nitrogen application and other agronomic factors and their effects on herbivore performance is therefore important to predict pest dynamics in agroecosystems.

Farming practices aiming at supporting soil fertility in the long-term, such as manure application and crop residue incorporation, increase the content of organic matter in the soil (Mäder et al. 2002; Birkhofer et al. 2008). Soil organic matter (SOM) greatly influences the soil ecosystem functioning, affecting soil structure and porosity, moisture holding capacity and plant nutrient availability (Magdoff \& Weil 2004; Six et al. 2004; Bot \& Benites 2005). Increased SOM content supports a more gradual release of nutrients to plants, avoiding disproportionate enhancement of $\mathrm{N}$ levels in plant tissues and, presumably, undesired pest population boost (Altieri \& Nicholls 2003; Wurst et al. 2003; Pimentel et al. 2005; Ke \& Scheu 2008). Soil management strategies aiming at enhancing organic matter content in agricultural soils have therefore been largely encouraged (Matson et al. 1997), although some studies showed contrasting effects on pests (Garratt, Wright \& Leather 2010; Garratt, Wright \& Leather 2011; Williams, Birkhofer \& Hedlund 2014). Nevertheless, the outcomes of increased SOM on aboveground pest performance have rarely been tested and the potential interactions with inorganic fertilizer inputs remain largely unknown (Garratt, Wright \& Leather 2011; Bommarco, Kleijn \& Potts 2013).

Climate change is expected to strongly influence agroecosystems (Schröter et al. 2005; Gustafson 2011). Summer droughts are predicted to increase in frequency, duration and/or severity in various geographical areas of the planet (Solomon 2007; Dai 2011). Prolonged water stress in plants can limit sap-feeding insect performance (Huberty \& Denno 2004) because of altered phloem properties (e.g. sap viscosity) and decreased turgor, which compromise feeding activity (Hale et al. 2003; Pescod, Quick \& Douglas 2007; Tariq et al. 2012). Nevertheless, the magnitude of drought effects on plants 


\section{Chapter 3}

and pests is also expected to depend on soil properties: SOM for example, improves soil physical properties, generally increasing water holding capacity (Bot \& Benites 2005). Higher levels of SOM might therefore mitigate water stress to plants and to the insects feeding on them.

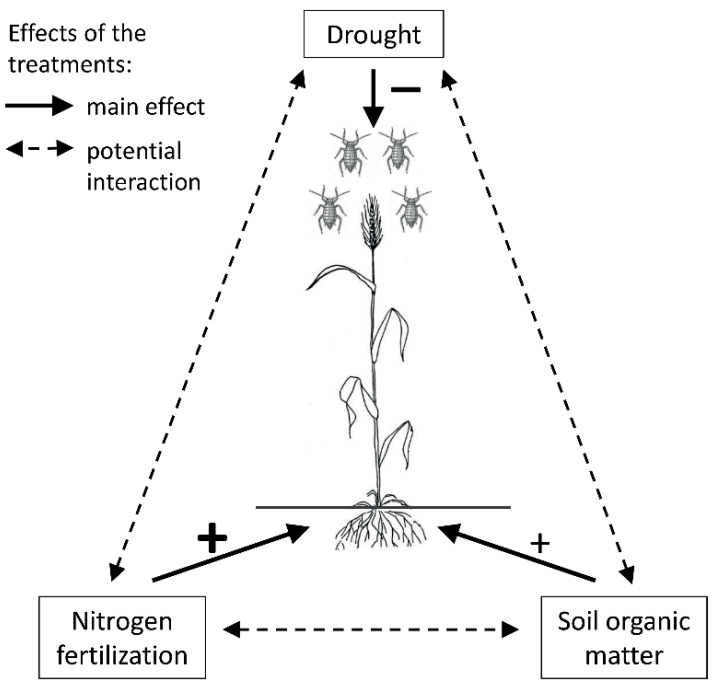

Fig. 3.1. Hypotheses underpinning the experimental set-up.

Our study aims to examine the effects of $\mathrm{N}$ fertilization on the performance of the grain aphid (Sitobion avenae F.), an important pest of cereal crops, under different levels of SOM content and water availability. In a greenhouse experiment we exposed wheat plants infested with S. avenae to contrasting levels of nitrogen fertilizer (13 vs. $\left.130 \mathrm{~kg} \mathrm{~N} \mathrm{ha}^{-1}\right)$, SOM (1.7 vs. $3.1 \%$ ) and to different water regimes (well-watered vs. drought conditions). The selected high levels of SOM content and N input represent realistic values for intensive cropping systems. We hypothesized that (Fig. 3.1): (i) high levels of $\mathrm{N}$ and SOM would increase aphid performance and that the $\mathrm{N}$ effect would be greater than the SOM effect; (ii) drought would limit aphid population growth. We also expected (iii) that the three experimental factors ( $\mathrm{N}$ fertilization, SOM and water availability) would interactively shape aphid performance. In particular, we hypothesized that high SOM would attenuate the negative effects of drought. 


\section{Drought and soil organic matter modify fertilization effects on aphid}

\section{Materials and methods}

Study set-up

\section{$\underline{\text { Soil organic matter and plant material }}$}

The soil was collected in May 2013 at an experimental field of Wageningen University \& Research located in Vredepeel (Limburg, The Netherlands) where a long-term experiment on soil health has been underway since 2006 (Korthals et al. 2014). The soil texture was $1.1 \%$ clay, 3.7\% silt and 94.9\% fine sand (Korthals et al. 2014). To investigate the effect of SOM on aphid performance keeping all the other physical and chemical properties unchanged, the soil was collected from the same area at two depths: $0-20 \mathrm{~cm}$ (c. 3.4\% SOM) and from $\mathrm{C}$ horizon $(\sim 100 \mathrm{~cm} ; 0 \% \mathrm{SOM})$ and then stored in plastic bags under similar environmental conditions. In December 2013 top soil was mixed with $10 \%$ soil from deeper layers (high SOM) and with 50\% soil from deeper layers (low SOM). We therefore achieved two levels of SOM, 3.1 and $1.7 \%$, reflecting realistic soil conditions in conventional cropping systems (Brady et al. 2015). After being sieved (1.0 cm mesh) the soils were set in 112 pots (5 L, 56 pots per SOM treatment). Six pairs of spring wheat seeds (Triticum aestivum var. Tybalt) were sown into the prepared pots and randomly placed in a climate controlled greenhouse at $60 \% \mathrm{RH}$, 16 L: $8 \mathrm{D}$, and $20 \pm 1{ }^{\circ} \mathrm{C}$ at day and $14 \pm 1{ }^{\circ} \mathrm{C}$ at night. Overhead lighting (sodium lamps, SON-T Philips, Eindhoven, The Netherlands) was supplied to ensure a minimum light intensity of $200 \mathrm{~W} / \mathrm{m}^{2}$ during the light period. After emergence, the best performing plant per pair was selected and the other clipped and removed in order to have six plants per pot. Plants were watered three times per week, with quantities as required, before applying different irrigation regimes.

\section{Water availability}

Two weeks after sprouting, pots were assigned to two different irrigation regimes, well-watered and drought conditions, achieved applying $300 \mathrm{ml}$ water/week (steady leaf turgor) and $150 \mathrm{ml}$ water/week (70\% of the plants showing wilting signs just before the weekly irrigation) respectively. Individual pots were placed on $3 \mathrm{~cm}$ deep plastic dishes to retain any excess water. 


\section{Chapter 3}

\section{$\underline{\text { Fertilization }}$}

Nitrogen fertilizer was added in the form of Hoagland nutrient solution, mainly consisting of calcium nitrate $\mathrm{Ca}\left(\mathrm{NO}_{3}\right)_{2}$ (see Hewitt (1966) for composition of the solution), at two different levels: $0.3 \mathrm{~g} /$ pot (high fertilization) and $0.03 \mathrm{~g} /$ pot (low fertilization) reflecting an amount of nitrogen of 130 and $13 \mathrm{~kg}$ $\mathrm{ha}^{-1}$, respectively. Following normal farming practices, nitrogen application was split in two occasions, at plant sprouting $(60 \%)$ and 4 weeks later $(40 \%)$. Pots were randomly rearranged once before the aphid inoculum and not moved again to not interfere with aphid growth.

\section{Aphid material}

Sitobion avenae (F.) (Hemiptera: Aphididae) adults were obtained from the Laboratory of Entomology, Wageningen University, and reared in a growth chamber maintained at $20-22^{\circ} \mathrm{C}, 16 \mathrm{~L}$ : 8 D. To support aphid population, new spring wheat plants were added approximately every two weeks, and old plants were removed after the aphids had settled on the new plants. A single apterous adult aphid of standard size was carefully placed with a fine brush on the oldest leaf of each plant (6 aphids per pot) three weeks after sprouting. Pots were placed individually in gauze nets. In order to measure development time (number of days between birth and reproduction) and aphid fecundity (number of offspring produced per adult), clip cages were placed on one adult aphid per pot. Once the adult aphid reproduced, only one neonate nymph was left inside the clip cage. The adult and the other nymphs (if present) were gently placed on another leaf. Clip cages were monitored daily and the nymph development time was scored for 11 days after the clip cage placement, the day by which most of individuals had reproduced. Five days later, fecundity was measured (number of third-generationoffspring) and the clip cages removed. Four weeks after inoculum all the aphids from each pot were removed with a soft brush, collected and stored at $4^{\circ} \mathrm{C}$ for weighing (total aphid biomass).

\section{Data analysis}

Data were analyzed with general linear models using the R software, version 3.1.1. (R Core Team 2015). We investigated the effect of $\mathrm{N}$ fertilization (high vs. low fertilization), SOM (high vs. low content) and drought (well-watered vs. drought conditions) and their interactions on three response 


\section{Drought and soil organic matter modify fertilization effects on aphid}

variables linked to aphid performance: development time, fecundity and total aphid biomass. Each treatment combination (eight in total) had 14 replicates. Development time and total aphid biomass were log-transformed to achieve normal distribution and homoscedasticity of model residuals. The analysis regarding aphid development time was based on data from 58 pots, fecundity on data from 94 pots (replicate loss were due to leaf damages caused by clip cages), and those regarding total aphid biomass on 110 pots (for two pots were lost during final measurements). Tukey multiple comparison test was applied to determine significant differences among treatments.

\section{Results}

Fertilization influenced aphid development time (Table 3.1): nymphs developed $8 \%$ faster when high $\mathrm{N}$ inputs were delivered to wheat plants (11.0 \pm 0.6 days, low $\mathrm{N}$ input; $10.0 \pm 0.6$ days, high $\mathrm{N}$ input). High level of SOM increased aphid fecundity (number of offspring per adult) by $44 \%$ compared to lower SOM content. Fertilization also influenced aphid fecundity. However, its effect depended on water availability: high $\mathrm{N}$ input increased the number of offspring by $63 \%$, but only under wellwatered conditions (Fig. 3.2), whereas it did not affect fecundity under drought conditions. All three treatments, as well as the two-way interactions between fertilization and SOM or water availability, affected the total aphid biomass. Fertilization strongly influenced this variable. However, the increment in total aphid biomass owing to higher N inputs depended on SOM content and water availability (Fig. 3.3). It was stronger under low SOM compared to high SOM content (Fig.3a, 194 vs. $65 \%$ total biomass increase) and under well-watered conditions compared to drought (Fig. 3b, 163 vs. $57 \%$, total biomass increase). 
Chapter 3

Table 1. Results of general linear models testing the effect of nitrogen fertilization (N; high vs. low), soil organic matter content (SOM; high vs. low) and water availability (water; well-watered vs. drought) and their interactions on development time, fecundity, and total aphid biomass of Sitobion avenae. Significant $(\mathrm{p}<0.05)$ effects are highlighted in bold.

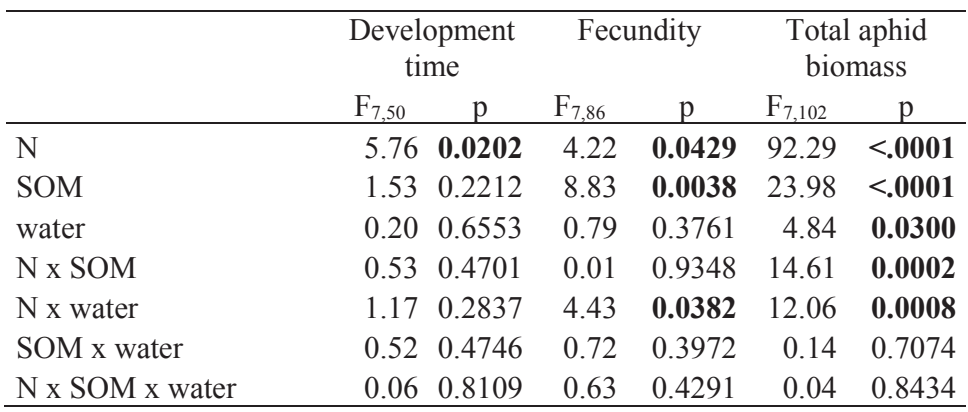

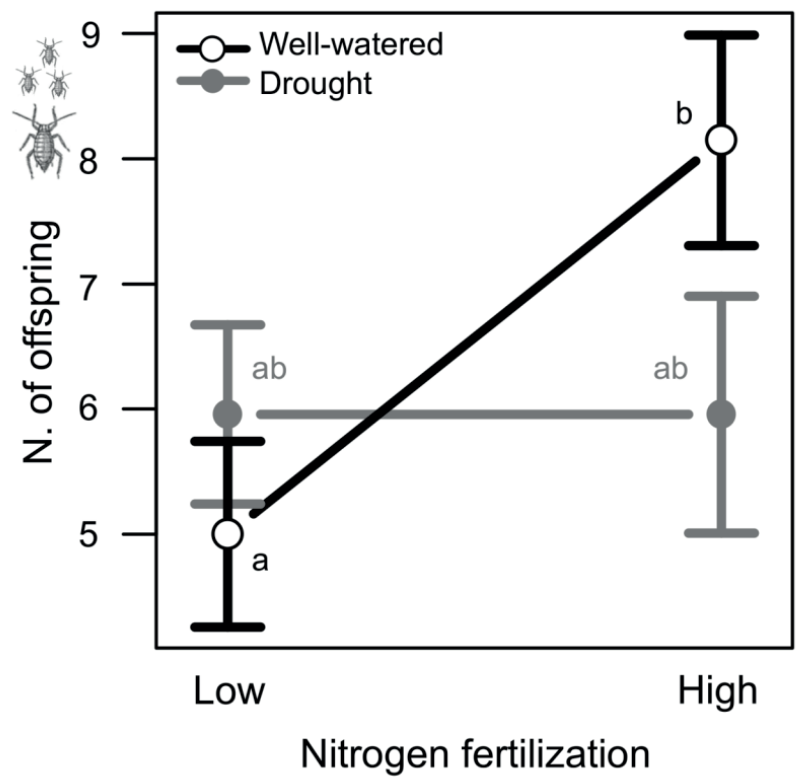

Fig. 3.2. Effects (mean \pm SE) of nitrogen fertilization and water availability on aphid fecundity (number of offspring per adult). Different letters indicate significant differences among treatment combinations ( $\mathrm{p}<0.05$, Tukey multiple comparison test). 
(a)

(b)

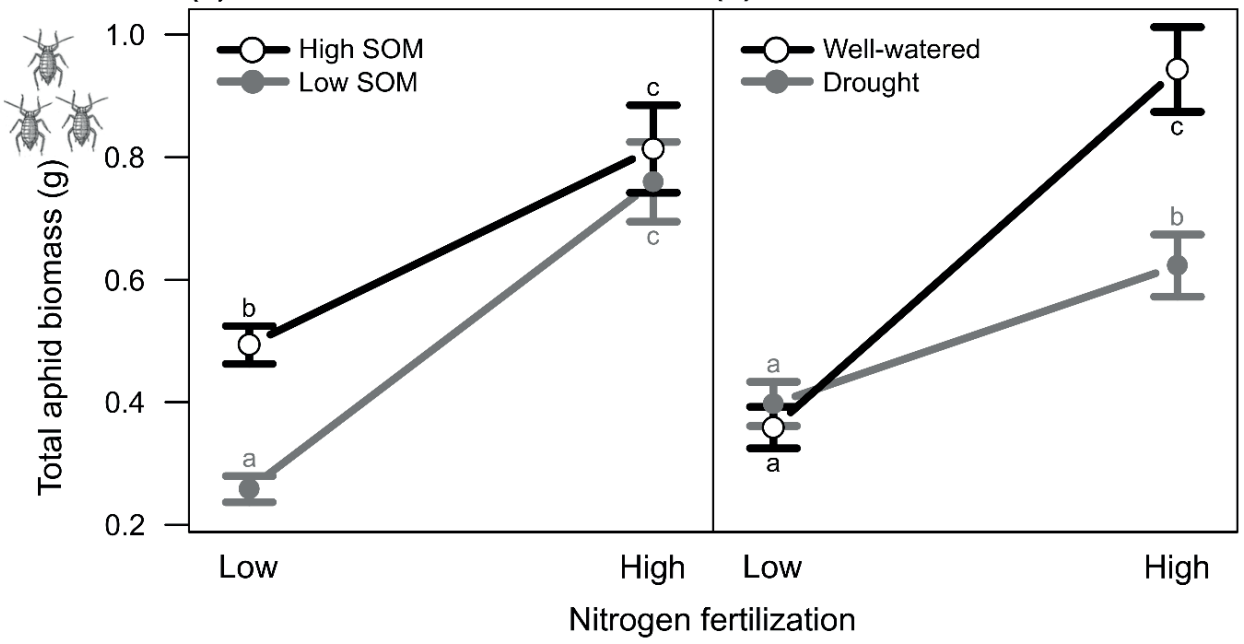

Fig 3.3. Effects (mean $\pm \mathrm{SE}$ ) of nitrogen fertilization, SOM and water availability on total aphid biomass per pot. Interactions between fertilization and SOM (a) and between fertilization and water availability (b). Different letters indicate significant differences among treatment combinations $(\mathrm{p}<$ 0.05 , Tukey multiple comparison test). 


\section{Chapter 3}

\section{Discussion}

We explored the combined effects of $\mathrm{N}$ fertilization, soil organic matter and water availability on the performance of the grain aphid, an important pest in cereals. We found SOM content and water availability to modify the positive effects of $\mathrm{N}$ inputs on aphid growth. Performance increase due to fertilization was stronger under low SOM levels and under well-watered conditions. Our study contributes to a deeper understanding of the factors shaping aphid performance, especially those linked to SOM management and drought. The results will help predicting the aphid population response to common soil management practices under a climate change scenario.

High $\mathrm{N}$ inputs to wheat plants led to higher aphid performance, decreasing development time and increasing fecundity and the total aphid biomass. As mentioned before, the positive effect of $\mathrm{N}$ fertilization on growth of the aphid S. avenae, via enhanced plant quality is well established (Khan \& Port 2008; Schütz, Bonkowski \& Scheu 2008; Nowak \& Komor 2010; Aqueel \& Leather 2011). Nitrogen level in the diet of herbivorous invertebrates is in fact the most important factor limiting their performance (Awmack \& Leather 2002). However, we found that the effects of $\mathrm{N}$ fertilization on aphid populations depended on SOM content and on water availability, confirming our third hypothesis. The increase in aphid performance owing to higher N inputs was stronger under low SOM compared to high SOM (individual body weight and total aphid biomass). The interaction between fertilization and SOM is probably explained by the effects of high fertilization that might have boosted aphid population hiding the growth due to high SOM, which was observable only under lower N inputs. Aphid populations probably reached a biological limit in growth rate caused by high fertilizer application under both poor and rich SOM conditions (Douglas 2003; Douglas et al. 2006; Sauge, Grechi \& Poëssel 2010). The effects of SOM on aphid growth were similar to those of fertilization, but with smaller effect size (e.g. no effect on development time). High SOM content increased fecundity and aphid biomass, indicating that organic matter in the soil acted as a source of nutrients for the crop, supporting higher plant quality and therefore increasing aphid performance. SOM is known to provide $\mathrm{N}$ to plants and to increase the availability of many micronutrients essential for crop growth (Matus \& Rodríguez 1994; Loveland \& Webb 2003) improving the nutritional status of tissues and 


\section{Drought and soil organic matter modify fertilization effects on aphid}

phloem, evidently favoring herbivores. We provide here evidence for the positive response of a sap feeding pest to increased levels of SOM, levels that represent realistic values for conventional cropping systems.

As expected, water availability strongly influenced aphid growth limiting the total aphid biomass. This result is in line with previous findings showing lower aphid performance in response to plant water stress (Sumner, Eikenbary \& Johnson 1986; Johnson et al. 2011; Pineda et al. 2016). The prolonged drought condition probably limited the ability of aphids to access plant resources via reduced turgor and increased sap viscosity (Hale et al. 2003). Drought negatively affected S. avenae, limiting fecundity and total aphid biomass increase under high $\mathrm{N}$ input. This might be the result of water stress effects both on aphid feeding ability (as mentioned before) and on plant performance. It is in fact known that $\mathrm{N}$ uptake by wheat plants is constrained by limited water availability (Barraclough, Kuhlmann \& Weir 1989). Prolonged water stress might therefore blur the well-known relationships between $\mathrm{N}$ fertilization and sap-feeding pests. Although drought can have severe negative impacts on winter wheat production (Eitzinger et al. 2003), the crop should be able to cope better with aphid attacks than under normal weather conditions, potentially reducing pest-related losses. Surprisingly, higher SOM content did not reduce the negative effect of drought on aphid growth. SOM is expected to increase soil water holding capacity, increasing water availability to plants under drought conditions (Bot \& Benites 2005). However, other soil characteristics such as soil texture are also known to strongly influence water holding capacity and its interaction with SOM has been explored in previous studies, with contrasting results (Bauer \& Black 1992; Hudson 1994).

Our study demonstrated that water availability and SOM modify fertilization effects on herbivore pest performance in cereals. SOM and its effect on plant nutritional status moderately increased pest performance only at very low $\mathrm{N}$ inputs, while under common fertilization rates the positive effect of SOM on pest growth disappeared. These results suggest that the current practices promoting SOM and associated ecosystems services such as soil fertility, carbon sequestration and flood regulation (Bommarco, Kleijn \& Potts 2013) might not have negative consequence on crop protection under conventional cropping systems. Moreover, drastic changes in precipitation patterns resulting in 


\section{Chapter 3}

prolonged droughts might disrupt the capacity of crops to access nutrients both applied by farmers and naturally present in the soil, reducing aphid performance. Our findings provide a first insight into the potential consequences of adopting different soil fertility management strategies on aboveground pest performance in a world exposed to climatic changes. However, more studies exploring the potential interactions between farming practices and abiotic conditions and their effects on pest dynamics are needed to develop more effective crop protection strategies.

\section{Acknowledgements}

We thank Christian Chabot for the work assistance and Enric Frago for providing invaluable advices. The research leading to these results has received funding from the European Community's Seventh Framework Programme under grant agreement no 311781, LIBERATION Project (www.fp7liberation.eu) to LM and WvdP. 


\section{Chapter 4}

\section{Soil organic matter effects on nutrient provisioning, pest suppression, and crop yield}

Stijn van Gils, David Kleijn, Jorge Martín Rodríguez, Sarah Redlich, Michael P. D. Garratt, Zoltán

Elek, Gergely Boros, András Báldi, Emily A. Martin, Ingolf Steffan-Dewenter, Simon G. Potts, Vesna

Gagic, Arjen de Groot, Wim H. van der Putten

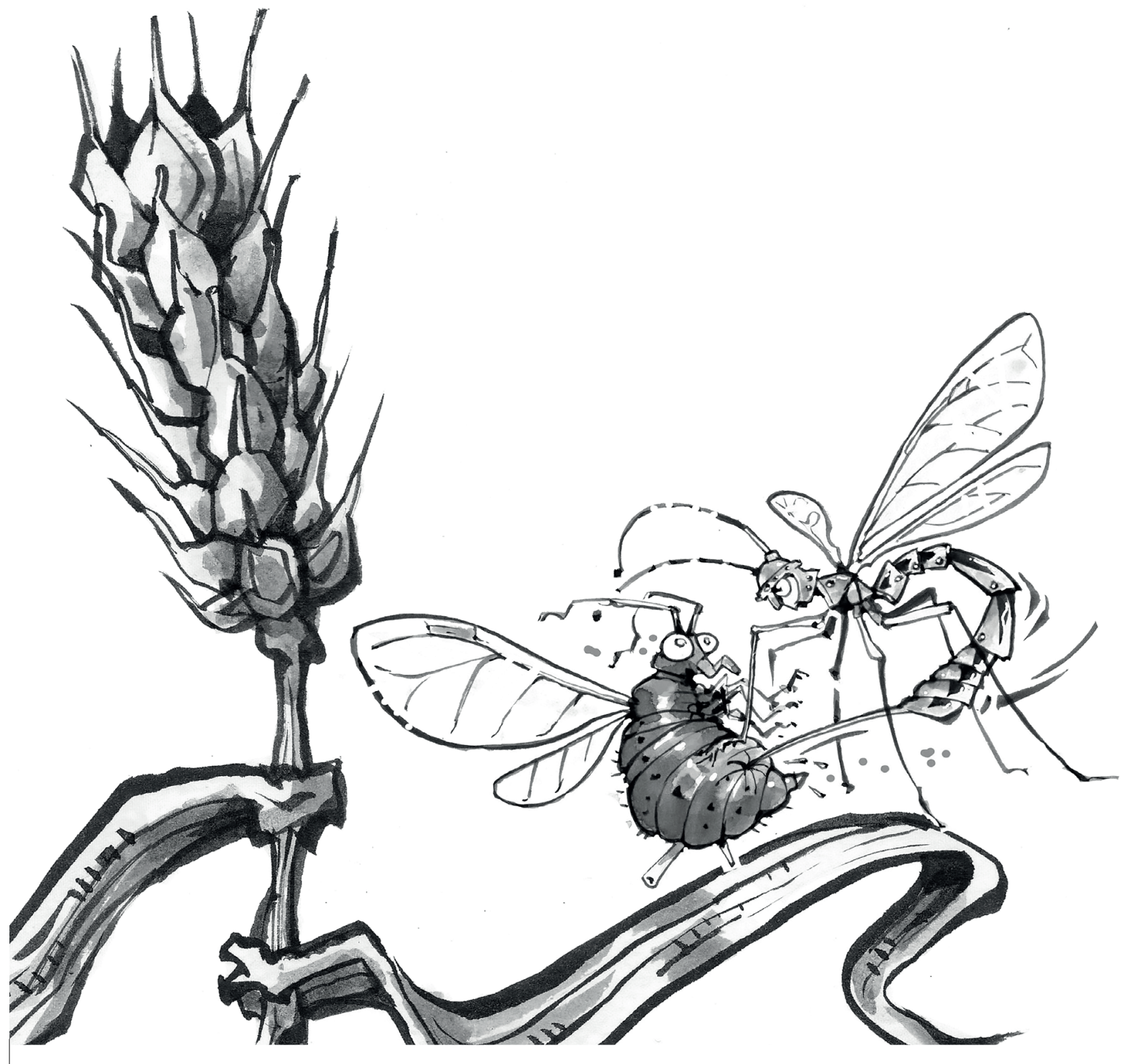




\section{Chapter 4}

\section{Abstract}

Enhancing soil organic matter, and thereby the soil organic carbon (SOC) content, is considered a method of counteracting the rise of atmospheric carbon dioxide levels. Increasing SOC content might be multi-functional, when also promoting nutrient availability, pest control, and other crop productionenhancing ecosystem services. However, multi-functionality of SOC is strongly based on theoretical considerations and small-scale experiments, whereas few, if any, have tested this under realistic conditions. We carried out field experiments with winter wheat (Triticum aestivum) in four European countries to examine how yield and other ecosystem services vary across a gradient of SOC contents. We selected 66 fields in United Kingdom, the Netherlands, Germany, and Hungary. In each country we paired fields with locally high and low SOC content and applied mineral fertilizer and control treatments. We assessed how low versus high SOC content and fertilizer application related to the potential availability of nitrogen, phosphorus and potassium, and how this affected performance and control of above-ground aphids. We also tested how potential nutrient availability influenced the relative effect of fertilizer on yield and found that a higher nutrient availability related to a decreased yield benefit from fertilizer. We show that within field pairs, a high SOC content did not relate to higher nutrient availability. Higher SOC content tended to relate to fewer aphids in fertilized plots, but this was not explained by aphid parasitism rate or ground-dwelling predator abundance. We conclude that higher SOC content does not necessarily translate into more nutrient availability, pest control, and higher wheat yield. Fields with high potential nutrient availability rates had less yield benefit from fertilizer. We propose that obtaining multifunctional benefits from carbon storage in agricultural soil requires more insights into effects of carbon storage on the quality of the soil organic matter and effects of that quality on ecosystem services. 


\section{Introduction}

The 21st Conference of the Parties to the United Nations (UN) Framework Convention on Climate Change (COP21) highlighted that an increase in Soil Organic Carbon (SOC) content may be an important tool in order to counteract climate warming. Without strong interventions the accumulation of carbon in terrestrial systems is too small to be significant (Post \& Kwon 2000), but it has been proposed that an increase of $0.4 \%$ per year in the global SOC content could compensate for global $\mathrm{CO}_{2}$ emission (Lal 2016). Agricultural soils are most promising for this purpose (Minasny et al. 2017). Such an approach could lead to an interesting multi-functionality, as increased SOC might also enhance various other ecosystem functions and services, such as soil structure and water-holding capacity (Lal 2006), below-ground disease suppression (Bailey \& Lazarovits 2003), and above-ground disease suppression (Birkhofer et al. 2008). However, it remains to be tested in the field whether higher levels of SOC indeed can promote multiple ecosystem services under a variety of environmental conditions.

SOC makes up approximately $50 \%$ of the total soil organic matter content (Fageria 2012) which forms the main energy source for soil organisms that decompose organic matter into plant-available nutrients such as N, P and K (Prescott 2010). According to a recent modelling study, enhancing SOC content may, at least partially, require less mineral fertilizer in order to obtain the same yield (Brady et al. 2015). However, decomposing soil organisms may also immobilize nutrients under enhanced levels of SOC (Tonitto et al. 2014). Although the immobilization of nutrients reduces leaching and subsequent environmental pollution (Goulding 2000), it can also reduce plant uptake of nutrients (Sebilo et al. 2013), suggesting a potential negative effect of SOC on yield. How mineralization and immobilization effects of SOC balance out across a variety of conditions in the field, and how this relates to crop yield, is poorly understood.

SOC and mineral fertilizer application both may alter the chemistry of crop plants, with possible consequences for the performance of pest organisms as these generally show enhanced performance when plant nutrient levels increase (Altieri \& Nicholls 2003; Garratt, Wright \& Leather 2010; Butler, Garratt \& Leather 2012). SOC and fertilization may, however, not have the same effects on pest 


\section{Chapter 4}

organisms; mineral fertilizer can enhance pest performance because the nutrients become more readily available, whereas an increase in SOC may lead to temporary nutrient immobilization, which makes plants less attractive for pests, even in combination with mineral fertilizer (Hasken \& Poehling 1995). Moreover, an increase in SOC content changes the soil microbial community composition (Fierer et al. 2009), which in turn might alter effects of fertilizer on aphids (Kos et al. 2015).

Besides a resource-based (named 'bottom-up') effect, SOC may also exert a possible predator (named 'top-down') effect on pests through an increase in the abundance of soil organisms involved in decomposition. These decomposer organisms may serve as alternative food for predators, thereby keeping their population density at a high level (Birkhofer et al. 2008). The energy input from this detrital system exceeds by far the energy input from the herbivore system, with the expected consequence that the detrital system pathway, as a side effect, also significantly influences control of plant herbivores (Scheu 2001). An increase in generalist predator species can be important in the suppression of pests, especially early during the growing season (Bianchi, Booij \& Tscharntke 2006; Martin et al. 2015). Therefore, increased SOC might, via enhanced amounts of predators feeding on decomposer organisms, indirectly enhance top-down control of above-ground insect pests.

A growing number of studies provides evidence that yields can be influenced by interaction of various regulating ecosystem services (Bennett, Peterson \& Gordon 2009; Lundin et al. 2013; Classen et al. 2014; Tamburini et al. 2015). These regulating ecosystem services may be related to SOC and effects are expected to depend, at least in part, on environmental conditions, such as soil texture (Grandy et al. 2009) and climate (Vleeshouwers \& Verhagen 2002; Conant et al. 2011). Therefore, a more complete understanding of the effects of SOC on multiple ecosystem services requires an integrated approach that includes multiple aspects of SOC (Bommarco, Kleijn \& Potts 2013), with experiments conducted under realistic field conditions (van Grunsven \& Liefting 2015). Thus far, many studies that consider the effects of SOC have predominantly focussed on one specific process, such as SOC decomposition or stabilization, in a carefully controlled setting or by modelling (Six et al. 2004; Schjønning et al. 2017). In contrast few, if any, studies have considered multi-functional aboveground and below-ground effects of SOC and consequences for yield under practical field conditions. 
Here, we report results from a replicated field experiment in four European countries along a northwest - south-east gradient. In each country we have chosen replicated paired field sites of relatively low and high SOC contents. Within each field, we experimentally assessed the effects of fertilizer application on wheat yield, examined mineralization of soil samples under controlled lab conditions, and quantified aphid numbers, parasitism rates and predator abundance in the field. We examined how SOC content relates to nutrient availability and above-ground pest control. We tested three hypotheses: (1) mineralization potential of N, P, K is highest in fields with high SOC content; (2) above-ground predatory arthropod abundance is highest and aphid performance lowest in fields with highest SOC content; (3) without mineral fertilizer, yield is higher in fields with highest mineralization potential of $\mathrm{N}, \mathrm{P}$, and $\mathrm{K}$. We will discuss the results with respect to multifunctional benefits of counteracting climate warming by storing $\mathrm{CO}_{2}$ (the so-called 4 per 1000 initiative) in agricultural soils (Minasny et al. 2017).

\section{Materials and methods}

Study design

In the winter of 2013-2014, we selected 16 winter wheat fields in each of three countries: the United Kingdom, the Netherlands, and Hungary, and 18 fields in Germany. The fields within countries were paired such that one field in each pair had relatively low and the other relatively high SOC content. At the same time, environmental factors that could be confounding, including soil characteristics such as, $\mathrm{pH}_{\text {water, }}$, soil texture (measured) and the previous crop (farmer interview), and the proportion of seminatural habitat in a $1 \mathrm{~km}$ radius around the plot (based on the topographic map), were matched within pairs as far as possible. At each of the 66 fields we established 2 plots with a minimum size of $14 \times 12$ $\mathrm{m}$. One subplot did not receive mineral fertilizer (F0), whereas the other plot received mineral fertilizer (F1). Mineral fertilizer was supplied manually and in accordance with the regional standard within each country: $90 \mathrm{~kg} \mathrm{~N} / \mathrm{ha}$ in Hungary (ammonium-nitrate), $170 \mathrm{~kg} \mathrm{~N} / \mathrm{ha}$ in the Netherlands (calcium- ammonium-nitrate), $190 \mathrm{~kg} \mathrm{~N} / \mathrm{ha}$ in Germany (ammonium-sulphate-nitrate) and United Kingdom (ammonium-nitrate). Fungicides and herbicides were applied by the farmers when they were spraying the entire fields. However, the plots used for our study were not treated with insecticides. 


\section{Chapter 4}

\section{Measurements}

All fields were visited at least six times during the growing season. In each sub-plot, numbers of aphids (mainly Metopolophium dirhodum, Rhopalosiphum padi, and Sitobion avenae) were counted at the development stages of wheat stem elongation, which corresponds with BBCH scale 35+ (Lancashire et al. 1991), booting (roughly BBCH 40-50) and at flowering (roughly BBCH 50-65). For every count we determined the number of aphids on 50-100 random tillers within each sub-plot. The data were used to calculate the average number of aphids and mummies (aphid parasitoids) per tiller.

Abundances of mobile ground-dwelling predators were determined using pitfall traps in the centre of each plot that were installed at the wheat booting stage (roughly BBCH 40-50) and left in the field for 10 days. Pitfall traps were filled with a propylene glycol solution to conserve the sample and avoid predation inside the trap, and covered with a roof to avoid dilution by rain water. After removal of the pitfall traps, the arthropods caught were put into vials filled with ethanol and subsequently classified into the groups Carabidae, Staphylinidae, Lycosidae, web spiders (various families), Opiliones, Dermaptera, Chilopoda, Formicidae, and unknowns. We lumped the most important predator groups (at least 50 occurrences in all pitfalls in the dataset being Carabidae, Staphylinidae, Lycosidae and Chilopoda) together to provide a single estimate for the overall number of ground-dwelling predators in each plot.

To determine potential mineralization of nitrogen $\left(\mathrm{NO}_{\mathrm{x}}-\mathrm{N}\right.$ and $\left.\mathrm{NH}_{4}-\mathrm{N}\right)$, phosphorus $\left(\mathrm{P}_{\text {Olsen }}\right)$, and potassium $(\mathrm{K})$, we used an incubation experiment. Prior to this incubation experiment, at wheat booting phase (roughly BBCH 40-50), we collected $\geq 15$ soil cores of $2.5-3 \mathrm{~cm}$ diameter from a surface of around $100 \mathrm{~m}^{2}$ from both fertilized and control plots. After collection, cores were kept at 4 ${ }^{\circ} \mathrm{C}$ in a closed plastic bag in a cool box, and shipped to the Netherlands, where the soil cores from each plot were carefully sieved using $4 \mathrm{~mm}$ mesh size, homogenized, and used for an incubation experiment. To estimate available $\mathrm{N}, \mathrm{P}$ and $\mathrm{K}$ at the start of the incubation experiment, we dried $50 \mathrm{~g}$ of soil at $40{ }^{\circ} \mathrm{C}$ for $\geq 120$ hours and stored the soil dry at room temperature. Next, we incubated 40 gram (based on dry weight) of the field soil in a glass bottle at $60 \%$ of the water holding capacity. Subsequently, we covered the bottle with parafilm to avoid evaporation, and placed it in a climatized 
chamber at $20{ }^{\circ} \mathrm{C}$. After 21 days we measured $\mathrm{NO}_{x}$ (usually mainly $\mathrm{NO}_{3}$ and some $\mathrm{NO}_{2}$ ) and $\mathrm{NH}_{4}$ using $\mathrm{KCl}$ extractions (Griffin et al. 2009), plant available $\mathrm{P}$ (Polsen) using $\mathrm{NaHCO}_{3}$ extraction (Olsen, Cole \& Watanabe 1954), and plant available $\mathrm{K}$ using $\mathrm{CaCl}_{2}$ extraction (based on Griffin et al. 2009). This measure produces a value for potential availability of N, P and K that can be compared among soil samples.

To estimate yield, we harvested wheat tillers from four random squares of $0.25 \mathrm{~m}^{2}$ in each sub-plot, and pooled these samples to have a representative sample of $1 \mathrm{~m}^{2}$. Wheat tillers were cut at $2 \mathrm{~cm}$ above the soil surface, placed in cotton bags, and air-dried. Seeds were collected using an automatic thresher, dried at $70^{\circ} \mathrm{C}$ and weighed.

Analyses

To test whether the amount of potential nitrogen $(\mathrm{N})$, phosphorous $(\mathrm{P})$ and potassium $(\mathrm{K})$ mineralization, numbers of aphids per tiller, aphid parasitism rate and the number of ground dwelling predators were affected by SOC content (low and high), mineral fertilizer application (no, yes) and their interaction, we used a linear mixed model with random intercept. In a complementary approach, we additionally tested whether there is an overall general relation - not necessarily caused by management -between SOC content and mineralization potential. For this we used the absolute percentage SOC (\%), mineral fertilizer application (no, yes) and their interaction. We related these variables to mineralization potential of $\mathrm{N}, \mathrm{P}$ and $\mathrm{K}$, by performing linear mixed models (see Appendix S4.1). All linear mixed models used random intercepts and country, field pair, and wheat field as nested random factors. We visually inspected whether residuals were normally distributed. Some data were removed prior to analysis: in two fields the intended unfertilized plots were accidentally fertilized and one pitfall trap was destroyed. There was one $\mathrm{K}$ data point that deviated extremely from all other points, suggesting an error during chemical analysis. This point was also omitted.

We calculated a Spearman correlation diagram in order to determine how mineralization potentials, aphids per tiller, parasitism rate and the number of ground-dwelling predators, and seed weight were 


\section{Chapter 4}

related to each other, while correcting the significance level $(\mathrm{P}=0.05)$ with a Bonferroni correction for multiple testing.

To test whether $\mathrm{N}$, $\mathrm{P}$ and $\mathrm{K}$ mineralization potential may have affected the contribution of mineral fertilizer on yield, we calculated the relative contribution of fertilizer on yield:

$F=\frac{Y_{f}-Y_{u}}{Y_{f}}$

where $F$ is the relative yield effect of mineral fertilizer application in a field, $Y_{f}$ the yield in the fertilized plot and $Y_{u}$ the yield in the unfertilized plot. We then performed a linear mixed model with $\mathrm{N}, \mathrm{P}$ and $\mathrm{K}$ mineralization potential and all two-way interactions to explain the relative contribution of fertilizer on yield. Additionally, we tested whether mineral fertilizer application, $\mathrm{N}$ mineralization potential, the number of aphids and all two way interactions were related to seed weight by performing linear mixed models.

All analyses were performed using R 3.2.2 (R Core Team 2015), with the package nlme (Pinheiro et al. 2014) for Linear Mixed Models. 


\section{Results}

Mineralization potential of $N, P$, and $K$

The mineralization potential of $\mathrm{N}$ and $\mathrm{P}$ were neither affected by low vs high SOC content nor by application of mineral fertilizer (Table 4.1, Fig. 4.1a, b). However, K mineralization potential was significantly influenced by an interaction between SOC content and fertilizer application (Table 4.1). Fertilizer application tended to increase $\mathrm{K}$ mineralization potential when SOC content was low, but decreased K mineralization when SOC content was high (Fig. 4.1c), however, these trends in K mineralization were not significant in a post-hoc test. In spite of the results from the factorial analysis, there was a positive correlation between percentage SOC content and potential $\mathrm{N}$ mineralization (see Appendix S.4.1 in Supporting Information). Therefore, SOC had a positive effect on N mineralization across a larger gradient of SOC contents, but not when comparing paired fields with low vs high percent SOC in a factorial analysis. 
Chapter 4

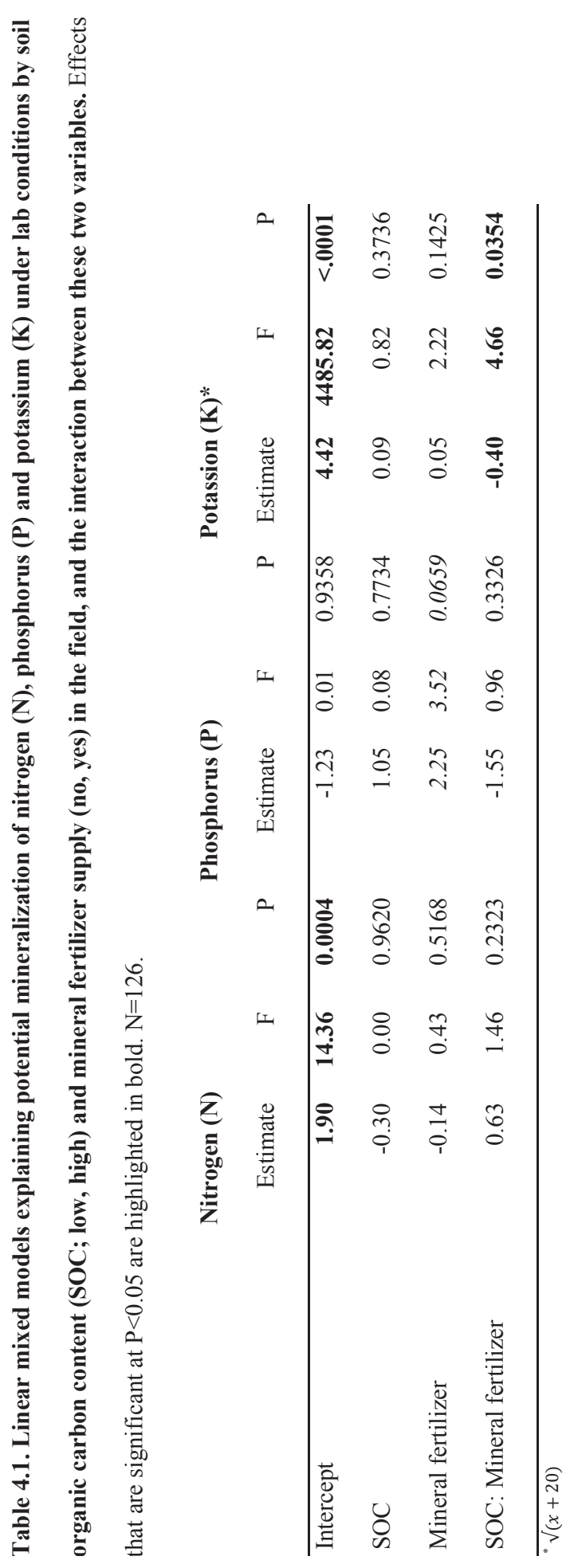



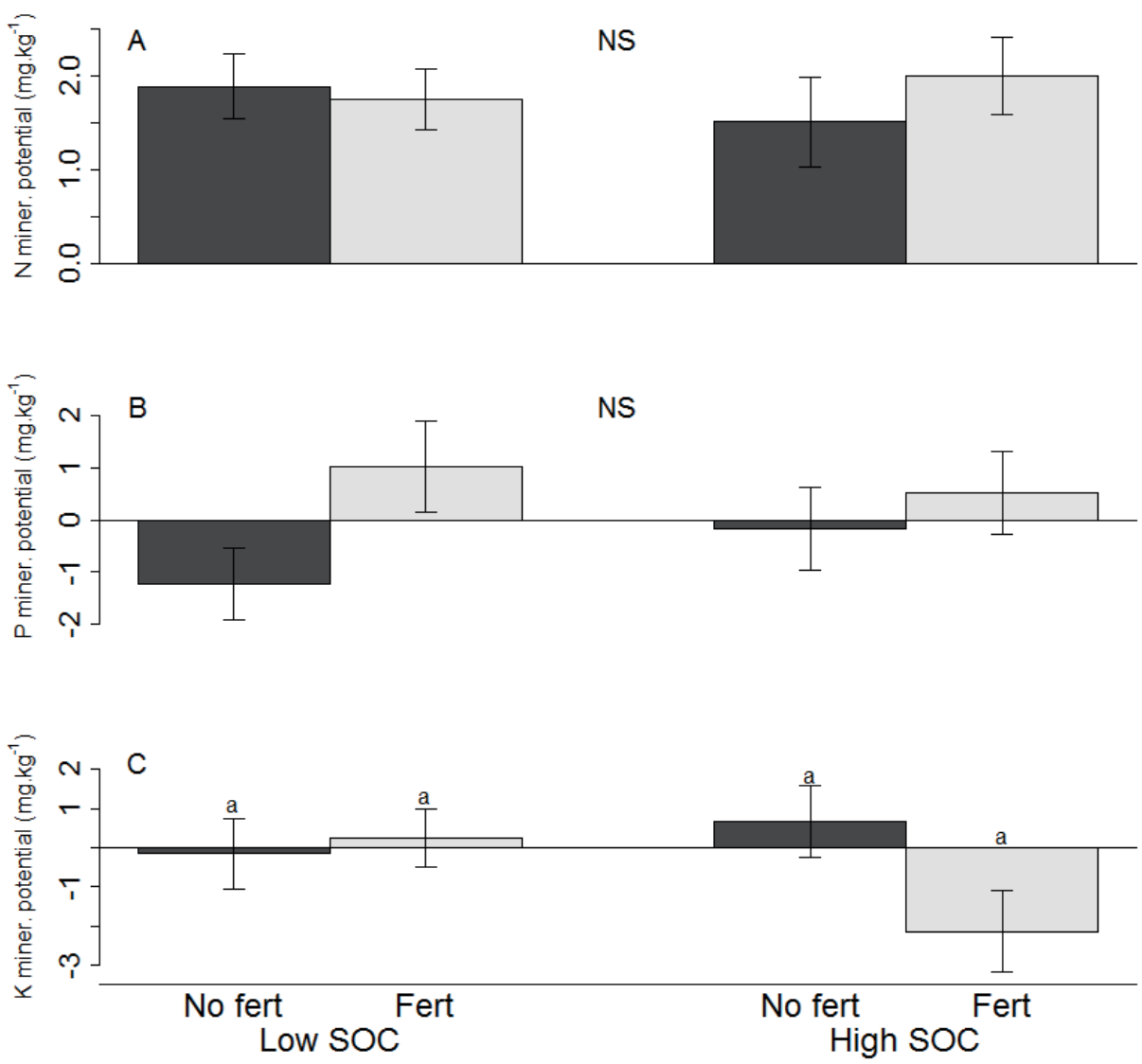

Fig. 4.1. Mineralized potential of (a) $\mathrm{N}\left(\mathrm{NO}_{\mathrm{x}}+\mathrm{NH}_{3}\right.$ ), (b) $\mathrm{P}$, and (c) $\mathrm{K}$ (all in mg.kg-1) explained by organic carbon content and with and without nitrogen fertilizer supply. Error bars represent standard errors. Significant differences between groups are indicated by different letters (Tukey Honest Significant Difference contrast test; see statistical model in Table 1). 


\section{Chapter 4}

Yield

Seed weight (yield) was significantly influenced by fertilizer application (7.6 ton/ha with vs. 4.9 ton/ha without fertilizer). However, the mineralization potential of $\mathrm{N}$ was negatively related to yield (Appendix S4.2, Table 4.2 respectively). In plots with high $\mathrm{N}$ mineralization potential the positive effect of mineral fertilizer on yield disappeared $(\mathrm{F}=5.38, \mathrm{p}=0.032, \mathrm{n}=60$, Fig. 4.2). In some plots with relatively high $\mathrm{N}$ mineralization potential yield was negatively influenced by mineral fertilizer application. The yield benefit of mineral fertilizer application did not change under increased mineralization potential of $\mathrm{P}$ and $\mathrm{K}(\mathrm{F}=0.16, \mathrm{p}=0.695, \mathrm{n}=60$ and $\mathrm{F}=0.067, \mathrm{p}=0.798$, respectively). However, the effect of $\mathrm{N}$ mineralization potential on seed yield depended on $\mathrm{P}$ mineralization potential $(\mathrm{F}=4.72, \mathrm{p}=0.043)$. Under a higher $\mathrm{P}$ mineralization potential, the negative relation between $\mathrm{N}$ mineralization potential and seed yield became weaker (Fig. 4.2). 
Multi-functionality of soil carbon storage

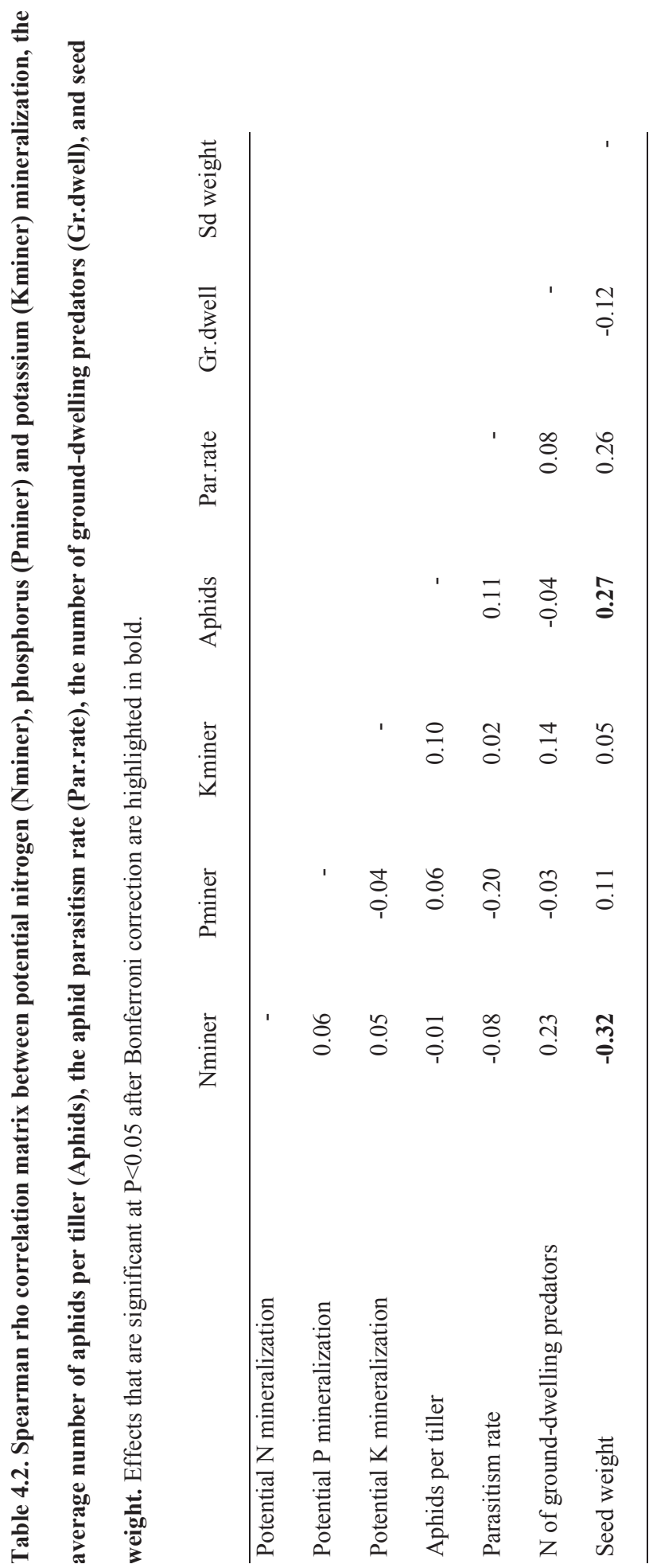




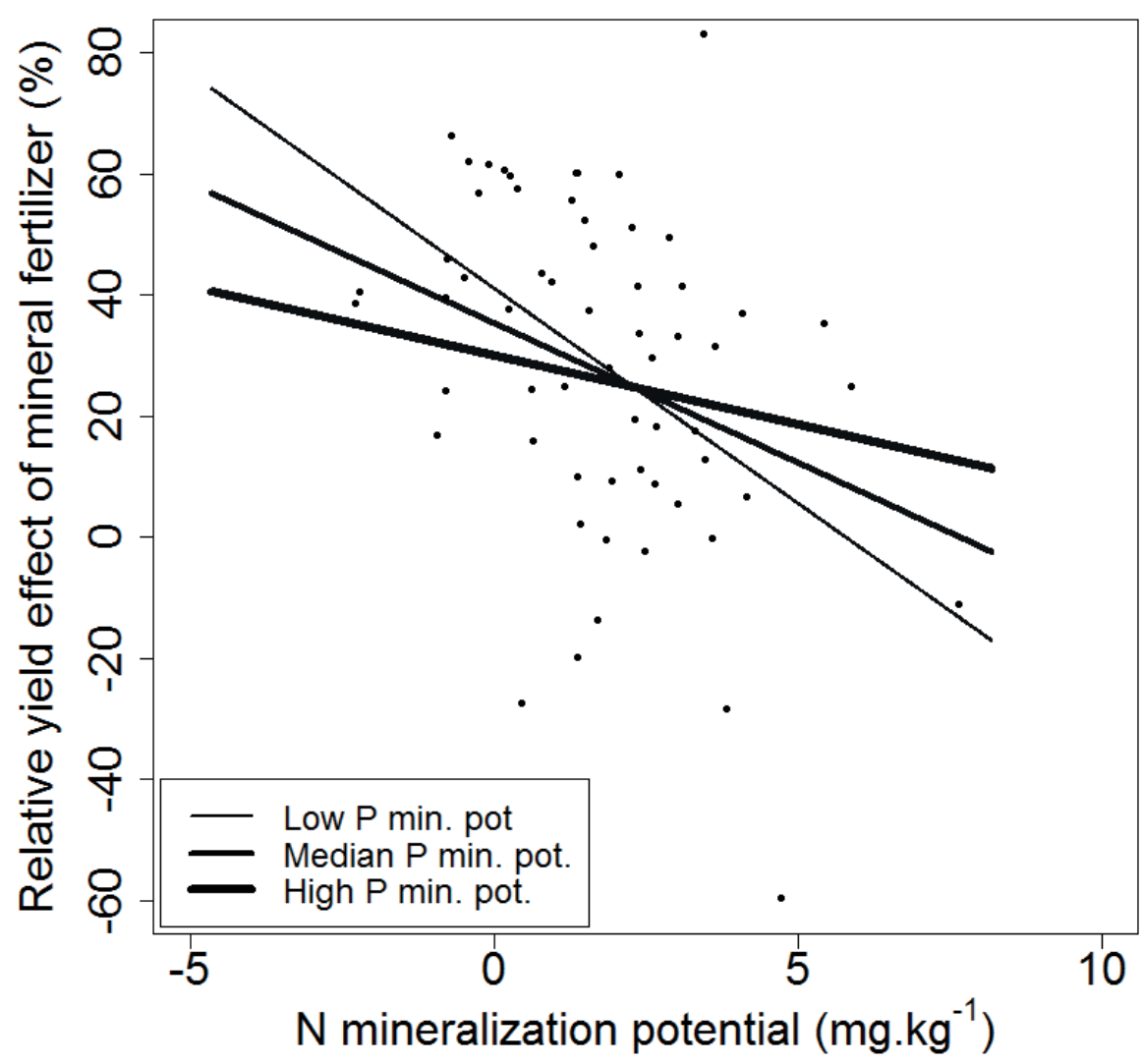

Fig. 4.2. Relative yield effect $\left(\frac{\text { yield fertilized plot-yield unfertilized plot }}{\text { yield fertilized plot }}\right.$, in \%) of mineral fertilizer application explained by $\mathrm{N}$ mineralization potential $\left(\mathrm{mg} \mathrm{kg}^{-1}\right)$ under different rates of $\mathbf{P}$ mineralization potential $\left(\mathbf{m g} \cdot \mathrm{kg}^{-1}\right)$. The thin line represents the first quantile of P mineralization potential $\left(-1.07 \mathrm{mg} \cdot \mathrm{kg}^{-1}\right)$, the medium line median P mineralization potential $\left(0.14 \mathrm{mg} \cdot \mathrm{kg}^{-1}\right)$ and the thick line the third quantile of P mineralization potential $\left(1.26 \mathrm{mg} \cdot \mathrm{kg}^{-1}\right)$. 
Above-ground arthropods

The number of aphids per tiller was affected by the interaction between SOC content and mineral fertilizer application (Table 4.3). However, the effects were not significant in a post-hoc test.

Therefore, in fields with low SOC content, mineral fertilizer application tended to decrease the number of aphids per tiller, whereas in fields with high SOC content mineral fertilization application tended to increase the number of aphids per tiller (Fig. 4.3a). Parasitism rate of aphids and the number of ground-dwelling predators were not influenced by SOC content, mineral fertilizer application or their interaction (Table 4.3, Fig. 4.3b and Fig. 4.3c respectively). The number of aphids correlated with yield. However, the number of aphids, parasitism rate of aphids, and the number of ground-dwelling predators did not correlate with any of the other measured variables (Table 4.2). 
Chapter 4

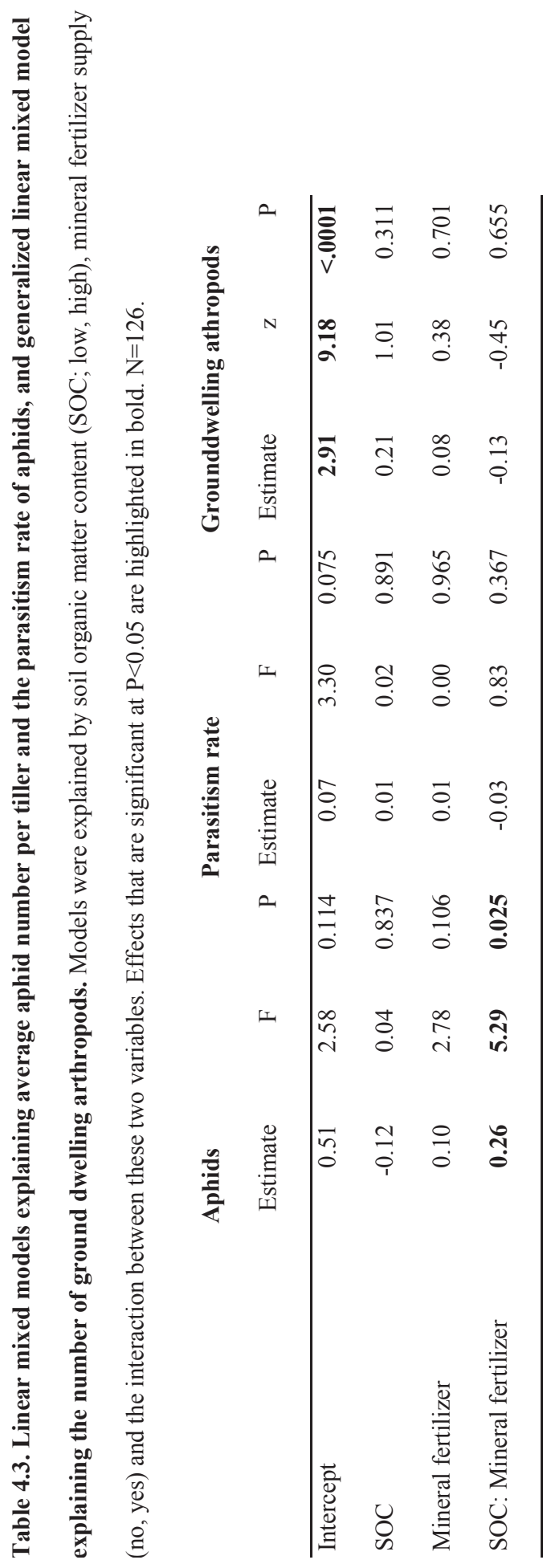



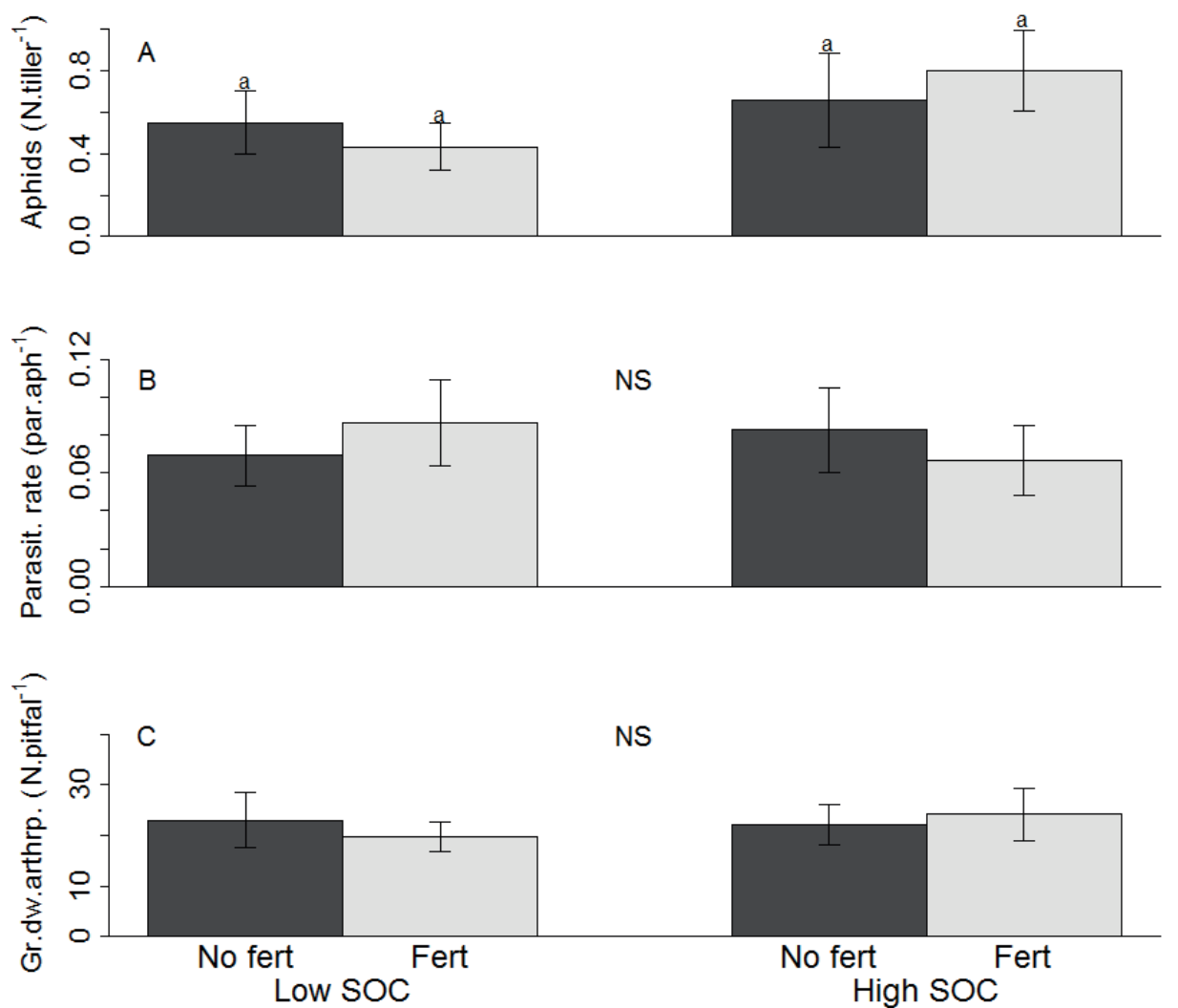

Fig. 4.3. Numbers of above-ground arthropods per pitfall trap explained by low and high soil organic matter content and with and without nitrogen fertilizer supply. (a) Number of aphids (N/tiller), (b) Parasitism rate of aphids (parasitized aphids/total aphids), and (c) number of ground dwelling arthropods (n/pitfall). Error bars represent standard errors. If the statistical model (Table 1) was significant, significant differences between groups are indicated by different letters (Tukey Honest Significant Difference contrast test). 


\section{Chapter 4}

\section{Discussion}

Increasing soil organic carbon (SOC) content has been proposed as a method to mitigate climate change via carbon storage (Lal 2016). At the same time, increasing SOC has also been proposed to promote ecological intensification (Bommarco, Kleijn \& Potts 2013), as it might make agriculture less dependent on external inputs of mineral fertilizer (Brady et al. 2015) and pest control chemicals (Birkhofer et al. 2008). We tested all these assumptions under a variety of environmental conditions in 66 wheat fields across Europe by comparing mineralization potential, aphid numbers, and yield in paired fields with low versus high SOC content. We studied how SOC content affected mineralization potential, pest control and seed yield of wheat. Opposite to expected, we found no differences between paired fields with high vs low SOC content in $\mathrm{N}$ mineralization potential and natural enemies of aphids. However, when correlating percentage SOC across all fields with $\mathrm{N}$ mineralisation, our data reveal that when considering a large SOC content gradient across all four regions in Europe, there is a positive correlation between SOC and $\mathrm{N}$ mineralization. Interestingly, in fields with high $\mathrm{N}$ mineralization potential, nitrogen fertilizer application had a less positive effect on yield than in fields with low $\mathrm{N}$ mineralization potential.

We tested the hypothesis that high SOC content would have a positive effect on mineralization potential of the macronutrients $\mathrm{N}, \mathrm{P}$, and $\mathrm{K}$ compared to low SOC content. When correlating all individual SOC contents with potential mineralization, $\mathrm{N}$ mineralization potential indeed related positively to percentage SOC content, but P and K not. Other work also supports the view that especially $\mathrm{N}$ cycling is strongly linked to SOC, whereas this pattern is less clear with P and $\mathrm{K}$ (Soon \& Arshad 1996). This linkage between SOC and N mineralization potential can be explained by the role of SOC content in steering biological processes, which are subsequently more strongly related to $\mathrm{N}$ than to $\mathrm{P}$ or $\mathrm{K}$ mineralization (Creamer et al. 2016). A correlation between SOC content, nutrient availability and yield, implies an effect of SOC content on nutrient availability, however, cause and consequence cannot be separated by our correlative approach. For example, high-productive fields may as well receive more organic matter as a result of high (root) biomass production (Hijbeek et al. 2016). 
Although we found that SOC content as percentage generally related to enhanced $\mathrm{N}$ mineralization, we observed that this relation disappeared in a factorial comparison of similar field pairs with low versus high SOC content. Although the differences between low and high SOC content may have been due to a variety of factors, our results suggest that management focussing on enhancing SOC content may not necessarily have multi-functional consequences for other ecosystem services. One possible explanation is that enhancing SOC leads to an increase in recalcitrant organic matter that does not contribute to mineralization (Janzen 2006), although it has been stated that accessibility of SOM in the soil is more important for decomposition than how recalcitrant the material is (Dungait et al. 2012). Nevertheless, our results do not support model results suggesting that measures to increase SOC and subsequently carbon sequestration, will enhance nutrient availability (Brady et al. 2015). These suggestions would be supported by our correlation approach, but not when taking a factorial approach. Apparently, our factorial approach provides a more conservative estimate of possible consequences of enhanced SOC content.

Our results do not support the view that more SOC automatically leads to a win-win situation in which carbon sequestration is combined with more nutrient availability (Lal 2004b; Lal 2016). This in itself is perhaps not unexpected, because SOC contributes to nutrient availability if it is being decomposed, while carbon sequestration in arable soils is higher when decomposition of SOC is lower (Janzen 2006; Wood et al. 2016). To obtain a higher nutrient availability from enhancing SOC contents it may be important to focus more on the quality (e.g. C:N ratio, secondary compounds, lignin content) of organic inputs than on quantity alone (Mamo et al. 1999). A high quality organic input, however, might contribute less to long-term C storage in soil than when using low quality organic material (Loveland \& Webb 2003), implying that conditions for a win-win strategy between carbon sequestration and enhanced nutrient availability by mineralization of the soil organic matter might not be easily met.

We expected that $\mathrm{N}$ mineralization potential would relate positively to wheat yield, and that the effect of mineral fertilizer application would be greater in fields with low $\mathrm{N}$ mineralization potential. Indeed, we found this to be the case, but in contrast to our expectation a higher mineralization potential related 


\section{Chapter 4}

negatively to wheat yield under fertilized conditions, rather than less positive. Net $\mathrm{N}$ mineralization is the result of gross $\mathrm{N}$ mineralization and $\mathrm{N}$ immobilization and both these processes are driven by bacteria and fungi that decompose SOC (Bauer \& Black 1994; Schimel \& Schaeffer 2012; Whitman et al. 2016). The SOC content usually correlates with microbial abundance and microbes may temporarily take up nutrients to enhance decomposition of SOM (Bronick \& Lal 2005). A higher percentage SOC content may, therefore, result in temporary immobilization of the $\mathrm{N}$ fertilizer. Although we attempted to select the paired fields such that other environmental and management conditions were as much the same, it is not possible to exclude that hidden factors did not play any role. For example, it could be that soils with a higher $\mathrm{N}$ mineralization potential were a bit wetter during the growing season, thereby indirectly affecting yield. Field experiments where SOC has been increased on purpose can be used to exclude such possibilities, which could be an interesting next step to take.

In the factorial analysis, aphid abundance was not affected by high SOC content and there was also no effect of mineral fertilizer on aphid abundance. However, in fields with low SOC content, mineral fertilizer application tended to decrease the number of aphids per tiller, while in fields with high SOC content mineral fertilization application tended to increase the number of aphids per tiller. An increase in aphid abundance under nutrient supply was expected (see Butler, Garratt \& Leather 2012 and references within). Our hypothesis was that aphids would be more suppressed in fields with high than with low SOC content, for example because of induced resistance in the crop plant and increased control by predators (Scheu 2001). However, we found no overall effect of SOC content on grounddwelling predators and only a weak positive relation between percentage SOC and aphids. It is possible that aphids were affected by differences in temporal nutrient dynamics caused by differences in SOC content (Hasken \& Poehling 1995), or that a high SOC content led to an altered soil community and therefore an altered induced response of the crop plant to this soil (microbial) community. There is increasing evidence that soil microbes may influence plant defences against above-ground insect pests (Biere \& Bennett 2013), however, unravelling the mechanistic basis for this requires further studies. 
There was no effect of SOC content or fertilizer application on numbers of predators in the pitfall traps. There are two possible explanations. First, we studied the effect of the whole species pool of the ground-dwelling predator community in the measured fields. Within this community, individual species might respond differently to the treatments. For instance, rove beetles (Staphylinidae) are more related to conventional types of agriculture, whereas wolf spiders (Lycosidae) are more associated with organic agriculture (Eyre et al. 2009). It is therefore likely that, depending on the species pool in the surrounding landscapes, SOC content may have variable effects on grounddwelling predators that range from none to positive. A second explanation for the absence of an effect of SOC and fertilizer application is that factors not included in our analysis determined the abundance of ground-dwelling predators; for example the quality of SOC steering microbial abundance, longterm effects of insecticides application in previous years, or other environmental conditions.

In conclusion, our study shows an overall positive relationship between percentage SOC and $\mathrm{N}$ mineralization potential, but there was no increase in $\mathrm{N}$ mineralization potential when we compared paired fields with low and high SOC content. Fields with higher N mineralization potential had less additional yield benefit from the application of mineral fertilizer. Therefore, we conclude that a higher SOC content per se may not necessarily lead to an enhanced nutrient provision of the crop and associated higher yields. Although we did not enhance SOC experimentally and made our results dependent on overall differences between paired fields, our results imply that multi-functional management of SOC for climate mitigation and other soil-related ecosystem services at the same time remains a challenge. Input of organic material that decomposes easily might enhance mineralization rates and increase nutrient supply to the crop more than adding recalcitrant organic matter, whereas the faster decomposition rate of added high-quality organic matter may not necessarily increase SOC content. Therefore, we suggest that the assumed win-win strategy of combatting climate warming by increasing SOC content, as proposed in the 4 per 1000 initiative, combined with the delivery of other ecosystem services as proposed in the ecological intensification concept, requires further studies to better understand how multi-functionality of enhanced SOC can be achieved by environmental policies. 
Chapter 4

\section{Acknowledgements}

We thank Christian Chabot, Sigrid Dassen, Minghui Fei, Dennis Lammertsma, Eke Hengeveld, Florentine van Noppen, Joyce Penninkhof and participating farmers for valuable help and/or use of land. This study was funded by the European Community Seventh Framework Program (grant no. 311781), LIBERATION (www.fp7liberation.eu). 
Appendix S4.1 Soil organic carbon and mineral fertilizer explaining mineralization potential of

\section{$\mathbf{N}, \mathbf{P}$ and $\mathbf{K}$}

We tested whether soil organic carbon (SOC) content related to mineralization potential of N, P and $\mathrm{K}$ by performing linear mixed models (see Materials and Methods). Mineralization potential of $\mathrm{N}$ increased with SOC content $(\mathrm{t}=3.70, \mathrm{p}<0.001, \mathrm{n}=122$, Fig. S4.1a). Mineralization potential of $\mathrm{P}$ and $\mathrm{K}$, however, did not respond to SOC content (Fig. S4.1b and S4.1c respectively).
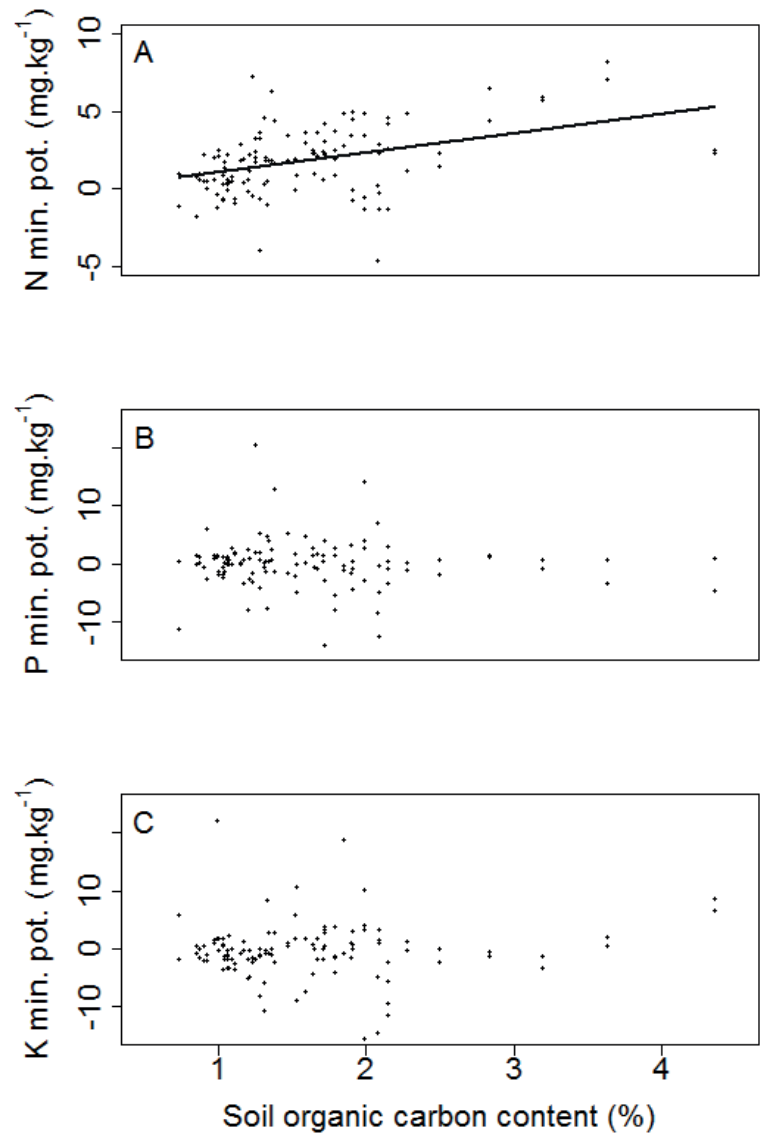

Figure S4.1. Potentially mineralized nutrients explained by soil organic carbon content (\%). (a)

Potentially mineralized nitrogen $\left(\mathrm{N}\right.$ : $\mathrm{NO}_{\mathrm{x}}$ and $\left.\mathrm{NH}_{3}, \mathrm{mg} \cdot \mathrm{kg}^{-1}\right)$, (b) potentially mineralized phosphorus $\left(\mathrm{P}, \mathrm{mg} \cdot \mathrm{kg}^{-1}\right)$, and (c) potentially mineralized potassium $\left(\mathrm{K}, \mathrm{mg} \cdot \mathrm{kg}^{-1}\right)$. 
Chapter 4

Appendix S4.2 Mineral fertilizer application, $\mathrm{N}$ mineralization potential, aphid number and yield

We tested how mineral fertilizer application, $\mathrm{N}$ mineralization potential, the number of aphids and all two-way interactions related to seed weight (yield) by performing linear mixed models (see Materials and Methods). Mineral fertilizer application had a positive relation with seed weight ( $\mathrm{F}=86.27$, $\mathrm{p}<0.001, \mathrm{n}=116)$, whereas the effect of $\mathrm{N}$ mineralization potential was marginally significant $(\mathrm{F}=3.84$ $\mathrm{p}=0.055$ ). Under high $\mathrm{N}$ mineralization potential, the positive effect of mineral fertilizer on seed weight disappeared $(\mathrm{F}=18.39, \mathrm{p}<0.001$, Fig. S4.3). The number of aphids per tiller had no significant relation with seed weight.

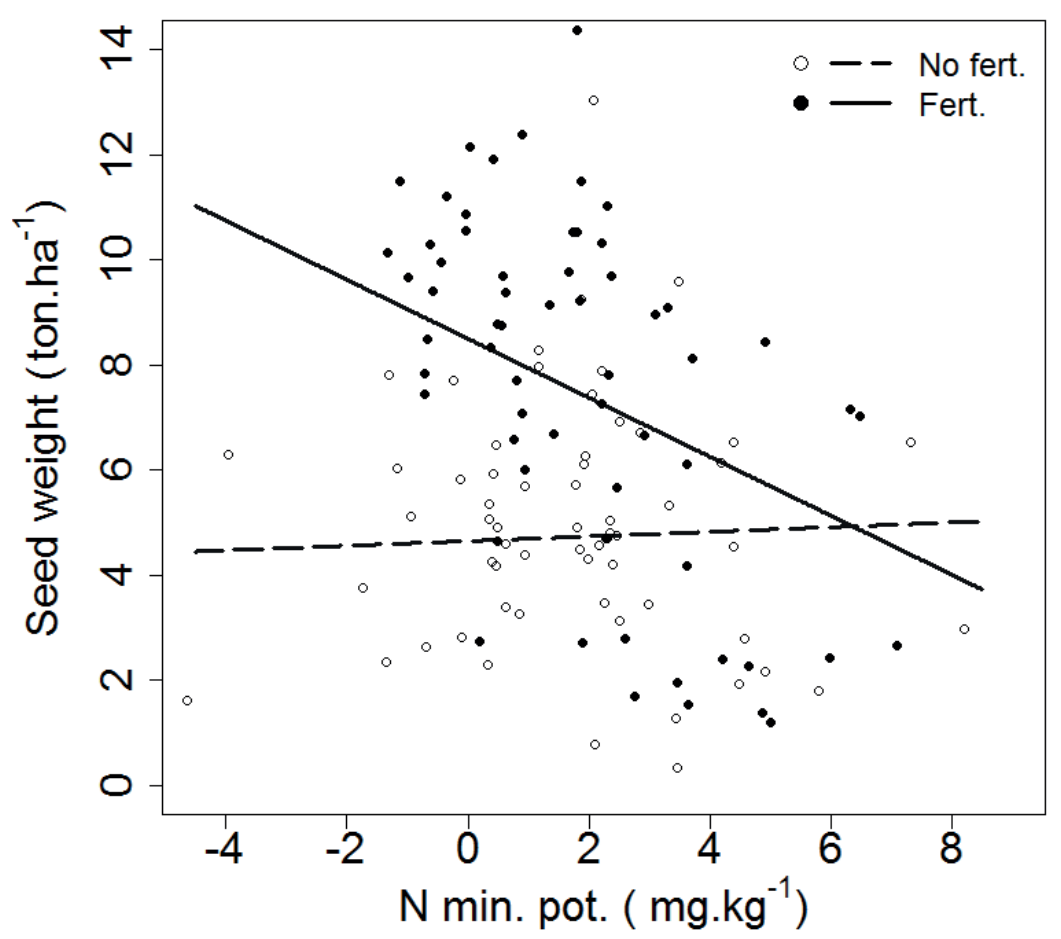

Figure S4.3. Seed weight (yield, ton.ha ${ }^{-1}$ ) explained by $\mathbf{N}$ mineralization potential (mg.kg ${ }^{-1}$ ). Thin lines and open circles represent plots without and thick lines filled circles with mineral fertilizer. 


\title{
Chapter 5
}

Can above-ground ecosystem services compensate for reduced fertilizer input and soil organic matter in annual crops?

Stijn van Gils, Wim H. van der Putten and David Kleijn

\author{
Published in:
}

Journal of Applied Ecology (2016) 53(4), 1186-1194

DOI: $10.1111 / 1365-2664.12652$

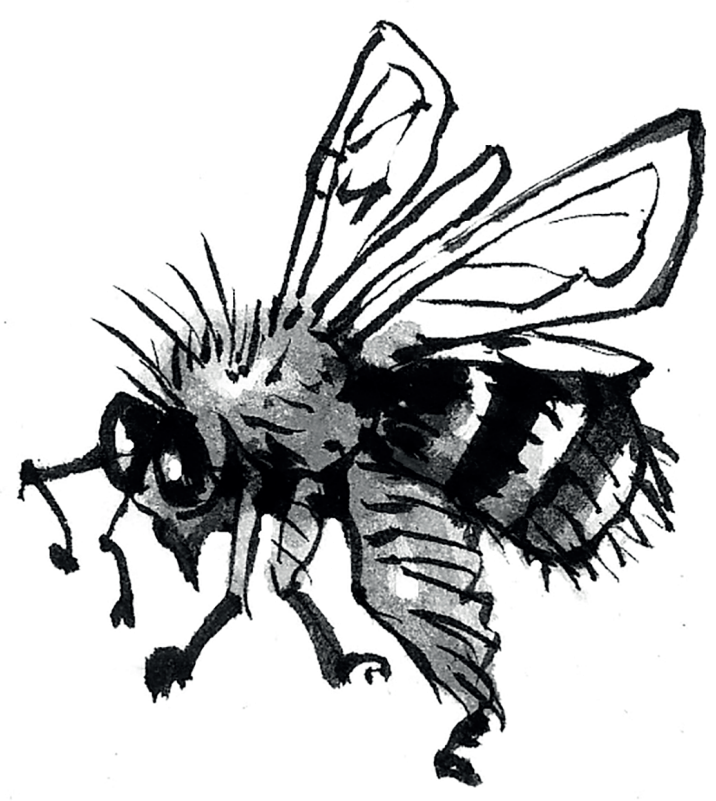




\section{Chapter 5}

\section{Abstract}

Above-ground and below-ground environmental conditions influence crop yield by pollination, pest pressure, and resource supply. However, little is known about how interactions between these factors contribute to yield. Here, we used oilseed rape Brassica napus to test their effects on crop yield. We exposed potted plants to all combinations of high and low levels of soil organic matter (SOM) and fertilizer supply, and placed all treatments at a variety of field sites representing a gradient in pollinator visitation rate and pest exposure. We determined the relative contribution of pollinators and pests, SOM and fertilizer supply to yield. We also tested whether SOM can moderate effects of fertilizer on yield and whether soil conditions influence the relationship between above-ground conditions and yield. Increases in pollinator visitation rate and decreases in pest pressure enhanced yield more than increase of fertilizer supply. Although higher SOM content resulted in plants with more biomass and flowers, under our experimental conditions SOM neither enhanced yield, nor influenced effects of fertilizer, pollinators or pests on yield. The relationships between yield, pollinator visitation rate and pest pressure did not depend on the level of fertilization suggesting that the effects of fertilizer application and above-ground (dis)services on yield were additive. In contrast, pollinator visitation rate was more strongly related to yield at low pest pressure than at high pest pressure indicating trade-offs between above-ground services and disservices. Our results show that it is possible to increase oilseed rape yield by enhancing pollination, irrespective of supplying mineral fertilizer. Moreover, the fact that below-ground conditions did not alter the effect of above-ground conditions, suggests that farmers may obtain even higher yields by maximizing both above-ground ecosystem services and external inputs. Further studies are needed to understand at which point the positive relationships between pollinator visitation and yield, as well as between fertilizer and yield will level off. Considering above-ground and below-ground services and inputs in agro-ecosystems in conjunction is crucial in order to optimize external inputs for crop yield from an economic and ecological perspective. 


\section{Introduction}

Crop plants are exposed to multiple above-ground and below-ground environmental factors that all together determine biomass production and crop yield. These factors operate at a variety of spatial and temporal scales and are under the influence of multiple management strategies. Nutrient status, water availability, and soil organic matter (SOM) are managed mainly by farmers through fertilizer supply, returning organic matter to the soil, and soil tillage. These factors influence each other as well increased percentage of SOM can reduce dependence on mineral nitrogen fertilizer (Brady et al. 2015). Exposure to pests, biocontrol of these pests and pollination are influenced by farmers through applying biocides and putting out bees, but these (dis)services are also provided by the surrounding landscape where pests and their natural enemies (Thies \& Tscharntke 1999), as well as pollinating insects (Steffan-Dewenter \& Tscharntke 1999) survive periods without crops. Growing crops and management to optimize yield therefore require explicit consideration of both below-ground and above-ground ecosystem properties and services. Relatively little is known about potential trade-offs and synergies between management practices focusing on either above-ground or below-ground subsystems (Tscharntke et al. 2012; Bommarco, Kleijn \& Potts 2013; Setälä et al. 2014). Here, we study possible trade-offs and synergies among SOM content, fertilizer supply, and above-ground influences of pollinators, pests, and pest control organisms as provided by the surrounding landscape.

Above-ground, field conditions may differ in the influx of pests, predators, and pollinators, because the supply of these organisms from surroundings can vary. For example, the quantity of semi-natural habitats near a field is generally positively related to arthropod diversity and subsequently to arthropod-delivered ecosystem services such as pollination and pest control (Steffan-Dewenter et al. 2002; Thies, Steffan-Dewenter \& Tscharntke 2003; Kennedy et al. 2013). In addition, the quality (e.g. flower abundance) of habitats near a field influence (dis)service-providing organisms (Albrecht et al. 2007), for example by providing overwintering refuges and alternative food sources for pollinators (Scheper et al. 2013), herbivores (Landis, Wratten \& Gurr 2000; Veres et al. 2013), and their natural enemies (Rusch et al. 2013; Sarthou et al. 2014). Knowledge of the influences of off-field management on delivery of ecosystem services and disservices is rapidly increasing, but information 


\section{Chapter 5}

about how comprehensive management strategies may enhance net effects of all local ecosystem services together is still mostly lacking (Schellhorn et al. 2008).

Below-ground, management interventions that influence soil structure and nutrient availability can have contrasting consequences. For example, ploughing and supplying mineral fertilizers may lead to a short-term improvement of soil conditions that enhance yield, but negatively affect soil biota such as earthworms and arbuscular mycorrhizal fungi that generally enhance crop growth by improving soil structure and nutrient availability in the long term (Helgason et al. 1998; Crittenden et al. 2014). Moreover, long term high input-output agriculture based on intensive soil tillage and nutrients predominantly supplied as mineral fertilizers usually lead to a decrease in SOM (Reeves 1997), which is an important ecosystem property that influences nutrient availability, prevents nutrient leaching and increases soil structure and water-holding capacity (Hendrix, Coleman \& Crossley 1992; Six, Elliott \& Paustian 2000; Lal 2006). Increasing SOM content is expected to enhance plant growth and reduce dependence on mineral fertilizer (Brady et al. 2015).

Nutrient availability in soil may also influence performance of above-ground antagonistic and mutualistic insects (Poveda et al. 2003; Otieno et al. 2011). However, fertilizer supply may also negatively affect herbivore performance (Mattson 1980). Effects of fertilization on insect performance are indirect: mineral nitrogen $(\mathrm{N})$ fertilization leads to more available $\mathrm{N}$ and a lower carbon $(\mathrm{C}): \mathrm{N}$ ratio (Zhang et al. 2012), which alters plant chemistry and growth (Bender \& van der Heijden 2015). Indirectly, fertilizer supply may change the nectar content of flowers (Viik et al. 2012), the number of flowers (Lau \& Stephenson 1993), and plant nutritional quality (Nowak \& Komor 2010).

Subsequently, all these plant properties are known to attract pollinators (Ohashi \& Yahara 1998; Viik et al. 2012; Klatt et al. 2013) and herbivores (Nowak \& Komor 2010), but little is known about the overall effects on yield.

Here, we examined how fertilizer supply interacts with SOM content in affecting the effect of a realistic exposure to pollinators and arthropods (both crop pests and their antagonists) on crop yield. We grew oilseed rape Brassica napus plants in pots under two levels of fertilizer supply and SOM. At the onset of flowering, potted plants were placed in fields that differed in the complexity of the 
surrounding semi-natural habitat, which was used as a proxy for pollinator abundance. After being pollinated, all plants were placed under the same growth conditions in order to examine the net effects of pollinator and pest exposure, fertilizer supply and SOM on above-ground biomass, number of flowers and seed yield. We addressed the following questions: (i) What is the relative importance of SOM, mineral fertilizer, pollinator visitation rate and pest pressure to yield? (ii) Can SOM, at least partly, replace the effects of mineral fertilizer on yield? (iii) How are the relationships between yield on the one hand and pollination and pest pressure on the other influenced by fertilizer application or SOM content?

\section{Materials and methods}

Experimental design

We used oilseed rape Brassica napus (variety Petranova; a spring-sown variety) as our model crop. Maximum yield of B. napus requires insect pollination (Klein et al. 2007) and the crop is susceptible to damage from various insect pest species (Valantin-Morison, Meynard \& Dore 2007). Brassica napus is an important (energy) crop worldwide; in Europe it is even the most abundant oilseed species (Verhoog 2002) and it has expanded in the last decade because of the renewable fuel directive of 2003 (Breeze et al. 2014). We grew B. napus plants under factorial combinations of two levels of SOM content and two levels of fertilizer addition, and placed four replicates of all four soil treatments in 15 different field sites, resulting in $2 \times 2 \times 4 \times 15=240$ experimental units. We used landscape complexity and quality as a proxy for pollinator abundance (Albrecht et al. 2007; Kennedy et al. 2013) and selected the 15 sites so that the experimental plants were positioned in a gradient of pollinator visitation rates (see Appendix S5.1). At four locations, we placed four extra plants (one for each treatment) covered by a gauze net (mesh size: $0.25-0.75 \mathrm{~mm}$ ) to exclude all insects (pollinators and herbivores), bringing the total to $240+16=256$ experimental units. We used the caged plants to check the level of seed set without insect pollination. Under the cages wind pollination was possible to some extent as the size of B. napus pollen ranges from 32-35 $\mu \mathrm{m}$ (Huesken \& Dietz-Pfeilstetter 2007). 


\section{Chapter 5}

\section{Plant growth conditions}

In the summer of 2013 we germinated B. napus seeds on glass beads, planted the seedlings in potting soil ('Lentse potgrond' no.4; Lent, the Netherlands), and placed them in a greenhouse at $20 \pm 1{ }^{\circ} \mathrm{C}$. After three weeks, seedlings were transplanted to 10-litre pots and placed in an open greenhouse with less control over the temperature. Seedlings were randomly assigned to one of the four soil treatments (2 SOM levels $\times 2$ fertilizer levels). High and low SOM treatments contained 3.0 and $1.3 \% \mathrm{SOM}$, fitting within the range between approximately $<1$ and $3 \%$ reported by (Brady et al. 2015). The SOM treatments were created using loamy fine sand from a long-term experiment (Korthals et al. 2014) at Vredepeel, south-eastern Netherlands (5132'26.0"N 5०51'13.0"E). The top soil (upper $25 \mathrm{~cm}$ ) contained 3.3\% SOM, while the subsoil from $100 \mathrm{~cm}$ below the soil surface was of the same origin but contained hardly any SOM at all. We used this difference to create our experimental soils with 3.0 and $1.3 \%$ SOM contents by thoroughly homogenizing a 9:1 mixture (high SOM) and a 2:3 mixture (low $\mathrm{SOM}$ ) of top soil and sub soils (dry w/w). Mineral fertilizer was supplied as $0.4 \mathrm{~g}$ nitrogen $(\mathrm{N})$ per plant, which corresponds with the average nitrogen supply per plant under regular farming practices, equalling an amount of $200 \mathrm{~kg} \mathrm{~N} \mathrm{ha}^{-1}$. Nitrogen was supplied in a dissolved form of $\mathrm{NO}_{3}{ }^{-}$, (mainly $\mathrm{Ca}\left(\mathrm{NO}_{3}\right)_{2}$ ), enriched with $0.5 \mathrm{~L} 1 / 2$ Hoagland solution (High), or as $0.5 \mathrm{~L}$ of tap water with $10 \%$ of this solution (Low) (see Hewitt 1966 for composition of the solution). Fertilizer was supplied when plants were transplanted to the $10 \mathrm{~L}$ pots. After another three weeks, all plants received $100 \mathrm{ml} \frac{1}{2}$ Hoagland solution without additional $\mathrm{N}$. When the first plants started to flower all plants were placed at their randomly assigned field sites.

We standardized conditions among sites by placing the experimental plants in an open field boundary at the corner of an arable field. Herbivory from e.g. roe deer and cattle was prevented; plants were placed outside managed grazing areas and fenced with a small wire fence. To ensure that plants received ample water, each pot was placed in a construction of two stacked crates. The top crate contained the plants, while the bottom crate contained water. Water absorbing coir rope was extended through holes in the bottom of the top crate into the bottom crate, keeping the soils of the potted plants moist for a longer period of time. In addition, plants were watered every three days. After five weeks 
in the field when most plants had finished flowering, all plants were returned to the greenhouse to let the seeds mature under standard conditions. Here, plants were not watered anymore to stimulate senescence.

\section{Observations}

In each site, eight observations were made about pollinators on the experimental plants. During each site visit, pollinators were observed for 15 minutes in order to record the number of unique pollinators that visited each plant (see Appendix S1 for more details). Such methodology is widely used in similar studies (e.g. Steffan-Dewenter \& Tscharntke 1999; Poveda et al. 2003).

We counted flower visits eight times and characterized pollinator visitation rates of every field site by averaging the number of bees and hoverflies at one site across all eight counting events. Prior to each pollinator count we counted the number of flowers per plant. For analyses we used the average number of counted flowers per plant per counting event.

Pods were harvested just before ripening in order to avoid loss of seeds and were stored at $4^{\circ} \mathrm{C}$. After all pods had been harvested we determined the total number of pods per plant and the weight of the seeds $\left(\mathrm{g} \mathrm{plant}^{-1}\right)$. Prior to opening pods, we also inspected them for signs of damage by herbivores. As pods were frequently damaged by larvae of the moth Evergestis extimalis, proportion of infected pods was determined. Remaining above-ground plant biomass was harvested, dried at $70^{\circ} \mathrm{C}$ for at least 48 hours, weighed and expressed as g plant ${ }^{-1}$.

Analyses

To examine which of our investigated variables significantly affected $B$. napus yield and whether the effects of one variable was influenced by the level of another, we related yield (g seeds plant ${ }^{-1}$ ) to the factors of SOM and fertilizer and the covariates pollinator visitation rate at the site level and proportion of infected pods at the plant level, using linear mixed models with the random intercept and field site as the random factor. Collinearity of explanatory variables can affect model outcome; however, in our case pollinator visitation rate and proportion of infected pods were not correlated (see Appendix S1). To avoid having too few replications per variable we only included all main effects and 


\section{Chapter 5}

two-way interactions. We log-transformed seed weight in order to obtain normally distributed residuals according to the Shapiro-Wilk test.

To understand the mechanisms underlying the observed yield patterns, we also ran models with average number of flowers per plant across the visits and total plant biomass at harvest. As we did not expect to find a relationship between the number of flowers or plant biomass on the one hand and pollinator visitation rate or proportion of infected pods on the other, these models initially only included the factors of SOM and fertilizer as explanatory variables. However, exploratory analyses showed highly significant relationships with pollinator visitation rate and the proportion of infected pods, which were therefore included in these models making the analyses essentially the same as for B. napus yield. In all analyses, we only included plants for which we had data for all response and explanatory variables; plants that died during the study were excluded, bringing the total number of experimental plants to 213 . We established that the number of excluded plants did not differ among treatments, or among the different field sites. Afterwards, we ran the models again with only significant explaining variables to estimate the relative contribution of these variables to yield.

A separate analysis was done for the four sites where additional plants had been grown under insect cages. Caged plants were compared with open pollinated plants, resulting in 79 plants on the four field sites. We examined effects of excluding all pollinators on plant biomass, flower number, seed weight and additionally the proportion of infected pods. There was not enough statistical power to test these sites for all treatments simultaneously. Therefore, as the treatments using SOM and fertilizer did not interact in affecting yield, flower number, plant biomass, and the proportion of infected pods we only tested effects of insect exclusion on these variables. Since normality could not be met for all variables of interest we used a Kruskal-Wallis test for these analyses.

All analyses were performed with R 3.1.1 (R Core Team), using the nlme package for linear mixed models (Pinheiro et al. 2014). 


\section{Results}

Yield (total seed weight)

Yield was significantly affected by fertilizer, but not by soil organic matter (SOM) and there was no significant interaction between fertilizer and SOM (Table 5.1). Model-predicted yields of plants from the high fertilizer treatment were $80 \%$ higher than of plants from the low fertilizer treatment (Fig.

5.1a). There was a significantly positive relationship between pollinator visitation rate and yield (Fig 5.2a, Table 5.1). Hoverfly visitation rate was significantly related to yield, whereas bee visitation rate and pollinator diversity were not (see Appendix S5.2). At field sites with the highest number of pollinators, model-predicted yields were $165 \%$ higher than at field sites with the lowest number of pollinators. There was no significant interaction effect on yield between pollinator visitation rate and SOM content, or fertilization, suggesting that the effects of pollinators and fertilizers are additive and do not strengthen or weaken one another. Yield was negatively related to the proportion of pods infected by Evergestis extimalis larvae (Fig. 5.2d). This negative relationship was more pronounced with increasing pollinator visitation rate (Fig. 5.3a, Table 5.1). At field sites with the highest proportion of E. extimalis infected pods, model-predicted yields were $153 \%$ lower than at sites with the lowest infestation rates. The relationship between yield and the proportion of infected pods was not influenced by SOM or fertilizer (Table 5.1). 
Chapter 5

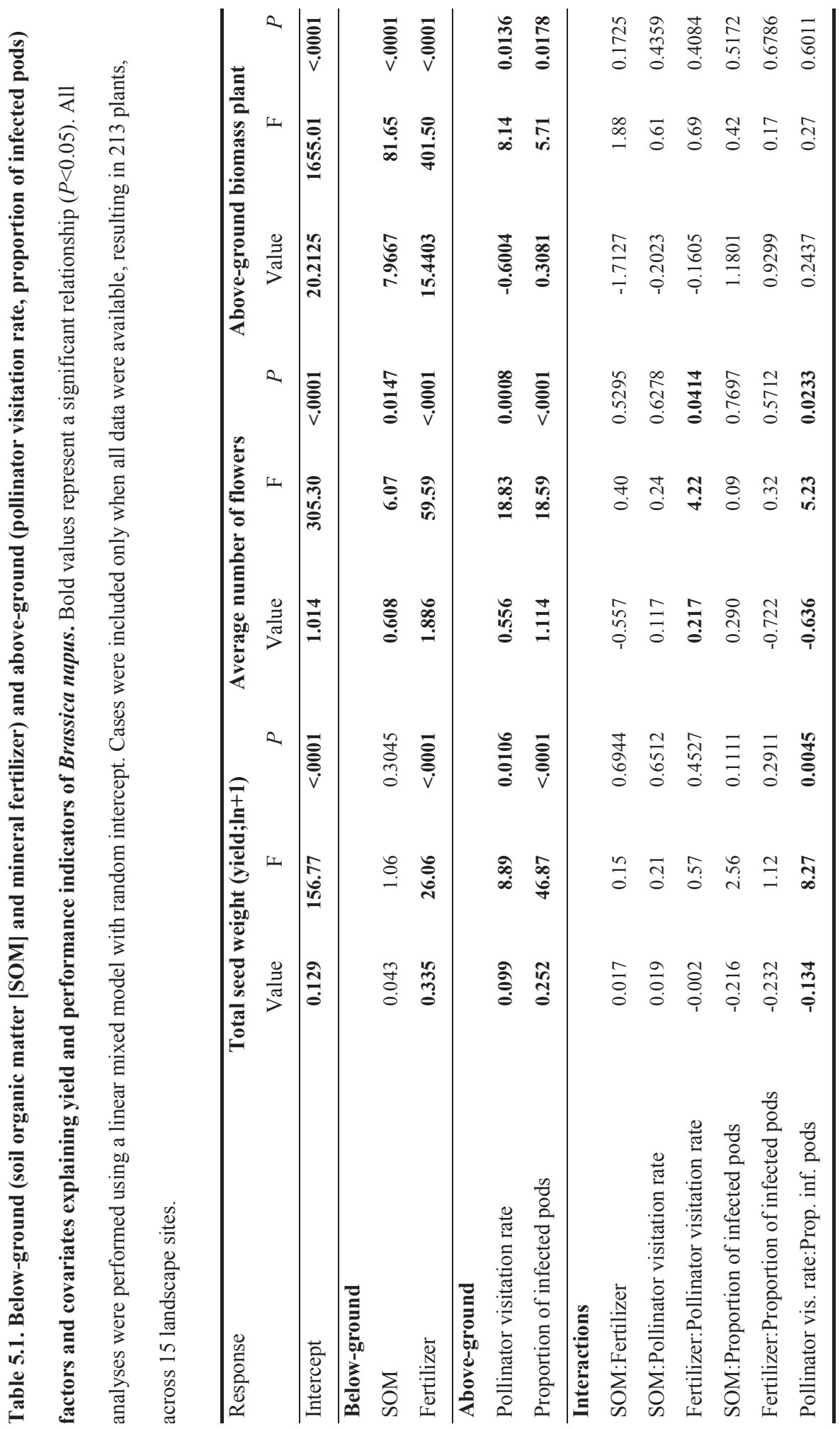


(a)

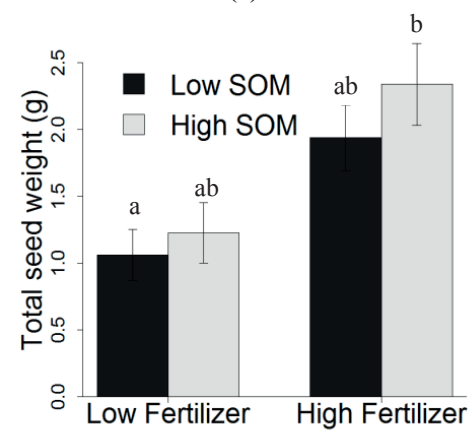

(b)

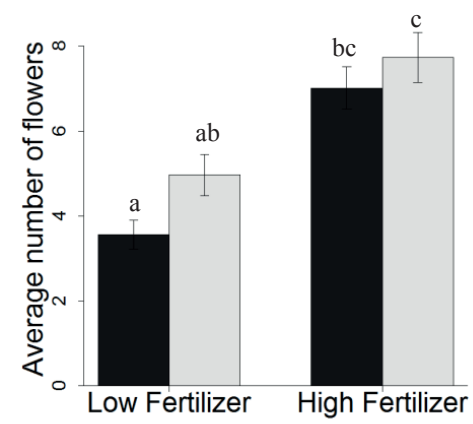

(c)

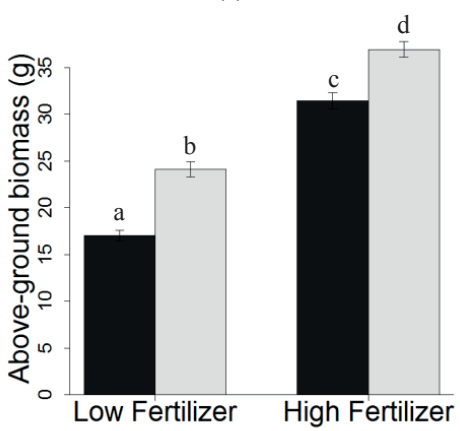

Fig. 5.1. Effects of soil organic matter (SOM) and mineral fertilizer on performance of Brassica napus: a) total seed weight, b) average number of flowers, c) above-ground biomass (excluding pods and seeds). Error bars represent standard error. Letters above the bar graph (a, b, c) indicate a significant $(P<0.05)$ difference between specific treatment combinations after a Least Squares Difference (LSD) contrast test. 
Chapter 5

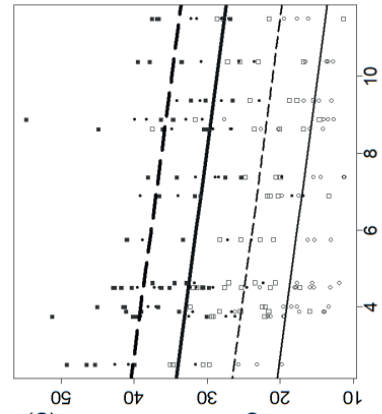

(6) ssemo!̣ punoג6-ə^оq $\forall$
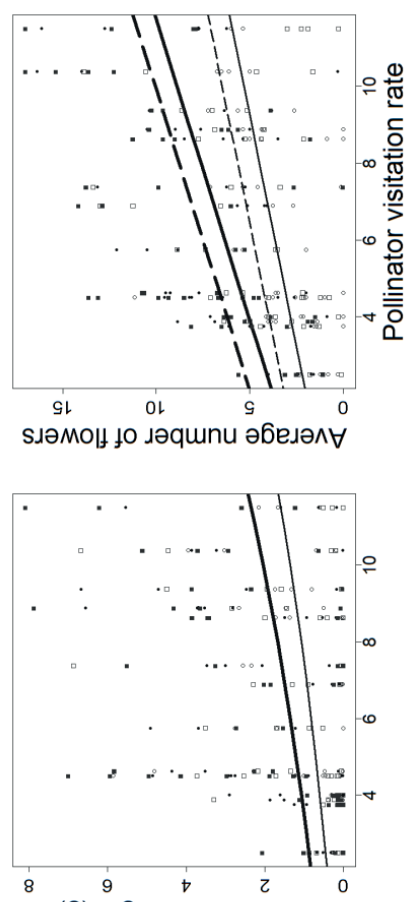

ङ

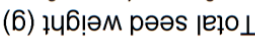

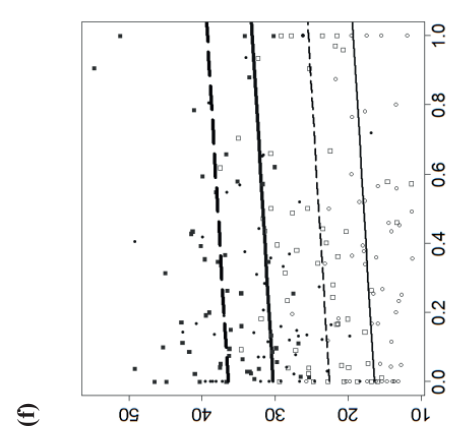

(6) ssemo!q punoı6-әлоq $\forall$

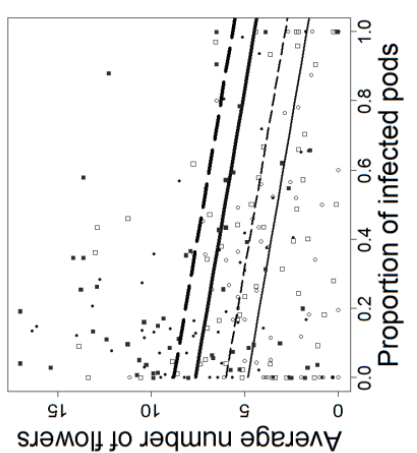

త

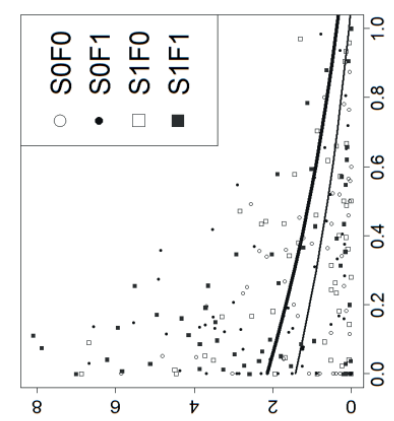

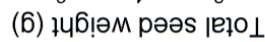


Continuation Fig. 5.2. Graphs are based on linear mixed models with field site (being a proxy for insect abundance) as the random factor. S0: low soil organic matter; S1: high soil organic matter; F0: low fertilizer; F1: high fertilizer. Only significant factors and covariates are used in the models. If significant covariates are not displayed, we used the average value in the model. Thin lines represent low fertilizer (F0 in legend) and thick lines represent high fertilizer (F1). If soil organic matter was significant we separated the treatment effect. Solid lines represent low (S0), and dashed high (S1) soil organic matter.

\section{Number of flowers}

The number of flowers was highest in the high SOM and fertilizer treatments, but there was no significant interaction between SOM and fertilizer (Fig 5.1b, Table 5.1). The number of B. napus flowers showed an overall positive relationship with pollinator visitation rate (Fig. 5.2b, Table 5.1). However, this relationship was more pronounced for plants with high than with low fertilizer supply, as indicated by the significant interaction between fertilizer and pollinator visitation rate on the number of flowers (Table 5.1). The number of flowers was significantly negatively related to the proportion of infected pods (Fig. 5.2e) and this relationship was stronger at field sites with higher pollinator visitation rates (Fig 5.3b, Table 5.1).

\section{Plant biomass}

Above-ground biomass, excluding pod mass, was significantly enhanced by high fertilizer supply, as well as by SOM content (Fig 5.1c, Table 5.1).There was a negative relationship between above-ground biomass and pollinator visitation rate (Fig. 5.2c, Table 5.1). However, there was a positive relationship between above-ground biomass and the proportion of infected pods (Fig. 5.2f). The relationship between plant biomass and pollinator visitation rate was not affected by SOM or fertilizer, as there was no significant interaction between these two soil factors (Table 5.1). 


\section{Chapter 5}

(a)

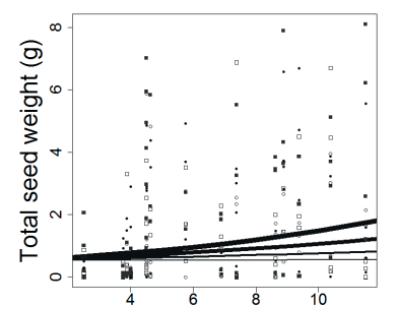

(b)

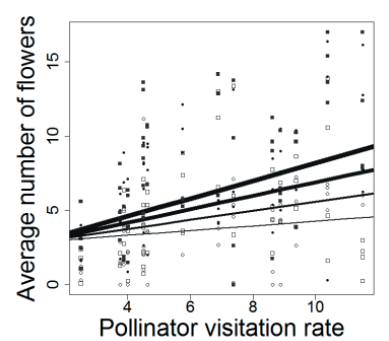

Fig. 5.3. Relationship between pollinator visitation rate and yield (a) and average number of flowers (b) of Brassica napus under different proportions of Evergestis extimalis infected pods.

Graphs are based on linear mixed models with field site (being a proxy for insect abundance) as the random factor. Line thickness from thick to thin represents the proportion of infected pods by Evergestis extimalis ( $0 \%$ infected, $25 \%$ infected, $50 \%$ infected, $75 \%$ infected). Treatments were visualized with the same symbols as explained in the legend of Fig. 2.

\section{Pollinator exclusion}

Caged plants produced less yield (average $0.11 \mathrm{~g}$ vs. $1.33 \mathrm{~g}$; Kruskal test, $\mathrm{X}^{2}=13.0623, P=0.0003$, d.f. $=1$ ) and fewer flowers (average 2.01 vs. 3.88; Kruskal test, $X^{2}=4.2119, P=0.0401$ ) than plants that were exposed to all insects. Biomass production was not significantly affected by pollinator exclusion (average 25.10 g vs. $29.52 \mathrm{~g}$; Kruskal test, $\mathrm{X}^{2}=1.7227, P=0.1894$ ). Cages also reduced pod infection by E. extimalis moths, resulting in a significantly lower proportion of infected pods (average $9 \%$ vs. $37 \%$; Kruskal test, $\mathrm{X}^{2}=5.5490, P=0.0185$ ). 


\section{Discussion}

We studied how soil organic matter (SOM), mineral fertilizer supply, and exposure to variations in pollinators and crop pests influence above-ground biomass, numbers of flowers, seed yield, and pod infestation of a partially insect-pollinated crop. We analysed how interactions between these belowground and above-ground factors contribute to crop yield using oilseed rape Brassica napus as a model crop. Our study showed that the relationships between yield, pollinator visitation rate and pest pressure did not depend on the level of below-ground services (nutrient supply) implying that effects of above-ground and below-ground (dis)services on yield were additive. In contrast, pollinator visitation rate was more strongly related to yield at low pest pressure than at high pest pressure. Under the present experimental conditions, differences in real-world pollinator visitation rate and pest pressure influenced yield of B. napus more strongly than fertilizer application.

A more pronounced relationship of yield with pollination than with fertilizer supply is to be expected in crops that largely depend on insect pollination for fruit set, such as cucumber (Cucumis sativus; Motzke et al. 2015). In the case of a partially insect-pollinated crop, such as B. napus, the contribution of insect pollination to maximum yield is generally considered to be relatively small (Klein et al. 2007). An explanation for the strong yield response to variability in pollinator visitation rate in our study may be that pollination did not only affect seed set directly (Steffan-Dewenter \& Tscharntke 1999; Garibaldi et al. 2013), but that exposure to pollinators also affected growth allocation patterns in B. napus. At sites with the highest pollinator visitation rates, experimental plants produced more flowers but less above-ground non-flower biomass. This could point at a trade-off between producing above-ground biomass and flowers; well-pollinated plants produced large numbers of flowers at the expense of other plant organs. Indeed, above-ground biomass and the number of flowers correlate negatively if the effects of fertilizer supply are accounted for (see Appendix S5.3).

Poorly pollinated plants may initially invest more in biomass possibly resulting in a more prolonged period of flower production, which enhances the likelihood of pollination later in the season. This is in line with findings by Brann and Lehtila (2007) that hand-pollination significantly enhances flower number in wild radish Raphanus raphanistrum, a close relative of B. napus. Under field conditions 


\section{Chapter 5}

pollinator visitation may even relate stronger to yield than after artificial pollination, as an increase in the number of flowers could subsequently also attract more pollinators to the plant (Ohashi \& Yahara 1998). Further testing is needed to unravel the relative contribution of this energy-reallocation effect (more energy allocated to flowers after pollination) and attraction effect (more pollinators due to a higher number of flowers), as well as their reinforcing interactions between energy-reallocation and attraction.

Infestation of pods by Evergestis extimalis larvae resulted in substantial yield losses. Herbivoryrelated yield losses were greater than yield reductions associated with the cessation of fertilizer applications. Under high pollinator visitation rates the negative relationship of E. extimalis with yield became stronger, virtually neutralizing all benefits from pollination. These results are in line with Lundin et al. (2013) who found a synergistic effect between pest control and pollination. In addition, we found that the proportion of pods infested by insect larvae was negatively related to flower number and positively related to leaf and stem biomass. As the moth E. extimalis places eggs on the leaves and larvae stay on the leaves until seed set when they migrate to the pods (Muus 2014 -

Microlepidoptera.nl), it is unlikely that the moth had a direct effect on flower number. However, it is unclear which mechanism may explain the relationship between the proportion of infected pods and the number of flowers, or above-ground plant biomass.

Whether E. extimalis has similar effects on oilseed rape planted at the field scale will depend on its population size, which may fluctuate strongly from year to year. This species is predominantly found in field edges, but rarely occurs in the centre of the field (Jeffrey A. Harvey, personal communication). This might explains why E. extimalis is not considered an important pest of B. napus in the Netherlands. Simultaneously, key pest species that normally occur on B. napus were not found in our study, possibly because the relatively small experimental patches were not attractive for pest species such as the pollen beetle Meligethes spec. that usually operates at a larger spatial scale (Zaller et al. 2008). This reduces the potential for direct generalizations from our study for day to day farming, but does not affect our main conclusion that effects of pollinators and pests are not influenced by soil conditions. 
Fertilizer supply increased seed yield by $80 \%$, whereas doubling the amount of SOM (increase from $1.3 \%$ to $3.0 \%$ ) did not have a significant effect. These results do not support earlier studies showing that SOM significantly enhances crop yield (van Eekeren et al. 2010) and modelling studies predicting that higher SOM content can allow for lower fertilizer application rate to obtain maximum yield (Brady et al. 2015). Soil organic matter enhanced the number of flowers and above-ground biomass produced by the oilseed rape plants, suggesting that providing nutrients through SOM or mineral fertilizer results in different temporal resource allocation patterns. The duration of plant exposure in the field in our experiment might have prevented finding a positive SOM effect, as seed set was not completed in the field, but under controlled experimental conditions. Considering that nutrients become available faster from mineral fertilizer than from SOM, as organic matter first needs to be decomposed by bacteria and fungi (Hendrix, Coleman \& Crossley 1992), plants with high fertilizer may have developed more rapidly, within the time frame of the experiment, than plants with high SOM content. Moreover, we have controlled moisture availability of all soil treatments. SOM usually has a positive effect on plant production by promoting soil water-holding capacity (Lal 2006).

We had expected that higher nutrient availability (high SOM plus high fertilizer) would lead to more attractive plants, resulting in more pollinator visits and, therefore, a more rapid saturation in pollination service demand. In line with earlier work (Otieno et al. 2011) fertilizer supply and SOM indeed led to more flowers, implying greater resource availability for pollinators. However, the relationship between pollination and yield was not more pronounced on soils with high fertilizer or high SOM levels than in soils with low fertilizer or low SOM. A number of recent studies addressing interacting effects of nutrient provision and pollination result in contrasting results. In line with the present study, Bartomeus, Gagic and Bommarco (2015) found no interaction between soil properties and pollinator visitation rate on B. napus yield, whereas Marini et al. (2015), found the greatest effects of pollination on oilseed rape yield at low fertilizer application rates. Finally, Tamburini et al. (2015) observed less pronounced effects of pollination on sunflower Helianthus annuus yield on low- than on high-nutrient soils. Therefore, whether soil nutrient status enhances or reduces the effects of pollination on yield it is most likely context dependent and will differ among crop species and 


\section{Chapter 5}

varieties, level and type of nutrient supply, and density and species composition of pollinator communities (Hudewenz et al. 2014; Marini et al. 2015).

\section{Synthesis and management implications}

Management focussing on combining both below-ground and above-ground ecosystem services requires integration of activities that operate locally, such as supplying fertilizer or organic matter, with landscape-scale activities focussing on promoting pollinator and pest control services (Tscharntke et al. 2012). However, soil organic matter (SOM) management and nutrient supply are usually considered independent from managing pollinators and pest control organisms. Our results show that real-world variation in pollinator visitation rate and pest pressure have yield effects that may be even larger than those of factors that have traditionally been the focus of farming practices, such as fertilizer application and management of SOM. Effects of pests and pollinators add up to those from fertilizer supply and, although less prominent in our study, SOM management. Moreover, as pollination is known to also enhance oil content of oilseed rape seeds (Bommarco, Marini \& Vaissiere 2012), the importance of considering pollination in combination with SOM and nutrient management might even be higher than appearing from our results. Therefore, we suggest that farmers can improve yield by optimizing both the nutrient provisioning of their crops and the services that are supplied largely by the landscape. Because the production value of insect-pollinated field crops is generally low (FAO 2014), enhancing crop pollination in such systems might best be achieved by managing existing field margins and semi-natural habitats in a more pollinator-friendly way rather than creating costly new pollinator habitat such as wildflower fields (Schellhorn, Gagic \& Bommarco 2015). Further field studies are required to determine when the positive relationship between pollinator visitation and yield, and between fertilizer and yield, will level off. This information is crucial in order to optimize ecosystem services and external inputs from an economic and ecological perspective. 


\section{Acknowledgements}

We thank Saman Bouman, Christian Chabot, Gregor Disveld, Rebecca Pas and various other people for technical assistance and Brabants Landschap, Gemeente Uden, Staatsbosbeheer, and farmers for providing us materials and sites to work in. We also thank three anonymous reviewers for their comments that strongly improved the quality of the manuscript. This work was funded via the EU FP7 project LIBERATION (grant 311781). Data available from Dryad Digital Repository: doi:10.5061/dryad.s08f7 (van Gils, van der Putten \& Kleijn 2016). 


\section{Chapter 5}

\section{Appendix S5.1. Field selection}

We tried to obtain a gradient in pollination intensity, based on landscape complexity and landscape quality. Field sites were selected as in Scheper et al. (2013), based on satellite images ranging from simple to complex landscapes (Tscharntke et al. 2005a), with the expectation to obtain a gradient in the number of pollinators using this method. To assure spatial independence we located sites at least 2 $\mathrm{km}$ apart from each other.

In each site, eight observations were made on pollinators on the experimental plants. During each site visit, pollinators were observed for 15 minutes in order to record the number of unique pollinators that visited each site (i.c.: individual pollinators that visited the same plant twice or more were counted as one unique pollinator visit). Our observations were done at the period bees and hoverflies were active, roughly between 9:00 and 17:00 h, and always at relatively sunny days without rain. To ensure that all sites were visited at different moments during the day we changed the order of the visits every day.

We distinguished between bees (both wild and managed), hoverflies and butterflies. When it was possible to identify individuals based on wing characteristics, we identified individuals to species level. However, for analyses we only considered bees and hoverflies, because few butterflies were observed and these are generally not very effective pollinators in temperate crops (Jennersten 1984). Moreover, as managed honey bees only added up to $6 \%$ of the total bees, and $2 \%$ of all pollinators we considered managed bees a minor importance in the present study.

From this method, we established a gradient in flower visitation (Fig. S5.1.1). The gradient length in visitation rate was comparable with Steffan-Dewenter and Tscharntke (1999). As pollinator visitation rate and functional group diversity were highly correlated (Pearson correlation $\mathrm{r}=0.83, \mathrm{p}=0.0001$, $\mathrm{N}=15$ ), we only used visitation rate in our statistical models (Fig. S5.1.2).

The gradient also differed in pest abundance represented in the average proportion of pods infected by Evergestis extimalis (Fig S5.1.3). At weeks 10 and 13 of the experiment we also estimated the number of aphids (Brevicoryne brassicae) on each plant, but they did not have a significant effect on yield, so were therefore excluded from the analysis. Instead, we focused on the proportion of infected pods 
only. This gradient in pest abundance was not related to the variation in pollination intensity (Spearman rank test: rho $=-0.03, \mathrm{p}=0.6371)$. Soil organic matter $(\mathrm{SOM})$ content had no effect on the proportion of infected pods (Kruskal test, $\mathrm{X}^{2}=0.6117, \mathrm{p}=0.4341$ ), but mineral fertilizer supply had a minor negative effect on the proportion of infected pods (Kruskal test, $X^{2}=4.9879, p=0.0255$ ).

Variance Inflation Factors (VIF's) were around $1(\mathrm{SOM}=1.001$, Fertilizer= 1.028, Pollinator visitation rate $=1.0013$, Proportion of infected pods $=1.0310$ ), meaning that collinearity did not affect the model. 
Chapter 5

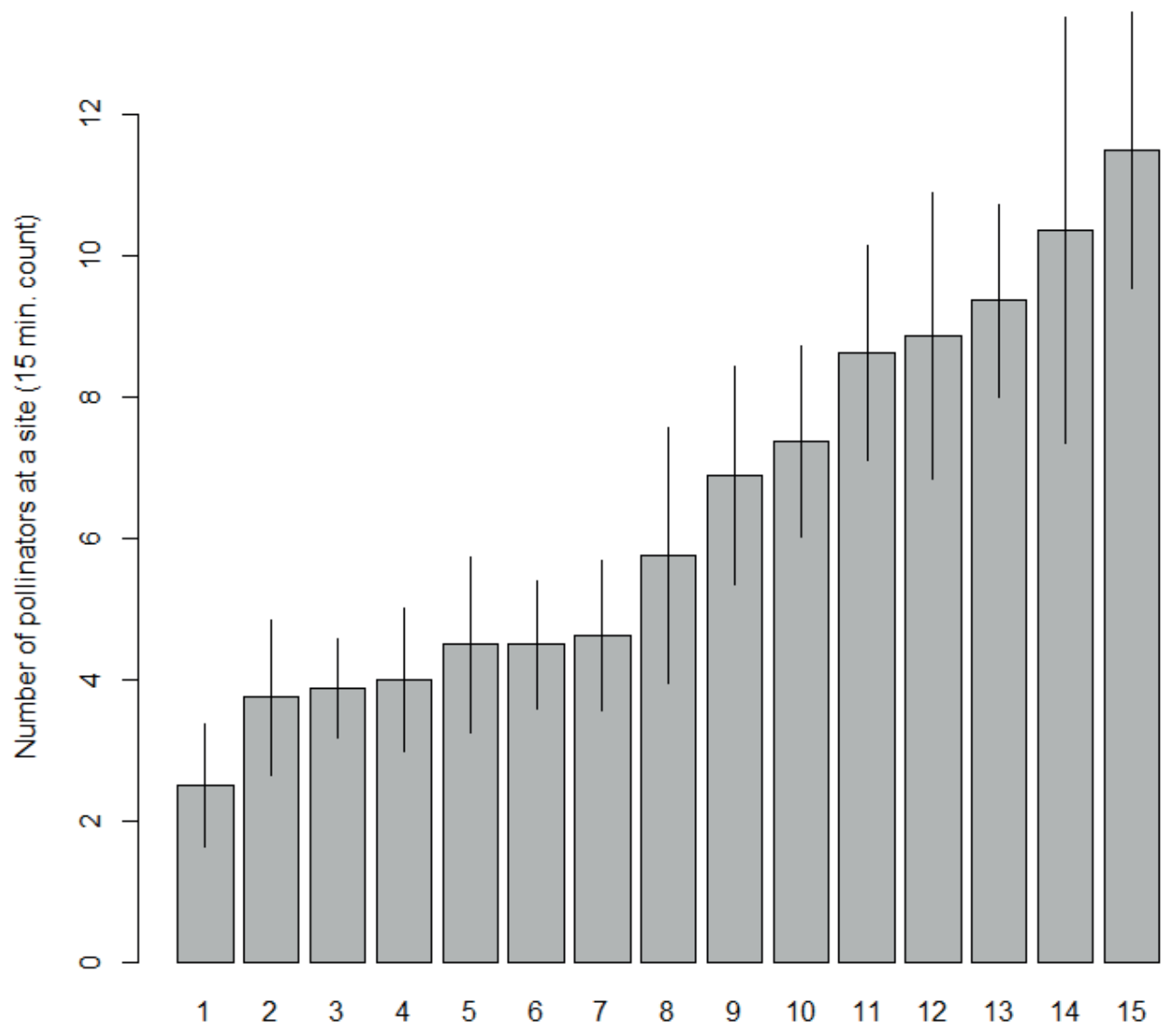

Fig. S5.1.1. Number of pollinators (bees and hoverflies) counted across the different landscapes

in a 15 minute count. Numbers on the $\mathrm{x}$ axis correspond with a field site. Province is mentioned in parentheses. 1: Haanwijk (Noord-Brabant); 2: Tongelaar (Noord-Brabant); 3: Keent (Noord-Brabant); 4: NIOO (Gelderland); 5: Oeffelt (Noord-Brabant); 6: Zwijnsweg (Flevoland); 7: Oudebosweg (Flevoland); 8: Vredepeel (Limburg); 9: Bedaf (Noord-Brabant); 10: Udensedreef (Noord-Brabant); 11: Sinderhoeve (Gelderland); 12: Staartjespeelweg (Noord-Brabant); 13: Sloefweg (Flevoland); 14: Kooldert (Noord-Brabant); 15: Munterweg (Noord-Brabant). Error bars show SE, based on eight observations per landscape. 


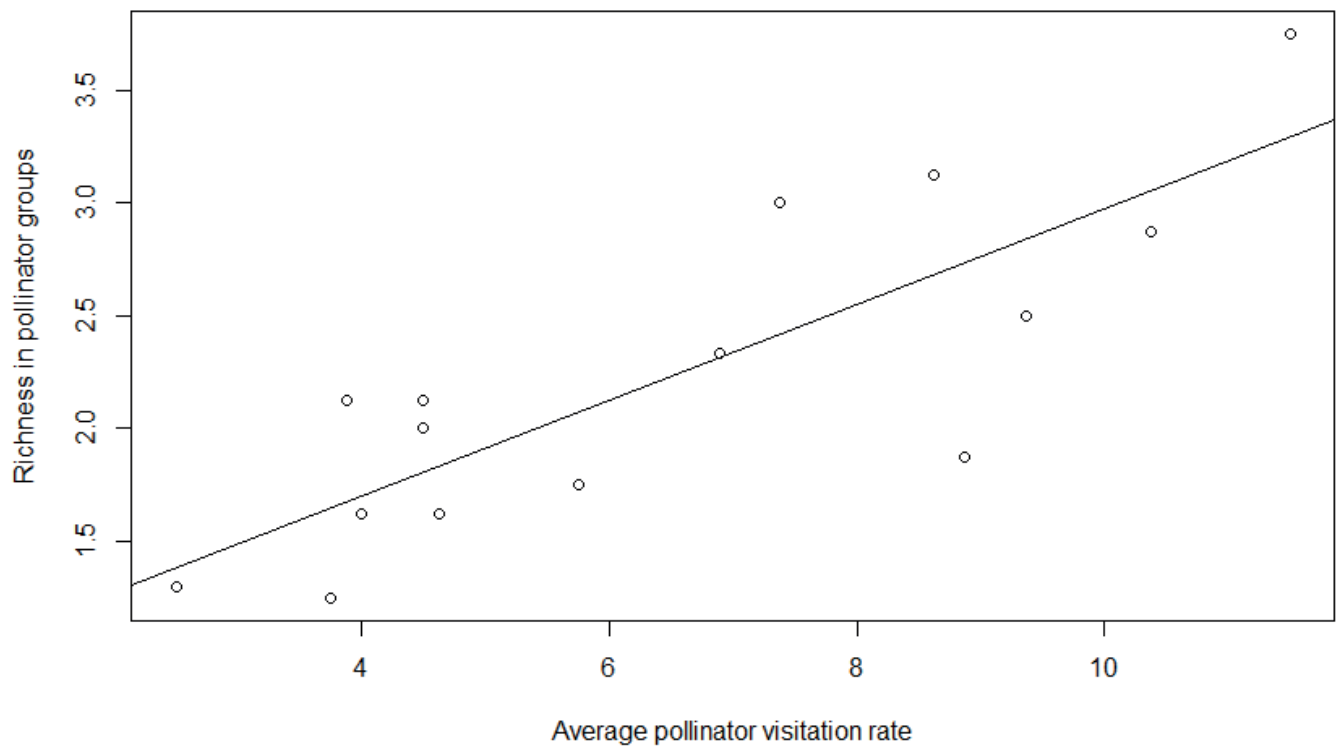

Fig. S5.1.2. Average number of pollinators (bees and hoverflies) counted across the different field sites during 15 minutes counts explaining average richness in pollinator groups (we distinguished different bumble bee species, and large and small bees and hoverflies as different groups). 
Chapter 5

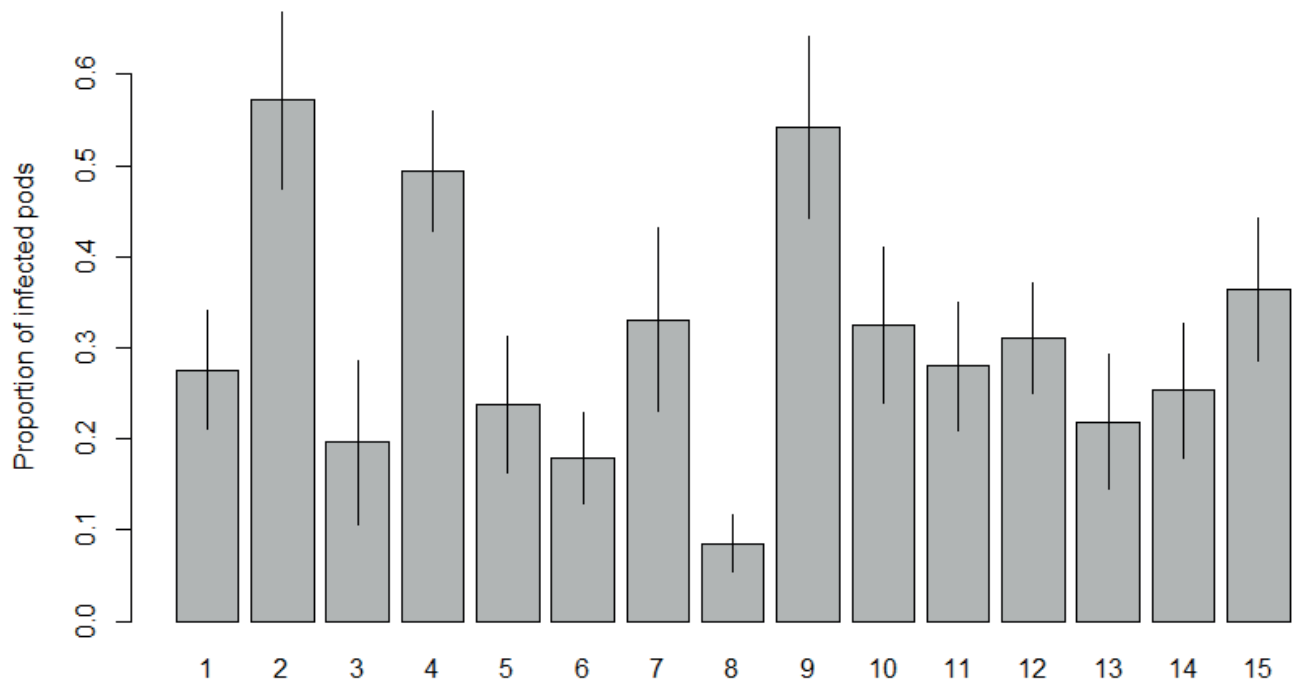

Fig. S5.1.3. Average proportion of infected pods of Evergestis extimalis counted in the different

landscapes. Numbers on the $\mathrm{x}$ axis correspond with a field site. Province is mentioned in parentheses.

1: Haanwijk (Noord-Brabant); 2: Tongelaar (Noord-Brabant); 3: Keent (Noord-Brabant); 4: NIOO

(Gelderland); 5: Oeffelt (Noord-Brabant); 6: Zwijnsweg (Flevoland); 7: Oudebosweg (Flevoland); 8:

Vredepeel (Limburg); 9: Bedaf (Noord-Brabant); 10: Udensedreef (Noord-Brabant); 11: Sinderhoeve

(Gelderland); 12: Staartjespeelweg (Noord-Brabant); 13: Sloefweg (Flevoland); 14: Kooldert (Noord-

Brabant); 15: Munterweg (Noord-Brabant). Error bars show standard error. 


\section{Appendix S5.2. Community effects of pollinators on yield}

To get some mechanistic understanding on specific effects of pollination on yield, we performed three linear mixed effects models (see Methods in the main article for more information) with yield explained by the different functional pollinator groups: (1) the average number of counted bees (2) the average number of counted hoverflies and with (3) the average species (group) richness consisting of honey bees, large bees (no bumble bee), small bees (no bumble bee), large hoverflies, small hoverflies, and the different bumble bee species. As these factors were collinear we performed these models separately.

Bees were not significantly related to yield whereas hoverflies were significantly positively related to yield (Table S5.2.1). Richness tended to be related to yield, but this effect was not significant (Table S5.2.1).

These results suggest that the positive effects of pollination to yield are mainly caused by abundance of hoverflies rather than diversity. However, our results should be interpreted with care as hoverflies were more abundant (average: 4.84 per count) in our study than bees (average: 1.64 per count) therefore having a higher potential to drive yield. Furthermore, richness was drawn based on the average number of species groups rather than species themselves or functional richness. Nevertheless, these results show the potential importance of hoverflies for the pollination of B. napus. 


\section{Chapter 5}

Table S5.2.1. Below-ground (soil organic matter [SOM] treatment, fertilizer treatment) and above-ground (pollinators, proportion of infected pods) factors (f) and covariates explaining yield (seed weight in g) of Brassica napus. Pollinators refers to: Bee visitation rate, Hoverfly visitation rate and Pollinator richness. Bold values represent a significant relationship $(\mathrm{P}<0.05)$. All analysis were performed using a linear mixed model with random intercept. Cases were included only when all data was available, resulting in 213 plants, across 15 landscapes.

\begin{tabular}{|c|c|c|c|c|c|c|}
\hline & \multirow{2}{*}{$\begin{array}{c}\text { Bee visitation rate } \\
\mathrm{F}\end{array}$} & & \multicolumn{2}{|c|}{ Hoverfly visitation rate } & \multicolumn{2}{|c|}{ Pollinator richness } \\
\hline & & $\mathrm{p}$ & $\mathrm{F}$ & $\mathrm{p}$ & $\mathrm{F}$ & $\mathrm{p}$ \\
\hline Intercept & 99.12 & $<.0001$ & 211.83 & $<.0001$ & 107.92 & $<.0001$ \\
\hline \multicolumn{7}{|l|}{ Below-ground } \\
\hline SOM (f) & 1.05 & 0.3065 & 1.05 & 0.3079 & 1.06 & 0.3035 \\
\hline Fertilizer (f) & 24.89 & $<.0001$ & 26.63 & $<.0001$ & 25.33 & $<.0001$ \\
\hline \multicolumn{7}{|l|}{ Pollinators } \\
\hline Bee visitation rate & 0.03 & 0.8571 & & & & \\
\hline Hoverfly visitation rate & & & $\mathbf{1 7 . 5 3}$ & 0.0011 & & \\
\hline Diversity & & & & & 2.14 & 2.1359 \\
\hline \multicolumn{7}{|l|}{ Pest } \\
\hline Proportion of infected pods & 43.04 & $<.0001$ & 49.71 & $<.0001$ & 43.63 & $<.0001$ \\
\hline \multicolumn{7}{|l|}{ Interactions } \\
\hline SOM:Fertilizer & 0.14 & 0.7046 & 0.15 & 0.6965 & 0.15 & 0.6997 \\
\hline SOM:Pollinators & 1.23 & 0.2691 & 0.01 & 0.9356 & 0.77 & 0.3802 \\
\hline Fertilizer:Pollinators & 0.19 & 0.6639 & 0.48 & 0.4873 & 0.43 & 0.5131 \\
\hline SOM:Prop. inf. Pods & 2.43 & 0.1207 & 2.71 & 0.1016 & 2.40 & 0.1228 \\
\hline Fertilizer:Prop. inf. Pods & 0.77 & 0.3804 & 1.58 & 0.2102 & 0.86 & 0.3541 \\
\hline Pollinators:Prop. inf. pods & 0.41 & 0.5238 & 10.87 & 0.0012 & 3.44 & 0.0652 \\
\hline
\end{tabular}




\section{Appendix S5.3. Correlation between biomass and the number of flowers}

To determine whether there is a trade off in Brassica napus between number of flowers and the production of above-ground biomass, we correlated above-ground biomass with the average number of flowers across the different field visits with the expectation that there would be a negative correlation. Opposite to our expectation, these two factors were weakly positively correlated (Spearman rank test: $\mathrm{rho}=0.16, \mathrm{p}=0.0177$ ), as fertilization both enhanced biomass and the number of flowers. If we only select the unfertilized plots there is a negative correlation (Spearman rank test: rho=-0.24, p=0.01628; Fig S3.1). A similar negative correlation was observed in the fertilized plots (Spearman rank test: $r h o=-0.27, \mathrm{p}=0.0051$; Fig S5.3.1).

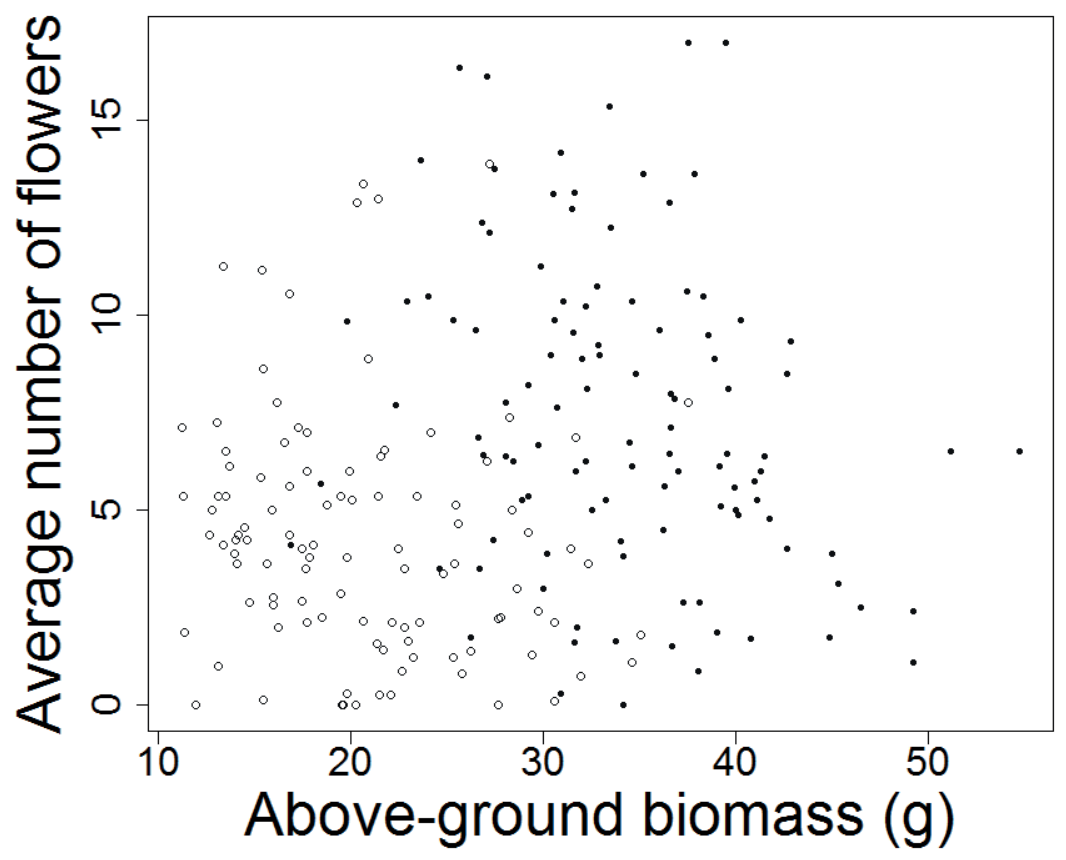

Fig. S5.3.1. Relation between above-ground plant biomass and average number of flowers in Brassica napus. Open dots represent unfertilized plants, whereas closed dots represent fertilized plants. 
Chapter 5

5 


\section{Chapter 6}

Soil biotic and abiotic properties during transition

from conventional to organic arable farming and potential consequences for plant and aphid performance

Stijn van Gils, David Kleijn, Gerard Korthals, Wietse de Boer and Wim H. van der Putten

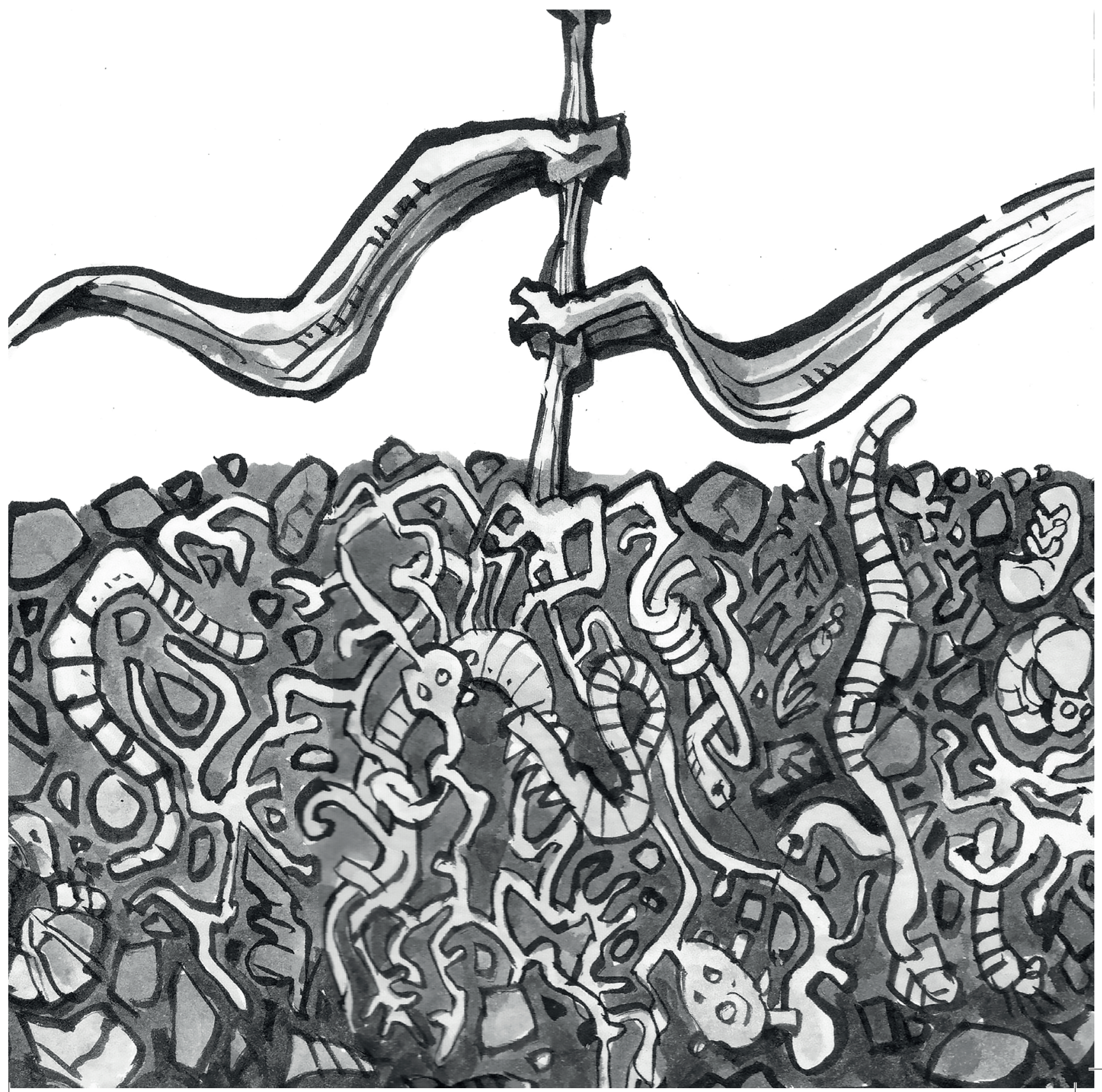




\section{Chapter 6}

\section{Abstract}

The growing demand for organic products is stimulating the conversion of conventional into organic agriculture. An assumption that is often implicitly made is that organic agriculture has a positive influence on soil properties, plant performance and pest suppression, however, many studies only compare short-term effects of changing farming systems, or results are obfuscated by environmental variability. Here we compare soils from organic farms with similar soils from nearby conventional farms with respect to soil organic matter (SOM) content, bacterial and fungal biomass, plant performance in these soils under controlled conditions, and the performance of aphids on these plants. We chose our farms such that they represent a 35 years' time series following conversion from conventional to organic. Soil from organic fields had more PLFA-based fungal biomass, however, ergosterol-based fungal biomass, bacterial biomass, and SOM content did not differ between conventional and organic fields. Duration of organic farming had no effect on soil properties. In the bioassay, plant biomass was higher on conventional soils than on organic soils, whereas aphids performed better on plants grown in soil from organic farms. Time since conversion did not relate to plant biomass or aphid performance. Plant biomass in the bioassay increased with $\mathrm{C}$ content, $\mathrm{N}$ content, bacterial biomass, fungal biomass (ergosterol), bacterial composition and bacterial diversity. We conclude that conversion of conventionally into organically farmed soil does not result in drastic changes in bacterial and fungal biomass. In a greenhouse trial there was, however, substantially lower wheat plant biomass on soils from organic farms, whereas these plants sustained more aphids. Our results suggest that the microbial community in organic soils allows fewer nutrients to become available for plant growth than in conventional soils, but that the plants become more susceptible to aphids. Future studies are needed to compare plant and pest performance under controlled conditions with those in the field. 
Organic agriculture soils through time

\section{Introduction}

The growing demand for organically grown food products has led to an increased land use for organic farming (Reganold \& Wachter 2016). Many studies have shown that organically farmed soils have a different microbial community with generally more microbial biomass, but that the yield in conventional systems is usually higher (Seufert, Ramankutty \& Foley 2012). Studies in natural ecosystems show that it can take years for soils to respond to land use changes such as land abandonment (Morriën et al. 2017), however, comparisons between organic and conventional farming systems rarely take such longer-term developments into account. Here, we assessed how soil properties develop with increasing time since conversion from conventional into organic soil management. Then, we experimentally tested under controlled conditions how duration of soil exposure to organic farming may affect the potential of the soil to support wheat (Triticum aestivum) growth and how aphid pests may perform on those plants.

Conventional and organic agricultural systems differ in various aspects. The most pronounced difference is that conventional agriculture makes use of pesticides and mineral fertilizer, whereas organic agriculture strongly depends on organic manure for nutrient provisioning, mechanical weeding for weed control, and more complex rotations for pest control (Zehnder et al. 2007). These different measures can have substantial consequences for biotic and abiotic soil properties, possibly resulting into different soil food web composition and functioning in organic compared to conventional farming systems (Fließbach et al. 2007). For example, supplying nutrients by organic manure instead of mineral fertilized may enhance colonization of plant roots by arbuscular mycorrhizal fungi (Gryndler et al. 2006). Omitting pesticides in organic agriculture may further enhance colonisation of plant roots by arbuscular mycorrhiza (Kjøller \& Rosendahl 2000). Organic farming also may allow more weed diversity (Bengtsson, Ahnström \& Weibull 2005), which could affect the composition and functioning of the microbial community (Grüter, Schmid \& Brandl 2006; De Deyn, Quirk \& Bardgett 2011).

It is unclear how fast the microbial community develops from a conventional to an organic farming system. Many soil microbes are known to colonize rapidly, as these are wind-dispersed (Nkem et al. 


\section{Chapter 6}

2006), whereas other species might have survived the recent intensified conventional farming, such as was suggested by Kardol et al. (2005) for nematodes. A possible shift in microbial and faunal community composition of soil organisms will also depend on the quality of the substrate (Wardle 2002). However, it is not well established how the net effects of all these changes influence transitions in the composition of the soil microbial community following altered farm management. For example, Lazcano et al. (2013) found an altered microbial structure after the application of different types of fertilizer already within one growing season, but systematic surveys including multiple years of land use change are relatively rare (Morriën et al. 2017).

The time needed for a conversion from conventional to organic farming might be due to the time needed for developing a sufficient amount of soil organic matter (SOM) with properties that make it more suitable for organic farming (Marriott \& Wander 2006). Soil organic matter refers to all organic materials in the soil that are at least partially decomposed (Fageria 2012). The quality and quantity of SOM relates to plant nutrient availability following decomposition by micro-organisms, the development of soil structure, and of soil water holding capacity, which all may affect the composition of the plant tissues and the amount of plant biomass produced (Lal 2006). It is generally assumed that increasing SOM content can be used to improve ecosystem services, such as nutrient provisioning and crop yield (Bommarco, Kleijn \& Potts 2013). However, there is less consensus about whether higher SOM may relate to improved yields: some studies support this view (Brady et al. 2015) and others not (Hijbeek et al. 2016).

Long-term application of mineral fertilizer in conventional farming systems and organic manure, green manure, and crop residues in organic farming systems may have an effect on the labile (fast decomposable) and recalcitrant (slow decomposable) fractions of SOM. However, these effects are not unidirectional (Bronick \& Lal 2005). For example, long-term conventional farming might lead to an increase in the proportion of recalcitrant SOM, which is less likely to become decomposed (Steiner et al. 2007; Majumder \& Kuzyakov 2010). Organic farming will result in high addition of organic manure that consists of macro-nutrients, including nitrogen $(\mathrm{N})$, phosphorous $(\mathrm{P})$ and potassium $(\mathrm{K})$, 
as well as high amounts of carbon (C) (Pimentel et al. 2005). Bacterial and fungal species mineralize SOM to plant available nutrients such as nitrogen $(\mathrm{N})$, which directly influences plant performance (Prescott 2010). As microbial decomposition depends on moisture content and temperature, organically managed soils are expected to have a different temporal nutrient release than conventionally managed soils (Zhou et al. 2016). Indeed, it has been shown that organic farming enhances microbial biomass, including a higher contribution of fungi to the soil microbial biomass (Maeder et al. 2002). However, such shifts in fungi to bacteria ratios may take place over relatively long time periods (Stagnari et al. 2014).

Differences in SOM content and the soil microbial community steered by organic agriculture, may not only affect crop yield by altered temporal dynamics in nutrient provisioning and enhanced soil structure, but could also have consequences for aboveground organisms (Poveda et al. 2005). For example, Bezemer et al. (2005) showed that the composition of soil community affects the performance of aphids and also of their parasitoids on aboveground plant parts. Soil conditions may affect herbivores aboveground by changed plant nutritional status and an altered composition of induced systemic plant defence (Kostenko et al. 2016). Aphids are known to respond positively to increased nitrogen contents in shoot tissues (Riedell, Beckendorf \& Catangui 2013) and reduced plant defence (Moran \& Thompson 2001). Therefore, as we expected soils from organic farms to release nutrients at a slower rate, we expected the shoot tissues of plants growing in organic farm soil to be less suitable for aphid multiplication than shoot tissues from plants grown in conventional soils (Hasken \& Poehling 1995). As arbuscular mycorrhizal fungi, which are stimulated by organic farming, may enhance the performance of aphids (Babikova et al. 2014), organic farming could also stimulate aphids. However, we do not expect this effect to be substantial, because the abundance of mycorrhizal fungi in organic field soil is still expected to be relatively low (Säle et al. 2015). 


\section{Chapter 6}

The overall aim of the present study is to determine how organic farming is altering abiotic and biotic soil properties, crop plant performance, and plant defense against pest insects. The first sub-aim of our study was to examine how long-term organic farm management influences the quantity (percentage C) and quality (C:N ratio) of SOM. The second sub-aim was to examine how the SOM content relates to the composition and abundance of the microbial community and subsequently plant biomass production in these soils and aboveground pest performance on those plants. We tested two hypotheses: (1) Fields with organic management history have soils with higher SOM content and more microbial biomass and -diversity compared to nearby conventional fields and this effect increases with increasing time of conversion from conventional into organic farming. (2) Increasing time of organic management correlates under controlled conditions with increasing plant biomass and decreasing aphid biomass. (3) In a bioassay under controlled greenhouse conditions, soil from fields with a higher SOM content and more bacterial biomass produce more plant biomass.

\section{Materials and methods}

Study design

In Spring 2016, we selected organic fields across the Netherlands in order to obtain a chronosequence (time series) representing a time since conversion from conventional to organic management. These soils were collected across the country in sand and clay soils. The organic fields were managed without pesticides and mineral fertilizer and the chosen fields varied from 1 up to 35 years of organic management, with an average duration of organic management of 13 years. In total we selected fields from 21 organic farms. If possible we selected multiple fields per organic farm that differed in number of years of organic management. Per organic farm we searched for at least one conventional field nearby with similar soil conditions to serve as a control. This selection procedure resulted in a total of 70 fields: 46 organically and 24 conventionally managed. From each field we collected $10 \mathrm{~kg}$ of soil from an area of $25 \mathrm{~m}^{2}$ using a $2.5 \mathrm{~cm}$ diameter gouge auger. Each sample consisted of approximately 70 subsamples that were collected from $0-20 \mathrm{~cm}$ below the soil surface. After collection, samples were stored at $4{ }^{\circ} \mathrm{C}$. A small subsample was sieved using a $4 \mathrm{~mm}$ mesh size, homogenized, and freeze-dried prior to soil analyses. All remaining soil was sieved at $5 \mathrm{~mm}$ mesh size for the bioassay. 


\section{Bioassay}

We used the soil from each field to fill 6 pots of $10 \times 10 \times 11 \mathrm{~cm}$. Three of the 6 pots from each field were randomly assigned to aphid treatment and three served as a control. The total experiment included 420 pots ( 70 fields $\times 2$ treatments $\times 3$ pseudo replicated pots of each field per treatment). All pots were placed fully randomized in a greenhouse with $16 \mathrm{~h}$ daylight. In each pot we placed 4 spring wheat seeds (Triticum aestivum var. Tybalt) and after germination we removed the three smallest seedlings to continue the experiment with one plant per pot. The pots were hand-weeded at the start and at week 3 of the experiment, whereas no extra fertilizer was supplied.

After 6 weeks, when the plants started to flower, the pots were re-randomized and covered by a gauze net (mesh size around $150 \mu \mathrm{m})$. Subsequently, in each pot assigned to the aphid treatment, we placed one adult apterous grain aphid (Sitobion avenae) on the spike of the plant using a fine brush. Once a week during five weeks of plant exposure to aphids we counted all aphids. If no aphid was present we placed a new single apterous aphid on the spike. After seed set, 12 weeks after sowing, the aboveground biomass was harvested and dried at $40{ }^{\circ} \mathrm{C}$ for at least 7 days, and weighed.

\section{Soil samples}

To estimate total carbon $(\mathrm{C})$ and nitrogen $(\mathrm{N})$ we homogenized the soil after grinding to a fine powder. Tin cups were filled with $5 \mathrm{mg}$ of this fine powder and analysed using combustion-reduction with an element analyser (Thermo flash EA 1112, Thermo Fisher Scientific Inc., Waltham, USA). To estimate microbial biomass we measured ergosterol content and phospholipid fatty acids (PLFA) in the soils. Ergosterol content was extracted from soil as a proxy for fungal biomass using the method described by Bååth (2001). We extracted ergosterol from 1 gram of soil using an alkaline-extraction protocol and determined the ergosterol content using a LC-MSMS. The PLFA extraction was done according to Frostegård, Tunlid and Bååth (1991). In brief, we extracted PLFA by breaking down the biological membrane of bacteria and fungi using several extraction steps in e.g. methanol and hexane. The final samples were measured using a GC-IRMS and peaks were classified using internal and commercial markers. 


\section{Chapter 6}

For PLFA fungal biomass we used marker C18:2w6c. For the bacterial group actinomycetes we used the markers 10Me16:0, 10Me17:0 and 10Me18:0. For Gram-negative bacteria we used the markers cy19:0, C18:1w7c, cy17:0 and C16:1w7c. For Gram-positive bacteria we used the markers i15:0, a15:0, C15:0, i16:0, i17:0, a17:0 and C17:0 (Frostegård, Tunlid \& Bååth 1993; Frostegård \& Bååth 1996; Zelles 1999; van der Wal et al. 2006; Rinnan \& Bååth 2009; Dungait et al. 2011; Whitaker et al. 2014). As the different bacterial groups were highly correlated to each other, we used only the sum of the biomasses of the different groups (see Appendix S6.1 in Supporting Information).

\section{Analyses}

Our response variables were $\mathrm{C}$ content (\%), $\mathrm{N}$ content (\%), C:N ratio, fungal biomass (measured as PLFA and ergosterol, $\mu \mathrm{g} \mathrm{g}^{-1}$ soil), bacterial biomass (PLFA, $\mu \mathrm{g} \mathrm{g}^{-1}$ soil), bacterial diversity, Bacterial composition (NMDS axis 1 and 2), aboveground plant biomass (g.pot ${ }^{-1}$ ) and aphid number (N.pot ${ }^{-1}$ ). Bacterial diversity was calculated using the Shannon index (Shannon 1948):

$$
H^{\prime}=-\sum_{i=1}^{S} p_{i} \ln \left(p_{i}\right)
$$

In the formula, $p_{i}$ is the proportion of species $i$ based on estimated biomass of the different PLFA peaks that are described as bacterial, and $S$ is the number of species. Bacterial composition was calculated using Non-Metric Multidimensional Scaling (NMDS) with the PLFA data as input. We made an NMDS with 2 axes. The stress level was 3.59\%. Although the use of PLFA data for determining soil community diversity and composition is criticized (Frostegård, Tunlid \& Bååth 2011), it may still be of some use (Wardle et al. 2015; Liao et al. 2016).

To test whether organic farming promotes SOM content, $\mathrm{N}$ content, bacterial and fungal biomass and the ratio between these, and whether organic farming causes bacterial diversity and composition to be different from conventional agriculture, we used a mixed linear model with random intercept. Organic versus conventional farming was used as fixed factor, farm as random factor and field was used as the experimental unit. The six pots from each treatment were considered pseudo replicates. To test 
whether duration of organic farming had an influence on these response variables, we selected only the organic fields and used a similar linear mixed model, but here with duration of organic management (y) as covariate and no fixed factor.

To test whether plant biomass in the bioassay differed between soil from organic and conventional farms we also used a similar mixed linear model. As we grew plants with and without aphid infestation, we used organic farming (yes, no) and aphid infection (yes, no) including interaction as fixed factors. As a result we had two experimental units per field: one with aphids and one without. Therefore, as random factors, we nested field in farm. The three pots from each treatment were considered pseudo replicates.

To test whether duration of organic management influenced plant biomass of the bioassay we calculated the relative biomass in organically managed soil compared to the nearby conventional field:

$$
R=\log _{10}\left(\frac{B_{o}}{B_{c}}\right)
$$

where $R$ is the relative plant biomass increase, $B_{o}$ is the biomass on an organic field and $B_{c}$ is biomass on the nearby conventional field. The test was performed as a linear mixed model with random intercept and duration of organic farming as covariate and field as random factor.

To test whether during the five counts aphid number on plants in soil from organic fields differed from conventional fields we used a linear mixed model with organic farming (yes, no) as fixed factor and aphid count (weeks 1 to 5) as covariate. As a result we had five experimental units per field: one for each aphid count. Therefore, as random factors, field was nested in farm. To test whether duration of organic farming had an effect on the number of aphids we used the same model, but replaced the fixed factor organic farming with the duration of organic farming (y). For this model, we only selected the organic fields. 


\section{Chapter 6}

Prior to analyses we verified that Variance Inflation Factors (VIFs) were not exceeding 3 (Zuur et al. 2009 ) in order to establish if collinearity would not affect model outcomes. Next, we visually inspected whether residuals were normally distributed. If this was not the case data was transformed so that an appropriate distribution resulted. In order to obtain normally distributed data, C content and yield were $\ln$-transformed-, ergosterol content was $\ln +1$-transformed, NDSM1 was $\sqrt{ }+3$-transformed, relative yield was $\log 10$-transformed, and aphid number was $\sqrt{ }+1$-transformed. All analyses were performed using R 3.2.2 (R Core Team), with the package nlme (Pinheiro et al. 2014) for Linear Mixed Models.

\section{Results}

\section{Soil conditions}

Organic farm soils had more fungal biomass when quantified as PLFA, but not if measured as ergosterol (Table 6.1, Fig 6.1a and 6.1b). Organic farm soils did not have significantly more bacterial biomass or a higher bacterial diversity (Table 6.1, Fig 6.1c and 6.1d). Organic farm soils also did not differ from conventional farms in $\mathrm{C}$ content, $\mathrm{N}$ content, $\mathrm{C}: \mathrm{N}$ ratio, the fungi/bacteria ratio and PLFAbased bacterial composition (Table 6.1). Opposite to expected, duration of organic farming did not influence any of the measured soil properties (Table 6.2). 
Table 6.1. Differences in measured soil properties between conventional and organic soils (median values are shown). Significant differences $(\mathrm{P}<0.05)$ are highlighted in bold. Tests were performed with a linear mixed model, with farm as random factor $(\mathrm{N}=70)$.

\begin{tabular}{|c|c|c|c|c|c|c|}
\hline & Transformation & Organic & Conventional & Unit & $\mathbf{F}$ & $\mathbf{P}$ \\
\hline C content & $\operatorname{Ln}$ & 2.27 & 2.45 & $\mathrm{~g} / \mathrm{g}$ & 0.13 & 0.725 \\
\hline $\mathrm{N}$ content & - & 0.15 & 0.14 & $\mathrm{~g} / \mathrm{g}$ & 0.71 & 0.405 \\
\hline $\mathrm{C}: \mathrm{N}$ ratio & - & 14.85 & 14.92 & ratio & 1.33 & 0.255 \\
\hline Bacterial biomass (PLFA) & $\log 10$ & 19.96 & 17.83 & $\mu \mathrm{g} / \mathrm{g}$ & 3.05 & 0.087 \\
\hline \multicolumn{7}{|l|}{ Fungal biomass } \\
\hline (Ergosterol) & $\ln +1$ & 1.35 & 1.17 & $\mu \mathrm{g} / \mathrm{g}$ & 0.41 & 0.405 \\
\hline Fungal biomass (PLFA) & $\ln +1$ & 0.41 & 0.34 & $\mu \mathrm{g} / \mathrm{g}$ & 4.12 & 0.048 \\
\hline \multicolumn{7}{|l|}{ Fungal/bacteria ratio } \\
\hline (PLFA) & - & 0.05 & 0.05 & ratio & 2.91 & 0.094 \\
\hline NMDS 1 (PLFA bacteria) & sqrt+3 & -0.15 & -0.51 & - & 3.21 & 0.080 \\
\hline NMDS 2 (PLFA bacteria) & - & -0.03 & 0.04 & - & 3.02 & 0.089 \\
\hline \multicolumn{7}{|l|}{ Shannon diversity } \\
\hline bacteria (PLFA) & - & 2.23 & 2.25 & - & 2.83 & 0.099 \\
\hline
\end{tabular}


Chapter 6

Table 6.2. Differences in soil properties explained by duration of organic farming (years). Tests were performed with a linear mixed model, with farm area as random factor $(\mathrm{N}=70)$.

\begin{tabular}{|c|c|c|c|c|}
\hline & Transformation & Slope & & \\
\hline C content & $\mathrm{Ln}$ & 0.01 & 1.28 & 0.269 \\
\hline $\mathrm{N}$ content & - & 0.00 & 2.65 & 0.110 \\
\hline $\mathrm{C}: \mathrm{N}$ ratio & - & -0.04 & 1.64 & 0.207 \\
\hline Bacterial biomass (PLFA) & $\log 10$ & 0.00 & 0.20 & 0.658 \\
\hline Fungal biomass (Ergosterol) & $\ln +1$ & 0.82 & 0.63 & 0.435 \\
\hline Fungal biomass (PLFA) & - & 0.00 & 1.21 & 0.283 \\
\hline Fungal/bacteria ratio (PLFA) & $\ln +1$ & 0.00 & 1.16 & 0.293 \\
\hline NMDS 1 (PLFA bacteria) & sqrt+3 & 0.00 & 0.31 & 0.586 \\
\hline NMDS 2 (PLFA bacteria) & - & 0.00 & 0.67 & 0.421 \\
\hline Shannon diversity bacteria (PLFA) & - & 0.00 & 3.44 & 0.076 \\
\hline
\end{tabular}


Organic agriculture soils through time
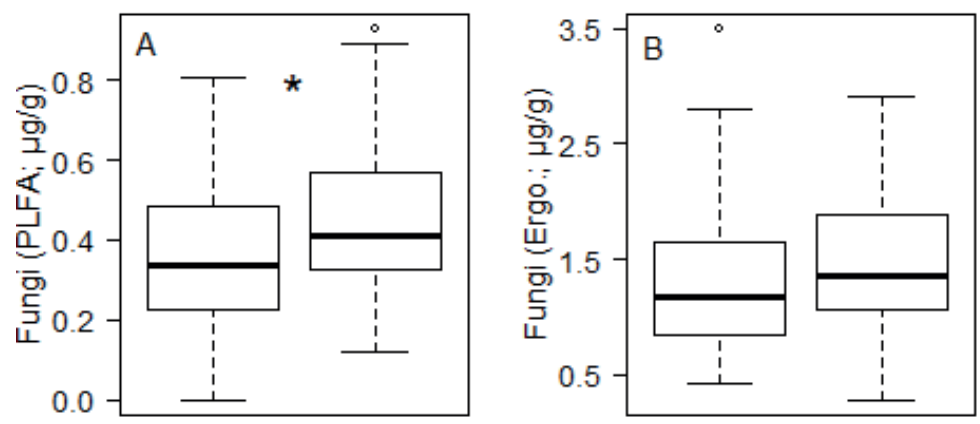

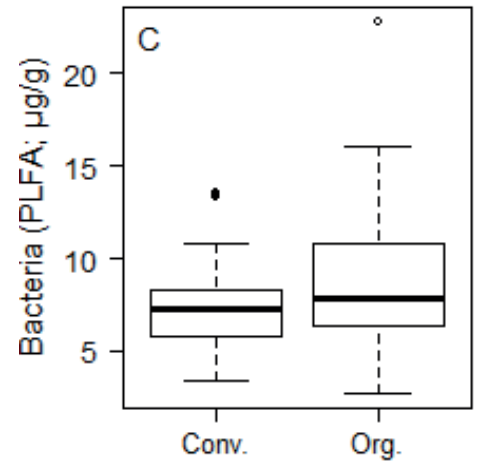

Management type

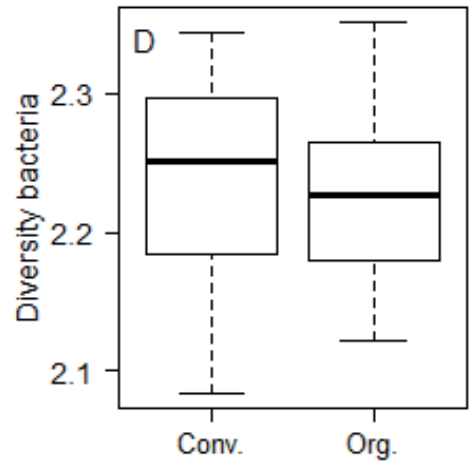

Management type

Fig. 6.1. (a) Fungal biomass (PLFA, $\mu \mathrm{g} / \mathrm{g}$ soil), (b) Fungal biomass (ergosterol, $\mu \mathrm{g} / \mathrm{g}$ soil), (c) Bacterial biomass (PLFA, $\mu \mathrm{g} / \mathrm{g}$ soil), and (d) Bacterial diversity (Shannon Index over PLFA bacterial markers) in conventional farms and organic farms. Significant differences $(\mathrm{P}<0.05)$ are indicated with an *. 


\section{Chapter 6}

\section{Plant biomass in bioassay}

Plant biomass in the bioassay was lowest in pots that were infected by aphids (mixed linear model, $\mathrm{F}=7.45, \mathrm{p}=0.007, \mathrm{~N}=140$, Fig. 6.2a) and in soil from organic fields $(\mathrm{F}=12.05, \mathrm{p}=0.0007$, Fig. 6.2b). Opposite to expected, the effect on aphid infection did not differ between plants grown in soil from organic and conventional fields $(\mathrm{F}=0.21, \mathrm{p}=0.646)$. The relative difference in plant biomass in soil from organic fields compared to soils from nearby conventional fields was not influenced by duration of organic farming $(\mathrm{F}=0.08, \mathrm{p}=0.777, \mathrm{~N}=46$, Fig. 6.3).
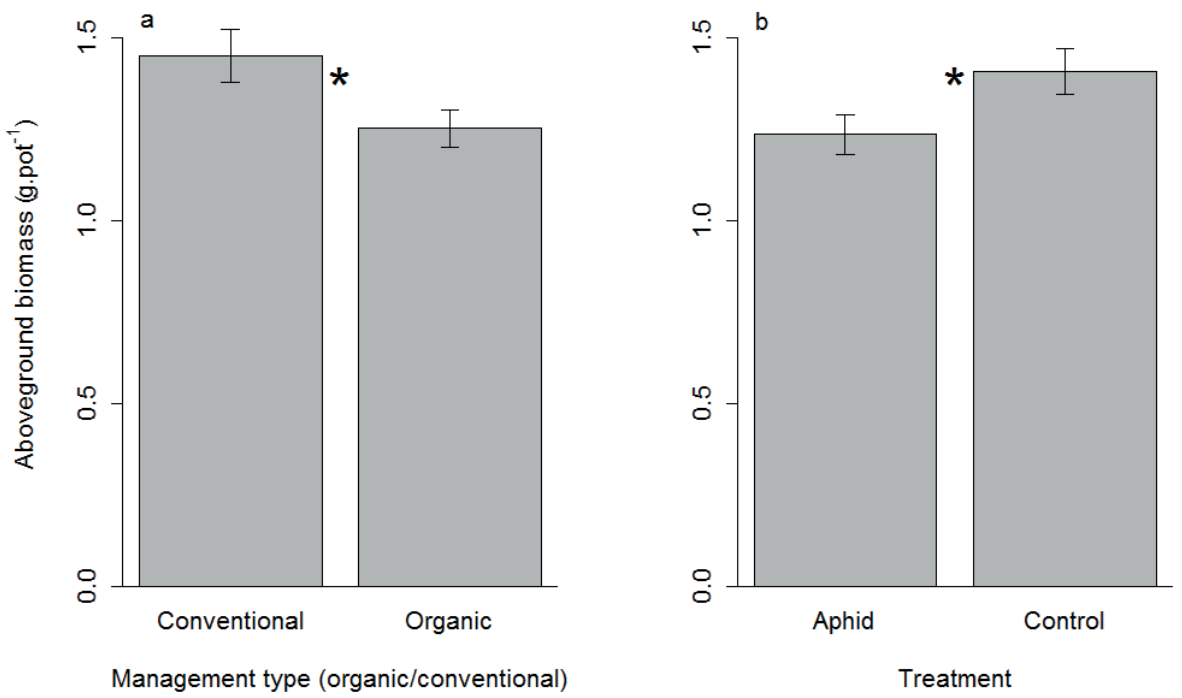

Fig. 6.2. Aboveground biomass of Triticum aestivum in; (a) conventional farms and organic farms; (b) with and without aphids. $\mathbf{N}=140$. Significant differences $(\mathrm{P}<0.05)$ are indicated with an *. 


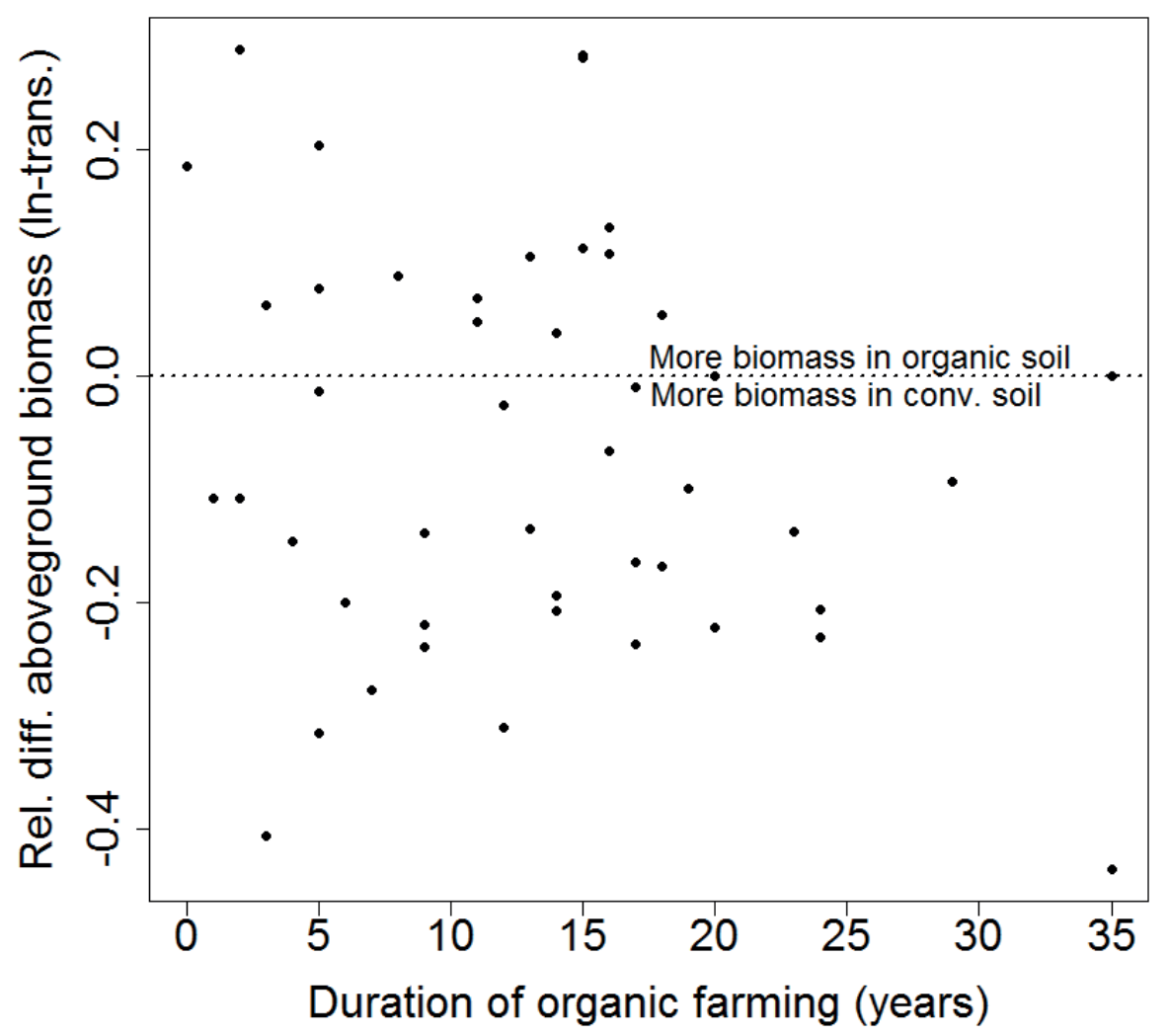

Fig. 6.3. Relative difference in aboveground biomass (thus: aboveground biomass of Triticum aestivum grown in organic soil / aboveground biomass in soil from nearby conventional field), explained by duration of organic farming (years). $\mathrm{N}=46$.

Plant biomass in the bioassay (both organic and conventionally managed soils) increased with C content, $\mathrm{N}$ content, bacterial biomass, fungal biomass (ergosterol), bacterial composition (NMDS 1 and NMDS 2) and bacterial diversity, whereas $\mathrm{C}: \mathrm{N}$ ratio tended to be inversely related to plant biomass (Table 6.3, Fig. 6.4). Content of C, N, Fungal biomass (ergosterol), and biomass bacteria were all positively correlated to each other (see Appendix S6.1 in Supporting Information). In a stepwise regression, a model with $\mathrm{C}$ content, $\mathrm{N}$ content, $\mathrm{C}: \mathrm{N}$ ratio, bacterial biomass and NMDS2 was selected. 
Chapter 6

Table 3. Relation between soil properties and aboveground biomass of Triticum aestivum (Intransformed) grown in organic and conventional soils. Tests were performed using a linear mixed model, with farm area as random factor $(\mathrm{N}=70)$. Significant relations are highlighted in bold.

\begin{tabular}{lccc} 
& Value & \multicolumn{2}{c}{$\mathrm{P}$} \\
& & & \\
\hline C content & 0.11 & 9.45 & 0.004 \\
N content & 1.76 & 11.81 & 0.001 \\
C:N ratio & -0.03 & 4.00 & 0.051 \\
Bacterial biomass (PLFA) & 0.04 & 12.40 & 0.001 \\
Fungal biomass (Ergosterol) & 0.24 & 14.26 & 0.000 \\
Fungal biomass (PLFA) & 0.33 & 2.68 & 0.108 \\
Fungal/bacteria ratio (PLFA) & -2.01 & 0.61 & 0.437 \\
NMDS 1 (PLFA bacteria) & 0.11 & 9.95 & 0.003 \\
NMDS 2 (PLFA bacteria) & 0.35 & 7.89 & 0.007 \\
Shannon diversity bacteria & & & \\
\hline (PLFA) & 2.36 & 9.81 & 0.003 \\
\hline
\end{tabular}



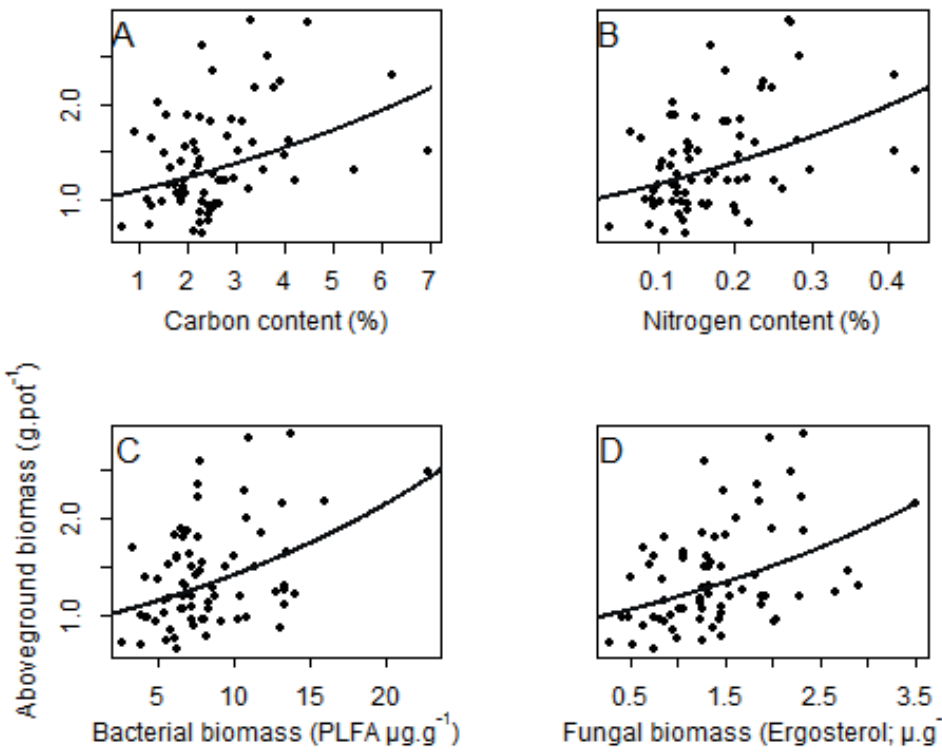

Fungal biomass (Ergosterol; $\mu . g^{-1}$ )

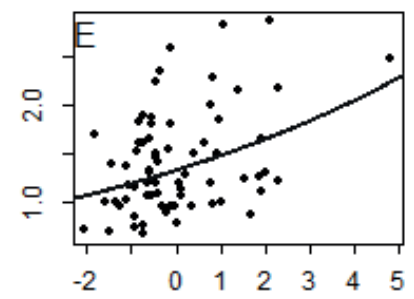

Bacterial composition (NMDS1)

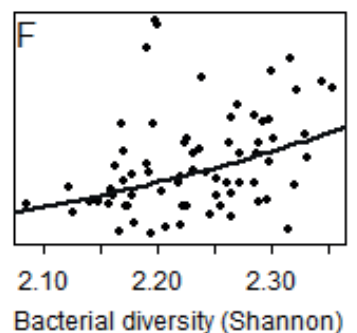

Fig. 6.4. Aboveground biomass of Triticum aestivum not infested by aphids explained by; (a) carbon content in the soil (\%); (b) nitrogen content in the soil (c) bacterial biomass in soil

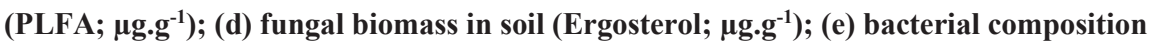
(NMDS1); and (f) bacterial diversity (Shannon Index over PLFA peaks). N=70. 
Chapter 6

\section{Aphid number}

Aphid number increased with time (mixed linear model, $\mathrm{F}=618.82, \mathrm{p}<0.001, \mathrm{~N}=350$ ), but there was no main difference between aphids on plants in organic and conventional soil $(\mathrm{F}=1.46, \mathrm{p}=0.234)$. The effect of the measurement week on aphid number, however, was different between conventional and organic soils; aphid populations grew fastest on plants grown in soil from organic fields $(F=4.79$, $\mathrm{p}=0.029$, Fig. 5). Duration of organic farming also did not influence the number of aphids ( $\mathrm{F}=0.05$, $\mathrm{p}=0.830, \mathrm{~N}=230$ ).

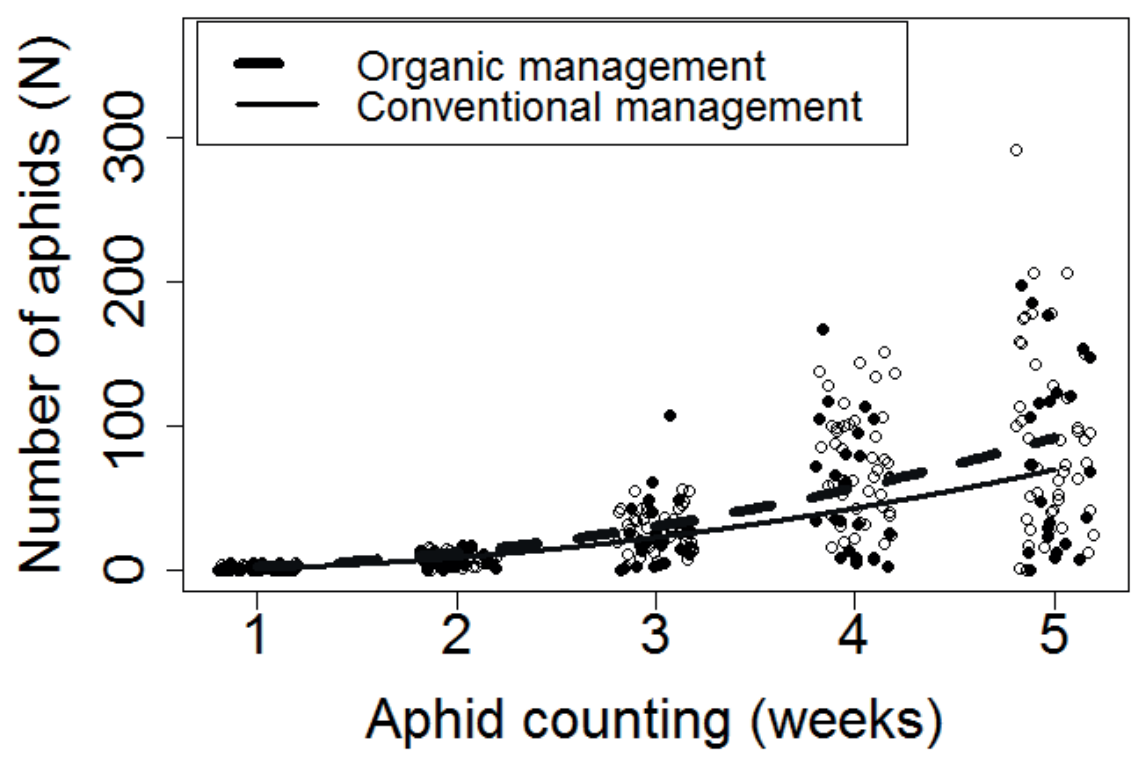

Fig. 6.5. Number of aphids during the five subsequent aphid counts in up following weeks ( $N=350)$, under conventional management and organic management. $(\mathrm{N}=350)$. 
Organic agriculture soils through time

\section{Discussion}

We studied how duration of organic farming affects soil properties, plant growth and aphid performance and show that organic fields had higher PLFA-based fungal biomass. However, organic farm soils did not have more overall bacterial biomass, and the duration of organic farming did not influence any of the measured biological parameters.

As management of organic arable farms differs substantially from that of conventional farms (De Ponti, Rijk \& van Ittersum 2012), we expected to find differences in soil community biomass and composition. Generally, fungal biomass increases after an increase in recalcitrant organic materials (Wardle et al. 2004). As organic farmers use more organic manure and no mineral fertilizers, an increase of fungal biomass in organic systems was to be expected. However, fungal biomass, was only higher if it was measured as PLFA and not when measured as ergosterol. We also expected fungal biomass to correlate with total soil organic matter (SOM) content, but this was only the case if fungal biomass was measured as ergosterol. It could be that the PLFA marker that correlates with fungal biomass, also responds to the biomass of some weed roots (Frostegård, Tunlid \& Bååth 2011). As organic fields have more weeds, this could be an explanation for the difference between ergosterol and PLFA 'fungal biomass'.

There was no indication that other groups of microbes were responding significantly to organic farming. The group of actinomycetes, for instance, also breaks down organic materials (Helfrich et al. 2015), however, there was no difference between organic and conventionally managed soil (see Appendix S6.2). Biomass of bacteria and fungi may not necessarily be indicative of their functional activity (Morriën et al. 2017), especially when their production rate equals their consumption rate. Moreover, microbes are not only controlled by resources, but also by species interactions, for example between actinomycetes and soil fungi (de Boer et al. 2005). Finally, our results also may be explained by soil community changes that take place at a lower taxonomic level than detected by PLFA analysis.

We tested the hypothesis that a longer history of organic farming promotes microbial biomass. However, in none of the species groups there were significant differences, not even a trend. It could 


\section{Chapter 6}

also be that gradual abundance changes take place on a lower taxonomic level, or that changes are reflected in function but not in total biomass. Morriën et al. (2017), for instance, found that recently restored semi-natural grasslands had similar biomass of saprotrophic fungi as grasslands that had been restored longer ago, but that the amount of carbon that these fungi processed increased substantially during succession. Agricultural practises, such as ploughing, and crop rotation, may also generate considerable dynamics in the soil community (Helgason, Walley \& Germida 2010; Smith et al. 2016). As a result differences between organic and conventional farming could be masked by farming practices that overrule possible differences in soil properties.

Our data are not in support of the hypothesis that organically managed fields have a higher SOM content, as there was no difference in SOM content between conventional and organic fields. In various other studies organic management was shown to result into a higher SOM content (Pulleman et al. 2000; Pimentel et al. 2005; Marriott \& Wander 2006; Syswerda et al. 2011). A lower SOM content in conventional fields can be explained by a lack of carbon inputs due to the application of mineral fertilizers. In the Netherlands, however, also in conventional farms a substation amount of manure and other organic inputs are incorporated in the soil, even in conventional systems (van Diepeningen et al. 2006).

We found that plant biomass in the bioassay increased with $\mathrm{C}$ content, $\mathrm{N}$ content, ergosterol content, and bacterial biomass. Improved biomass production in the bioassay may be caused by enhanced nutrient provisioning and increased disease suppression, and both factors may be enhanced by increasing SOM content (Garbeva, van Veen \& van Elsas 2004; van Eekeren et al. 2010). In spite of so few differences between organic and conventional soil properties, plant biomass was clearly less promoted in organic than in conventional soil. As we did not supply any additional nutrients, our results suggest that per unit of time, in organic soils fewer nutrients become available for plant growth. Conventional soils might still contain residues of pesticides that continue to protect crop plants against some diseases (Stockdale et al. 2002; Lo 2010), but it may also be that fungi were not more abundant but were more active in organic systems (Morriën et al. 2017). Interestingly, the differences in 
biomass production of wheat plants between organic and control soils showed substantial variation. In some cases wheat biomass was higher in soil from organic farming than under conventional farming, whereas the reverse prevailed in many other cases. Future studies are needed in order to investigate whether the differences between organic and control soils might relate to other factors, for example management strategies, and how these comparisons work out in the field.

We tested the hypothesis that plants in soil from fields with a long organic management history have fewer aphids than plants with a short organic management history. In contrast to this hypothesis we found more aphid biomass on plants grown on organic, than on plants grown in conventional soils and this effect was more pronounced with an extended growing period of the plant. We expected that nutrients would become less rapidly available under organic management (Prescott 2010), subsequently leading to less nutritious plants and therefore a lower performance of aphids (Hasken \& Poehling 1995). As we found more fungal biomass and less biomass of plants grown in organic soils, it is likely that this mechanism indeed occurs. Perhaps the negative effect of organic soil management on aphids was overruled by other mechanisms, for example more arbuscular mycorrhizal fungi in organic soils might decrease the plant defence against aphids (Mäder et al. 2002). Conventionally managed soils might as well contain residues of systemic insecticides that may have suppressed aphid performance (Hallmann et al. 2014). These two mechanisms might have overruled the growth depressing effect of a slower release of nutrients on aphids.

\section{Conclusions and future perspective}

We conclude that in our time series, conversion of conventionally into organically farmed soil did not result in drastic changes in the abundance of bacteria and fungi. However, apart from a trend, there was no significant effect that organic farming resulted in more bacterial biomass. The time since conversion did not explain observed patterns in total microbial biomass. Overall, conventional soils produced more plant biomass than organic soils in a bioassay without additional nutrient supply. Our results suggest that the microbial community in organic soils allows fewer nutrients to become available for plant growth than in conventional soils. However, aphids were not suppressed by this 


\section{Chapter 6}

lower nutrient availability in organic soils. To better understand how soils develop during transition from conventional to organic farming, it is important to study organic fields of different times since conversion also in the field and for a wider array of crop species.

\section{Acknowledgements}

We thank Anna Clocchiatti, Martina Gorla, Haikun Ma, Ciska Raaijmakers, Marlies van den Berg, Johnny Visser, Minggang Wang, Carolin Weser, Bionext, SPNA and various farmers for valuable help and use of land. This study was funded by the European Community Seventh Framework Program (grant no. 311781) LIBERATION (www.fp7liberation.eu). 


\section{Chapter 7}

General discussion and synthesis

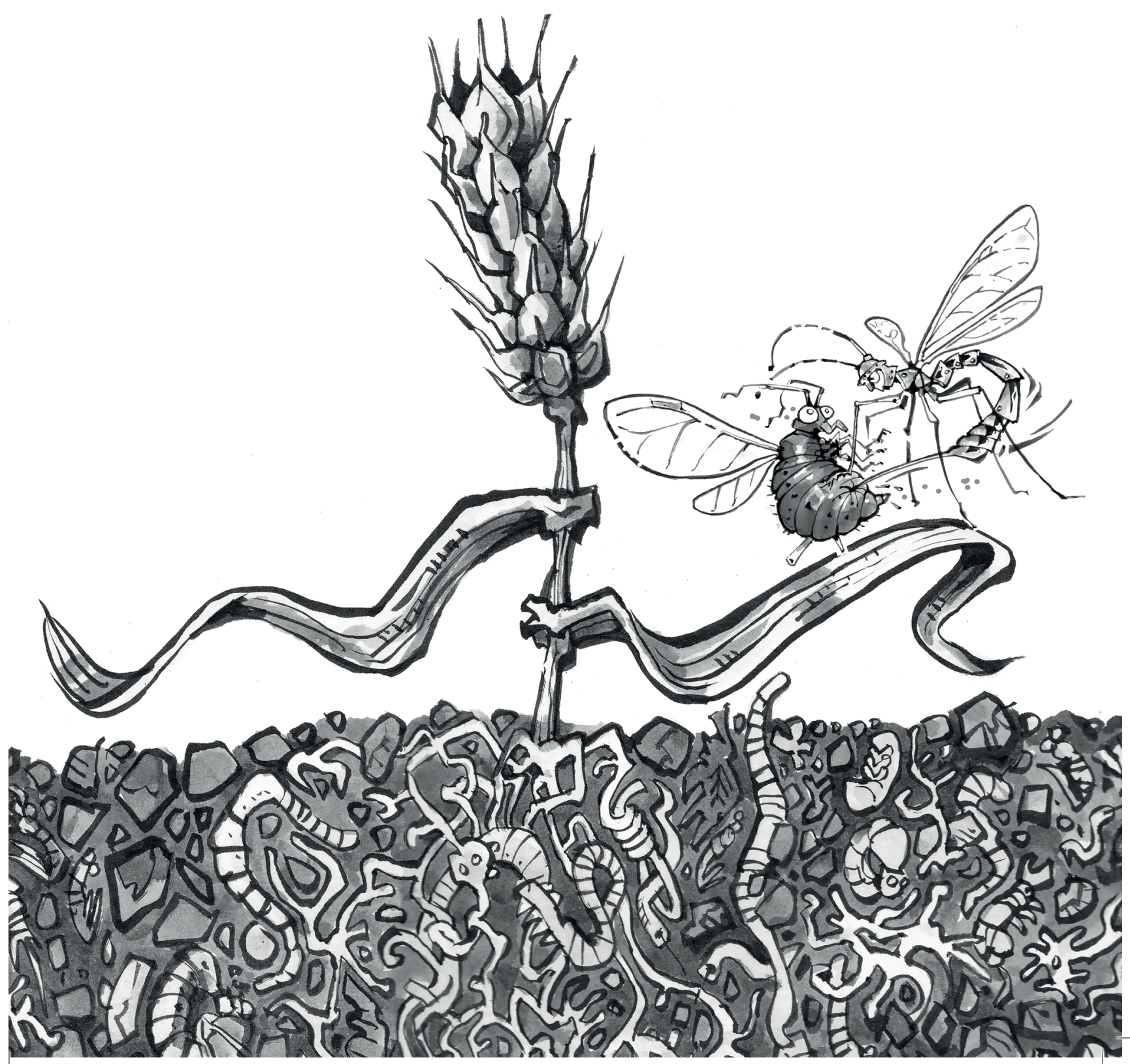




\section{Chapter 7}

The crop yield in arable systems is influenced by various ecosystem processes and external inputs simultaneously (Bommarco, Kleijn \& Potts 2013). In this thesis I studied how multiple aboveground and belowground ecosystem processes affect crop yield, both separately and in conjunction. I assessed whether and how soil organic matter (SOM) content alters the effect of ecosystem processes and external inputs on crop yield. Here I discuss and synthesise the results of my experiments.

Soil organic matter is considered as an important ecosystem property as it plays a key role in various ecosystem processes. These ecosystem processes include prevention of nitrate leaching (He et al. 2016), prevention of pesticide leaching (Ahmad et al. 2001) and - as around 50\% of SOM consists of carbon -carbon sequestration (Ahmad et al. 2001); through carbon sequestration and prevention of the release of greenhouse gases, soils play an important role in mitigating climate change (Ahmad et al. 2001; Lal 2016). Moreover, soil organic matter enhances ecosystem processes that directly underpin yields in arable agriculture (Hendrix, Coleman \& Crossley 1992). Under higher SOM content, generally more nutrients - especially nitrogen $(\mathrm{N})$ - are available to the plant, which subsequently may lead to higher yields (Brady et al. 2015).

\section{No general yield promoting effect soil organic matter}

In my thesis I empirically tested the effects of SOM content on biomass production of winter wheat and oilseed rape, two important arable crops species (Verhoog 2002; Lobell, Schlenker \& CostaRoberts 2011). I found that effects of different levels of SOM content on crop biomass were inconsistent. In Chapters 2 and 3, I present different results of one experiment, where SOM content was artificially diluted by mixing top soil with subsoil. In this study, higher SOM related to more crop biomass, but only if no mineral fertilizer was supplied. In Chapter 4, I compared pairs of fields, one with a relatively high and one with relatively low SOM content. In the pairs, fields with highest SOM had no higher yield than the nearby fields with lowest SOM content. In Chapter 5 (where I used the same soil origin to create high and low SOM content treatment as in Chapter 2 and 3) a higher SOM content related to more plant biomass, but not to more seed yield. Finally in Chapter 6 a clear positive relation between SOM content and aboveground plant biomass was found. The fact that a higher SOM 
content sometimes does and sometimes does not relate to higher plant biomass or yield could imply that (1) the conditions under which an experiment is performed alter the effect of SOM and, (2) that differences in the properties of SOM content across different experiments alter the effect of SOM on yield. Whereas various studies show that the latter is indeed important, less studies explicitly describe the importance of the context under which SOM content enhances yield.

Under some conditions it is more likely that SOM correlates to $\mathrm{N}$ mineralization on yield than under other conditions. A high SOM content could lead to both enhanced N mineralization as well as enhanced $\mathrm{N}$ immobilization (Tonitto et al. 2014). Directly available supplied $\mathrm{N}$ could temporarily be taken up by the soil microbial community living from SOM (Prescott 2010). This would suggest that a high SOM content is especially beneficial for crop yield if conditions for $\mathrm{N}$ mineralization are favourable, such as a high moisture content, while remaining a high oxygen content (Leirós et al. 1999). Indeed, in the experiment of Chapter 3, SOM content benefited plant biomass under normal, but not under dry conditions (data not shown). Under the incubation experiment (Chapter 4) and most greenhouse experiments (Chapter 3 and 6 ) soil conditions were brought under more optimal conditions, which could mean that SOM content had a larger effect on $\mathrm{N}$ mineralization and yield than under less optimal field conditions. In addition, soil was also mixed and sieved in these experiments, which could enhance the availability of SOM for soil microbes, subsequently leading to an overestimation of the effects of SOM on $\mathrm{N}$ mineralization in these experiments.

Under $\mathrm{N}$ fertilized conditions, also the plant demand for $\mathrm{N}$ decreases, which also suggests a decreased effect of SOM content on yield if mineral fertilizer is supplied (van Ittersum \& Rabbinge 1997). Indeed, in Chapter 2 and 3 the effect of SOM content decreased if mineral fertilizer was supplied. In Chapter 4, there was a positive relation between percentage SOM and $\mathrm{N}$ mineralization potential. It was expected that this extra mineralized $\mathrm{N}$ would be less important in explaining yield, if mineral fertilizer was supplied. However, whereas $\mathrm{N}$ mineralization indeed tended to relate positively to yield under unfertilized conditions, it even related negatively to yield if mineral fertilizer was supplied. It could be that under a higher SOM content the microbial community is more abundant and diverse, subsequently leading to more immobilization (Castellano et al. 2015). Alternatively it could be that 


\section{Chapter 7}

unmeasured factors that correlated with a higher SOM content and mineralization rate under controlled conditions do correlate with lower yields.

Apart from the conditions under which SOM is correlated to yield, also the quality of SOM could affect the relation between SOM and yield. In Chapter 4 I correlated absolute percentage SOM content to $\mathrm{N}$ mineralization potential, but I also used a factorial approach. I compared whether fields with similar soil conditions but a contrast in SOM differed in N mineralization potential. Interestingly, the positive relation between percentage SOM and $\mathrm{N}$ mineralization potential, disappeared in the factorial approach. Fields with a higher SOM content had not a higher N mineralization potential than nearby fields with a low SOM content. It could be that farmers in fields with a high SOM content perhaps added more or more often recalcitrant fertilizers, i.e. resulting in SOM content of a lower quality, on their field. Adding recalcitrant materials is a fast way to enhance the SOM content, but these recalcitrant materials contribute less to $\mathrm{N}$ mineralization than when organic materials with a relatively low $\mathrm{C} / \mathrm{N}$ ratio are added (Janzen 2006). The way how farmers enhanced the SOM content on their fields, however, is not exactly known in this experiment. It could be that, apart from historical fertilizer management also other aspects of the long-term history of the high SOM versus low SOM fields is different. For instance it could be that at some fields over the longer history ploughing which does influence SOM content (Stockfisch, Forstreuter \& Ehlers 1999) - took more often place than at other fields. A review by Dungait et al. (2012) shows that accessibility of organic compounds is more important in explaining decomposition rates than how recalcitrant the organic materials are, making it questionable whether the addition of recalcitrant materials indeed leads to a smaller effect of a high SOM content on $\mathrm{N}$ mineralization.

In my thesis I did not take into account how accessible SOM was for the microbial community. There are, however, several ways in which SOM could become inaccessible. Soil organic matter could be chemically bounded to soil particles thereby no longer being accessible to the microbial community (Schmidt et al. 2011). Coarse SOM (Particulate Organic Matter; POM) can however, be mineralized rapidly (Wood et al. 2016). If chemically bounded SOM is more abundant in the high SOM plot of 
Chapter 4, it could explain why SOM pairs with a high SOM content did not have more mineralization.

Soil organic matter can alter aboveground-belowground interactions among soil, plants and herbivores

Soil organic matter could influence aboveground plant-associated organisms in at least three different pathways. First, SOM content could alter the nutrient and water availability for the plant, which subsequently influence performance of herbivores (Garratt, Wright \& Leather 2011; Fageria 2012). Second, SOM could alter interactions between plants microbes and insects. Plant-microbe interactions, e.g. association with arbuscular mycorrhiza or infection with a belowground pathogen, could lead to an altered plant chemistry aboveground, subsequently leading to an altered performance of aboveground herbivores (Babikova et al. 2014; Biere \& Goverse 2016). A higher SOM content may lead to a higher abundance of saprophytic and mycorrhizal fungi that do compete with pathogenic endophytic fungi (de Boer et al. 2015). A higher abundance of saprotrophic and arbuscular mycorrhizal fungi could therefore lead to disease suppression belowground directly. Third, under field conditions, a high SOM content leads to more microbial biomass (Fierer et al. 2009) and thus more organisms involved with the decomposition of SOM (Birkhofer et al. 2008). These organisms are predated by generalist predators that also feed on plant herbivores. As the energy flow originating from decomposition of organic materials is much bigger than the energy flow originating from herbivory, relatively small changes in the decomposition pathway can have large consequences for the predation of herbivores (Scheu 2001).

In my $\mathrm{PhD}$ I performed empirical tests whether SOM influenced performance of aphids, which are important pests of crops (Larsson 2005). I tested for the significance of a few pathways by which SOM could influence aboveground herbivores. In Chapter 2 I tested whether the addition of the pathogenic root fungus Rhizoctonia solani affected the number of aphids and whether this relationship was different under high versus low SOM content. SOM content enhanced aphid abundance and altered the effect of $R$. solani on aphids. However, in spite of the general significances, the significances disappeared in the comparison of individual treatments: in soil with low SOM content $R$. 


\section{Chapter 7}

solani tended to decrease aphid biomass, whereas it tended to increase aphid biomass under high SOM content. Apparently, the effects of SOM on pathogen effects on aphids were at the edge of significance. In Chapter 3, I showed that SOM content did not change the effect of drought on aphid performance (development time, fecundity, body weight and total biomass). In the experiment of Chapter 6 there was a positive relation between SOM content and the number of aphids, but this effect was only visible in the last counts of the experiment (data not shown). Also organic farming led in this experiment to higher aphid numbers in the last counts, but this effect did not change with SOM content (data not shown). Finally, in Chapter 4, under field conditions high versus low SOM content did not affect aphid abundance, aphid parasitism rate and the number of ground-dwelling predating arthropods.

Overall, the results across the different experiments show that under controlled conditions an increase in SOM content may lead to an increase in aphids. This will have been due to enhanced plant quality or an increase in plant biomass and thus resource availability (the first pathway)(Garratt, Wright \& Leather 2010). The SOM content also altered the effect of mineral fertilizer supply (Chapters 2 and 3), most likely because the SOM content can alter the availability of mineral fertilizer supply (see previous session). However, the effects of SOM are generally not very strong under controlled conditions. This may explain why under field conditions no effects of SOM on aphids could be established. Most likely, the effect strength was further obfuscated because other environmental factors, such as rain and wind may have caused so much variation that possible SOM effects will not be detectable. Moreover, lack of a clear relation between SOM content and N availability (Duffield et al. 1997) may also explain why SOM not necessarily influences aphid performance. The effect of drought stress on aphids was not altered by SOM (Chapter 3). I expected that SOM content would change the water holding capacity, subsequently altering drought stress and therefore insect performance (Tariq et al. 2012). Perhaps SOM content does not affect the water holding capacity under greenhouse conditions with plants growing in pots.

The SOM content could also alter the effect of belowground pathogens on aphids aboveground (second pathway), but the mechanisms behind this effect are not clear. Literature suggests that SOM 
content leads to disease suppression as a higher SOM content relates to more saprotrophic fungi (de Boer et al. 2015), but the results of Chapter 3 suggest the opposite. Mixing of the soil, prior to the experiment, could have affected the hyphae of other saprotrophic fungi, thereby giving the introduced species a competitive advantage. Nevertheless, these results show that SOM content could alter the effect of belowground organisms on aboveground herbivores. However, it is unclear how important this effect is. Under field conditions (Chapter 4) no effect of SOM content was found, suggesting that the relevance under field conditions might be low.

Moreover, this $\mathrm{PhD}$ thesis did not provide any evidence for a pathway under which SOM content enhanced the number of predators. In this field experiment I took only the total number of ground dwelling predators into account, in order to give an overall estimation of the number of grounddwelling predators. A study partially based on the same data but then replicated in seven instead of four countries, showed that rove beetles (Staphylinidae) responded positively to an enhanced SOM content, whereas ground beetles (Carabidae) and wolf spiders (Lycosidae) were not affected by an enhanced SOM content (Gagic et al. in prep.).

\section{Integrating scales in the management of agro-ecosystems}

In Chapters 5 and 6, I tested whether spatial and temporal scales matter in aboveground-belowground interactions. Many belowground processes (e.g. nutrient supply on an arable field) are managed at a smaller spatial scale (Tamburini et al. 2016) than aboveground processes (e.g. increasing semi-natural habitat around crop fields for more pest control; Thies, Roschewitz \& Tscharntke 2005; Rusch et al. 2013). To steer crop yield from the perspective of aboveground-belowground interactions it has been suggested that spatial scales should be taken into account (Tscharntke et al. 2012). In Chapter 5 I tested whether the landscape in which oilseed rape was growing, changed the effect of SOM content and mineral fertilizer supply on biomass and yield of oilseed rape. I found that there was a considerable difference between the areas in levels of pest pressure and pollinator visitation rate and that these aboveground factors had an even stronger relation with yield than SOM content and fertilizer supply. The effect of pollinator visitation rate and pest pressure, however, operated completely independently from the belowground factors, suggesting that yield effects of these 


\section{Chapter 7}

aboveground and belowground factors were additive, instead of interactive, as I had assumed. While Bartomeus et al. (2015) found similar results, various other studies found synergistic effects (Marini et al. 2015) or trade-offs (Tamburini et al. 2015) between belowground factors and pollination, which is often dependent on landscape scale processes. Therefore, it seems that yield benefits from aboveground-belowground interactions as a result of integrating local (soil) and landscape (pollinator) management may be context dependent. Under which conditions integration of spatial scales can be beneficial for crop yield remains unknown. Potential factors are crop species or even variety (Hudewenz et al. 2014; Marini et al. 2015), the range of pollinator visitation rates and pest pressure across different landscapes, weather conditions during the growing season (Sánchez et al. 2017), and even the scale of which an experiment is performed (Van Gils \& Harvey, in prep.).

Apart from spatial scales, also understanding temporal scales could improve the management of aboveground-belowground interactions. An important contrast in farming management practice may depend on whether an organic management strategy (no mineral fertilizer supply, no chemical pesticides) or a conventional strategy is applied (De Ponti, Rijk \& van Ittersum 2012). Currently, the usual case is that organic management starts after stopping conventional management. It is, however, unknown after how much time these contrasting management practices start to affect plants and aboveground organisms differently, if effective at all. In Chapter 6 I studied conventional soils and soils from a nearby organically managed field that had a different duration of organic management. I found, however, no general effect of duration of organic on belowground biotic factors such as bacterial biomass or SOM content. In a bioassay with these soils I grew wheat plants with and without aphids. Here, organic management or duration of it had no effect on the aboveground parameters plant biomass and aphid biomass. These results suggest that the duration of organic farming is not important in explaining aboveground-belowground interactions. It is, however, important that the effects of duration of organic management, will be also assessed under field conditions. 


\section{Context dependency should be incorporated more actively}

Across the different chapters in this thesis, I used experiments with variable degrees of control on environmental conditions. Under the most controlled conditions, the context of the experiments differs greatly from those of agricultural practices. Indeed, the experimental results turned out to be highly context dependent. For instance, in Chapter 5 I show that under high SOM content and fertilizer supply, the relation between pollinator visitation rate and yield remains the same as compared to low SOM and no fertilizer supply. An experiment from Marini et al. (2015) who also used oilseed rape, however, shows that on soil with much nutrient input, the effect of pollination on yield becomes smaller. Experiments from Tamburini et al. (2015) and Redlich at al. (in prep.) using sunflower, moreover, shows that on soil with much nutrients, the effect of pollination on yield increases. None of these experiments were performed under real farming conditions: For example, in Chapter 5, patch sizes with oilseed rape were much smaller than in farmers' fields. This could lead to unrealistic densities of pollinators, making it debatable whether the general results - no interaction between pollinator visitation rate and SOM content on yield - exemplify what may happen in farmers' fields (Van Gils \& Harvey, in prep.).

Social research shows that farmers are not much interested in statistical results or in general principles (Morgan et al. 2002). Instead, they are generally highly interested in management practices that do work in their specific case. This would argue for research that is more focussed on a specific realworld context, such as on-farm studies, rather than research that is focused on general principles. Ironically, scientific journals are often not interested in case studies as these do not apply to multiple systems (Memmott et al. 2010). This could potentially lead to research that is a bit informative for all kind of agricultural systems, but not really informative for any real-world agricultural system.

\section{Limited room for the optimization of ecosystem processes using soil organic matter}

The ultimate goal of my thesis was to unravel how multiple aboveground and belowground ecosystem processes affect crop yield. With this information it would be possible to optimize ecosystem processes that do contribute to arable agricultural production, by enhancing natural processes. In my 


\section{Chapter 7}

experiments I focussed on how SOM content may affect yield either in combination with, or as an alternative of mineral fertilizer supply. I studied SOM content in the relation of drought stress, nutrient provision, pest control and pollination. In none of these experiments SOM content turned out to be a clear alternative for mineral fertilizer supply. Also, SOM content did not significantly increase other ecosystem processes that do contribute to yield. Although it is important to study whether this is also the case under realistic farming conditions, my thesis research does not provide strong evidence that farmers with a higher SOM content have more yield benefitting ecosystem processes provided from SOM. Farmers, therefore, do not necessarily have an immediate direct interest in the enhancement of these processes that do not directly contribute to crop yield. It is important to understand under which conditions and with which quality of SOM, SOM results in a benefit for yield. Nevertheless, also in cases that SOM does not directly or indirectly contribute to yield, SOM may still contribute to ecosystem services that do not directly contribute farmers, such as carbon sequestration and prevention of nutrient leaching (Lal 2004a; Banwart et al. 2014). It is important that this is acknowledged in agricultural policies.

\section{Future research directions}

My thesis research is an attempt to see how SOM content contributes to multiple ecosystem processes that contribute to crop yield and how ecosystem processes could be optimized. The next step in this research should consist of two elements: going deeper into the mechanisms and testing hypotheses under more real (field) dimensions and conditions.

From a mechanistic perspective, subsequent studies should incorporate more aspects of SOM, and especially the SOM quality. Three aspects could receive more attention: First, studies could determine whether the quality of SOM, e.g. the small size fraction of Particulate Organic Matter, correlates better with disease suppression than the total SOM content itself. Moreover, it could be studied how management practices that enhance total SOM content influence SOM quality and whether the relation between SOM content and SOM quality is consistent across multiple soil types. Second, to understand better how SOM alters aboveground-belowground interactions, future studies could incorporate more chemical analysis in order to unravel how the effects of SOM on aboveground organisms are 
explained by an altered nutritional quality (e.g. leaf C:N ratio or measurements of specific amino acids) and by plant secondary compounds, such as volatile organic compounds. Third, instead of trying to understand how SOM correlates with the abundance of whole groups of soil organisms and subsequently aboveground-belowground interactions, future studies could focus on the effect of SOM on individual species level on the activity of these species. Perhaps, the functioning of the soils is not much related to total abundances, but to activity of different functional groups. Having more knowledge about these mechanisms driving aboveground-belowground interactions would contribute to a deeper understanding on how SOM content could be used in the optimization of aboveground and belowground ecosystem processes and properties.

Future research, should also mimic actual farming practices more accurately, preferably on realistic scales and over a long timeframe that includes whole growing seasons or even whole rotations. As this approach would potentially shift away from understanding specific mechanism, it could reduce the general understanding across multiple cropping system. It is therefore important that in such studies, enough attention will be paid to mechanisms causing effects, in order to translate results to different systems. Such farming systems research would increase the applicability within one specific cropping system as it is targeted to a real-world situation. It would also generate specific knowledge on when the optimization of aboveground and belowground ecosystem is beneficial to crop yield and when it is not. I think it is important to limit this type of research not to specific disciplines such as ecology, but to expand it to other disciplines such as agro-technology. Combining different research areas on an applied level could potentially lead to the implementation of novel solutions that are currently not even imagined (Garnett et al. 2013). 


\section{References}

Ahmad, R., Kookana, R.S., Alston, A.M. \& Skjemstad, J.O. (2001) The nature of soil organic matter affects sorption of pesticides. 1. Relationships with carbon chemistry as determined by $13 \mathrm{C}$ CPMAS NMR spectroscopy. Environmental Science \& Technology, 35, 878-884.

Albrecht, M., Duelli, P., Mueller, C., Kleijn, D. \& Schmid, B. (2007) The Swiss agri-environment scheme enhances pollinator diversity and plant reproductive success in nearby intensively managed farmland. Journal of Applied Ecology, 44, 813-822.

Altieri, M.A. \& Nicholls, C.I. (2003) Soil fertility management and insect pests: harmonizing soil and plant health in agroecosystems. Soil \& Tillage Research, 72, 203-211.

Aqueel, M.A., Collins, C.M., Raza, A.-b.M., Ahmad, S., Tariq, M. \& Leather, S.R. (2014) Effect of plant nutrition on aphid size, prey consumption, and life history characteristics of green lacewing. Insect Science, 21, 74-82.

Aqueel, M.A. \& Leather, S.R. (2011) Effect of nitrogen fertilizer on the growth and survival of Rhopalosiphum padi (L.) and Sitobion avenae (F.) (Homoptera: Aphididae) on different wheat cultivars. Crop Protection, 30, 216-221.

Awmack, C.S. \& Leather, S.R. (2002) Host plant quality and fecundity in herbivorous insects. Annual Review of Entomology, 47, 817-844.

Bååth, E. (2001) Estimation of fungal growth rates in soil using 14C-acetate incorporation into ergosterol. Soil Biology and Biochemistry, 33, 2011-2018.

Babikova, Z., Gilbert, L., Bruce, T., Dewhirst, S.Y., Pickett, J.A. \& Johnson, D. (2014) Arbuscular mycorrhizal fungi and aphids interact by changing host plant quality and volatile emission. Functional Ecology, 28, 375-385.

Bailey, K.L. \& Lazarovits, G. (2003) Suppressing soil-borne diseases with residue management and organic amendments. Soil and Tillage Research, 72, 169-180.

Banwart, S., Black, H., Cai, Z., Gicheru, P., Joosten, H., Victoria, R., Milne, E., Noellemeyer, E., Pascual, U. \& Nziguheba, G. (2014) Benefits of soil carbon: report on the outcomes of an international scientific committee on problems of the environment rapid assessment workshop. Carbon Management, 5, 185-192.

Barbosa, P., Krischik, V.A. \& Jones, C.G. (1991) Microbial mediation of plant-herbivore interactions. John Wiley \& Sons.

Bardgett, R.D. \& van der Putten, W.H. (2014) Belowground biodiversity and ecosystem functioning. Nature, 515, 505-511.

Barraclough, P., Kuhlmann, H. \& Weir, A. (1989) The effects of prolonged drought and nitrogen fertilizer on root and shoot growth and water uptake by winter wheat. Journal of Agronomy and Crop Science, 163, 352-360.

Bartomeus, I., Gagic, V. \& Bommarco, R. (2015) Pollinators, pests and soil properties interactively shape oilseed rape yield. Basic and Applied Ecology, 16, 737-745.

Bauer, A. \& Black, A. (1992) Organic carbon effects on available water capacity of three soil textural groups. Soil Science Society of America Journal, 56, 248-254.

Bauer, A. \& Black, A.L. (1994) Quantification of the Effect of Soil Organic Matter Content on Soil Productivity. Soil Science Society of America Journal, 58, 185-193.

Bender, S.F. \& van der Heijden, M.G.A. (2015) Soil biota enhance agricultural sustainability by improving crop yield, nutrient uptake and reducing nitrogen leaching losses. Journal of Applied Ecology, 52, 228-239.

Bengtsson, J., Ahnström, J. \& Weibull, A.-C. (2005) The effects of organic agriculture on biodiversity and abundance: a meta-analysis. Journal of Applied Ecology, 42, 261-269.

Bennett, E., Peterson, G. \& Gordon, L. (2009) Understanding relationships among multiple ecosystem services. Ecology Letters, 12, 1394-1404.

Bezemer, T.M., De Deyn, G.B., Bossinga, T.M., van Dam, N.M., Harvey, J.A. \& Van der Putten, W.H. (2005) Soil community composition drives aboveground plant-herbivore-parasitoid interactions. Ecology Letters, 8, 652-661.

Bezemer, T.M. \& Van Dam, N.M. (2005) Linking aboveground and belowground interactions via induced plant defenses. Trends in Ecology \& Evolution, 20, 617-624. 
Bianchi, F.J.J.A., Booij, C.J.H. \& Tscharntke, T. (2006) Sustainable pest regulation in agricultural landscapes: a review on landscape composition, biodiversity and natural pest control. Proceedings of the Royal Society of London B: Biological Sciences, 273, 1715-1727.

Biere, A. \& Bennett, A.E. (2013) Three-way interactions between plants, microbes and insects. Functional Ecology, 27, 567-573.

Biere, A. \& Goverse, A. (2016) Plant-Mediated Systemic Interactions Between Pathogens, Parasitic Nematodes, and Herbivores Above- and Belowground. Annual Review of Phytopathology.

Birkhofer, K., Bezemer, T.M., Bloem, J., Bonkowski, M., Christensen, S., Dubois, D., Ekelund, F., Fließbach, A., Gunst, L., Hedlund, K., Mäder, P., Mikola, J., Robin, C., Setälä, H., TatinFroux, F., Van der Putten, W.H. \& Scheu, S. (2008) Long-term organic farming fosters below and aboveground biota: Implications for soil quality, biological control and productivity. Soil Biology and Biochemistry, 40, 2297-2308.

Birkhofer, K., Fließbach, A., Wise, D.H. \& Scheu, S. (2011) Arthropod food webs in organic and conventional wheat farming systems of an agricultural long-term experiment: a stable isotope approach. Agricultural and Forest Entomology, 13, 197-204.

Bodenhausen, N. \& Reymond, P. (2007) Signaling pathways controlling induced resistance to insect herbivores in Arabidopsis. Molecular Plant-Microbe Interactions, 20, 1406-1420.

Bommarco, R., Kleijn, D. \& Potts, S.G. (2013) Ecological intensification: harnessing ecosystem services for food security. Trends in Ecology \& Evolution, 28, 230-238.

Bommarco, R., Marini, L. \& Vaissiere, B.E. (2012) Insect pollination enhances seed yield, quality, and market value in oilseed rape. Oecologia, 169, 1025-1032.

Boreux, V., Kushalappa, C.G., Vaast, P. \& Ghazoul, J. (2013) Interactive effects among ecosystem services and management practices on crop production: Pollination in coffee agroforestry systems. Proceedings of the National Academy of Sciences, 110, 8387-8392.

Bot, A. \& Benites, J. (2005) The importance of soil organic matter: Key to drought-resistant soil and sustained food production. Food \& Agriculture Org.

Brady, M.V., Hedlund, K., Cong, R.-G., Hemerik, L., Hotes, S., Machado, S., Mattsson, L., Schulz, E. \& Thomsen, I.K. (2015) Valuing Supporting Soil Ecosystem Services in Agriculture: A Natural Capital Approach. Agronomy Journal, 107, 1809-1821.

Brann, K.H. \& Lehtila, K. (2007) Maternal plant responses to high pollen loads. International Journal of Plant Sciences, 168, 1013-1019.

Breeze, T.D., Vaissiere, B.E., Bommarco, R., Petanidou, T., Seraphides, N., Kozak, L., Scheper, J., Biesmeijer, J.C., Kleijn, D., Gyldenkaerne, S., Moretti, M., Holzschuh, A., Steffan-Dewenter, I., Stout, J.C., Paertel, M., Zobel, M. \& Potts, S.G. (2014) Agricultural Policies Exacerbate Honeybee Pollination Service Supply-Demand Mismatches Across Europe. Plos One, 9.

Bronick, C.J. \& Lal, R. (2005) Soil structure and management: a review. Geoderma, 124, 3-22.

Butler, J., Garratt, M.P.D. \& Leather, S.R. (2012) Fertilisers and insect herbivores: a meta-analysis. Annals of Applied Biology, 161, 223-233.

Carvalho, S., Macel, M., Schlerf, M., Skidmore, A.K. \& van der Putten, W.H. (2012) Soil biotic impact on plant species shoot chemistry and hyperspectral reflectance patterns. New Phytologist, 196, 1133-1144.

Castellano, M.J., Mueller, K.E., Olk, D.C., Sawyer, J.E. \& Six, J. (2015) Integrating plant litter quality, soil organic matter stabilization, and the carbon saturation concept. Global Change Biology, 21, 3200-3209.

Classen, A., Peters, M.K., Ferger, S.W., Helbig-Bonitz, M., Schmack, J.M., Maassen, G., Schleuning, M., Kalko, E.K., Böhning-Gaese, K. \& Steffan-Dewenter, I. (2014) Complementary ecosystem services provided by pest predators and pollinators increase quantity and quality of coffee yields. Proceedings of the Royal Society of London B: Biological Sciences, 281, 20133148.

Conant, R.T., Ryan, M.G., Ågren, G.I., Birge, H.E., Davidson, E.A., Eliasson, P.E., Evans, S.E., Frey, S.D., Giardina, C.P. \& Hopkins, F.M. (2011) Temperature and soil organic matter decomposition rates-synthesis of current knowledge and a way forward. Global Change Biology, 17, 3392-3404.

Creamer, R.E., Hannula, S.E., Leeuwen, J.P.V., Stone, D., Rutgers, M., Schmelz, R.M., Ruiter, P.C.d., Hendriksen, N.B., Bolger, T., Bouffaud, M.L., Buee, M., Carvalho, F., Costa, D., Dirilgen, T., 
Francisco, R., Griffiths, B.S., Griffiths, R., Martin, F., Silva, P.M.d., Mendes, S., Morais, P.V., Pereira, C., Philippot, L., Plassart, P., Redecker, D., Römbke, J., Sousa, J.P., Wouterse, M. \& Lemanceau, P. (2016) Ecological network analysis reveals the inter-connection between soil biodiversity and ecosystem function as affected by land use across Europe. Applied Soil Ecology, 97, 112-124.

Crittenden, S.J., Eswaramurthy, T., de Goede, R.G.M., Brussaard, L. \& Pulleman, M.M. (2014) Effect of tillage on earthworms over short- and medium-term in conventional and organic farming. Applied Soil Ecology, 83, 140-148.

Dai, A. (2011) Drought under global warming: a review. Wiley Interdisciplinary Reviews: Climate Change, 2, 45-65.

de Boer, W., Folman, L.B., Summerbell, R.C. \& Boddy, L. (2005) Living in a fungal world: impact of fungi on soil bacterial niche development $\star$. FEMS Microbiology Reviews, 29, 795-811.

de Boer, W., Hundscheid, M.P.J., Klein Gunnewiek, P.J.A., de Ridder-Duine, A.S., Thion, C., van Veen, J.A. \& van der Wal, A. (2015) Antifungal Rhizosphere Bacteria Can increase as Response to the Presence of Saprotrophic Fungi. Plos One, 10, e0137988.

De Deyn, G.B., Quirk, H. \& Bardgett, R.D. (2011) Plant species richness, identity and productivity differentially influence key groups of microbes in grassland soils of contrasting fertility. Biology Letters, 7, 75-78.

de Haan, J., Sukkel, W. \& Stilma, E. (2010) Technology versus agro-ecology in designing vegetable production systems in the Netherlands. pp. 123-130. International Society for Horticultural Science (ISHS), Leuven, Belgium.

De Ponti, T., Rijk, B. \& van Ittersum, M.K. (2012) The crop yield gap between organic and conventional agriculture. Agricultural Systems, 108, 1-9.

de Vos, M., van Oosten, V.R., van Poecke, R.M.P., van Pelt, J.A., Pozo, M.J., Mueller, M.J., Buchala, A.J., Métraux, J.-P., van Loon, L.C., Dicke, M. \& Pieterse, C.M.J. (2005) Signal Signature and Transcriptome Changes of Arabidopsis During Pathogen and Insect Attack. Molecular Plant-Microbe Interactions, 18, 923-937.

de Vries, F.T., Thebault, E., Liiri, M., Birkhofer, K., Tsiafouli, M.A., Bjornlund, L., Jorgensen, H.B., Brady, M.V., Christensen, S., de Ruiter, P.C., d'Hertefeldt, T., Frouz, J., Hedlund, K., Hemerik, L., Hol, W.H.G., Hotes, S., Mortimer, S.R., Setala, H., Sgardelis, S.P., Uteseny, K., van der Putten, W.H., Wolters, V. \& Bardgett, R.D. (2013) Soil food web properties explain ecosystem services across European land use systems. Proceedings of the National Academy of Sciences of the United States of America, 110, 14296-14301.

Douglas, A., Price, D., Minto, L., Jones, E., Pescod, K., François, C., Pritchard, J. \& Boonham, N. (2006) Sweet problems: insect traits defining the limits to dietary sugar utilisation by the pea aphid, Acyrthosiphon pisum. Journal of Experimental Biology, 209, 1395-1403.

Douglas, A.E. (2003) The nutritional physiology of aphids. Advances in insect physiology, 31, 73-140.

Duffield, S., Bryson, R., Young, J., Sylvester-Bradley, R. \& Scott, R. (1997) The influence of nitrogen fertiliser on the population development of the cereal aphids Sitobion avenae (F.) and Metopolophium dirhodum (Wlk.) on field grown winter wheat. Annals of Applied Biology, 130, 13-26.

Dungait, J.A.J., Hopkins, D.W., Gregory, A.S. \& Whitmore, A.P. (2012) Soil organic matter turnover is governed by accessibility not recalcitrance. Global Change Biology, 18, 1781-1796.

Dungait, J.A.J., Kemmitt, S.J., Michallon, L., Guo, S., Wen, Q., Brookes, P.C. \& Evershed, R.P. (2011) Variable responses of the soil microbial biomass to trace concentrations of 13Clabelled glucose, using 13C-PLFA analysis. European Journal of Soil Science, 62, 117-126.

Eitzinger, J., Štastná, M., Žalud, Z. \& Dubrovský, M. (2003) A simulation study of the effect of soil water balance and water stress on winter wheat production under different climate change scenarios. Agricultural Water Management, 61, 195-217.

Eyre, M.D., Sanderson, R.A., Shotton, P.N. \& Leifert, C. (2009) Investigating the effects of crop type, fertility management and crop protection on the activity of beneficial invertebrates in an extensive farm management comparison trial. Annals of Applied Biology, 155, 267-276.

Fageria, N.K. (2012) Role of Soil Organic Matter in Maintaining Sustainability of Cropping Systems. Communications in Soil Science and Plant Analysis, 43, 2063-2113. 
FAO (2014) Statistics Division. Food and Agriculture Organization. Rome. http://faostat3.fao.org/faostat-gateway/go/to/home/E, last accessed on 28-9-2014.

Felton, G.W. \& Korth, K.L. (2000) Trade-offs between pathogen and herbivore resistance. Current Opinion in Plant Biology, 3, 309-314.

Fiddaman, P.J. \& Rossall, S. (1993) The production of antifungal volatiles by Bacillus subtilis. Journal of Applied Bacteriology, 74, 119-126.

Fierer, N., Strickland, M.S., Liptzin, D., Bradford, M.A. \& Cleveland, C.C. (2009) Global patterns in belowground communities. Ecology Letters, 12, 1238-1249.

Fließbach, A., Oberholzer, H.-R., Gunst, L. \& Mäder, P. (2007) Soil organic matter and biological soil quality indicators after 21 years of organic and conventional farming. Agriculture, Ecosystems \& Environment, 118, 273-284.

Fortuna, T.M., Eckert, S., Harvey, J.A., Vet, L.E.M., Müller, C. \& Gols, R. (2014) Variation in plant defences among populations of a range-expanding plant: consequences for trophic interactions. New Phytologist, 204, 989-999.

Frostegård, Å. \& Bååth, E. (1996) The use of phospholipid fatty acid analysis to estimate bacterial and fungal biomass in soil. Biology and Fertility of Soils, 22, 59-65.

Frostegård, Å., Tunlid, A. \& Bååth, E. (1991) Microbial biomass measured as total lipid phosphate in soils of different organic content. Journal of Microbiological Methods, 14, 151-163.

Frostegård, Å., Tunlid, A. \& Bååth, E. (1993) Phospholipid fatty acid composition, biomass, and activity of microbial communities from two soil types experimentally exposed to different heavy metals. Applied and Environmental Microbiology, 59, 3605-3617.

Frostegård, Å., Tunlid, A. \& Bååth, E. (2011) Use and misuse of PLFA measurements in soils. Soil Biology and Biochemistry, 43, 1621-1625.

Fuhrer, J. (2003) Agroecosystem responses to combinations of elevated CO 2, ozone, and global climate change. Agriculture, Ecosystems \& Environment, 97, 1-20.

Gange, A.C. \& West, H.M. (1994) Interactions between arbuscular mycorrhizal fungi and foliarfeeding insects in Plantago-lanceolata L. New Phytologist, 128, 79-87.

Garbeva, P., van Veen, J.A. \& van Elsas, J.D. (2004) Microbial diversity in soil: Selection of microbial populations by plant and soil type and implications for disease suppressiveness. Annual Review of Phytopathology, 42, 243-270.

Garibaldi, L., Steffan-Dewenter, I., Kremen, C., Morales, J., Bommarco, R., Cunningham, S., Carvalheiro, L., Chacoff, N., Dudenhöffer, J., Greenleaf, S., Holzschuh, A., Isaacs, R., Krewenka, K., Mandelik, Y., Mayfield, M., Morandin, L., Potts, S., Ricketts, T., Szentgyörgyi, H., Viana, B., Westphal, C., Winfree, R. \& Klein, A. (2011) Stability of pollination services decreases with isolation from natural areas despite honey bee visits. Ecology Letters, 14, 1062-1072.

Garibaldi, L.A., Steffan-Dewenter, I., Winfree, R., Aizen, M.A., Bommarco, R., Cunningham, S.A., Kremen, C., Carvalheiro, L.G., Harder, L.D., Afik, O., Bartomeus, I., Benjamin, F., Boreux, V., Cariveau, D., Chacoff, N.P., Dudenhoeffer, J.H., Freitas, B.M., Ghazoul, J., Greenleaf, S., Hipolito, J., Holzschuh, A., Howlett, B., Isaacs, R., Javorek, S.K., Kennedy, C.M., Krewenka, K.M., Krishnan, S., Mandelik, Y., Mayfield, M.M., Motzke, I., Munyuli, T., Nault, B.A., Otieno, M., Petersen, J., Pisanty, G., Potts, S.G., Rader, R., Ricketts, T.H., Rundlof, M., Seymour, C.L., Schueepp, C., Szentgyoergyi, H., Taki, H., Tscharntke, T., Vergara, C.H., Viana, B.F., Wanger, T.C., Westphal, C., Williams, N. \& Klein, A.M. (2013) Wild Pollinators Enhance Fruit Set of Crops Regardless of Honey Bee Abundance. Science, 339, 1608-1611.

Garnett, T., Appleby, M.C., Balmford, A., Bateman, I.J., Benton, T.G., Bloomer, P., Burlingame, B., Dawkins, M., Dolan, L., Fraser, D., Herrero, M., Hoffmann, I., Smith, P., Thornton, P.K., Toulmin, C., Vermeulen, S.J. \& Godfray, H.C.J. (2013) Sustainable Intensification in Agriculture: Premises and Policies. Science, 341, 33-34.

Garratt, M.P.D., Wright, D.J. \& Leather, S.R. (2010) The effects of organic and conventional fertilizers on cereal aphids and their natural enemies. Agricultural and Forest Entomology, 12, 307-318.

Garratt, M.P.D., Wright, D.J. \& Leather, S.R. (2011) The effects of farming system and fertilisers on pests and natural enemies: A synthesis of current research. Agriculture Ecosystems \& Environment, 141, 261-270. 


\section{References}

Gebbers, R. \& Adamchuk, V.I. (2010) Precision agriculture and food security. Science, 327, 828-831.

Gershenzon, J. (1984) Changes in the Levels of Plant Secondary Metabolites Under Water and Nutrient Stress. Phytochemical Adaptations to Stress (eds B.N. Timmermann, C. Steelink \& F.A. Loewus), pp. 273-320. Springer US, Boston, MA.

Gilbert, L. \& Johnson, D. (2015) Plant-mediated 'apparent effects' between mycorrhiza and insect herbivores. Current Opinion in Plant Biology, 26, 100-105.

Glazebrook, J. (2005) Contrasting mechanisms of defense against biotrophic and necrotrophic pathogens. Annu. Rev. Phytopathol., 43, 205-227.

Goulding, K. (2000) Nitrate leaching from arable and horticultural land. Soil Use and Management, 16, 145-151.

Grandy, A.S., Strickland, M.S., Lauber, C.L., Bradford, M.A. \& Fierer, N. (2009) The influence of microbial communities, management, and soil texture on soil organic matter chemistry. Geoderma, 150, 278-286.

Griffin, G., Jokela, W., Ross, D., Pettrinelli, D., Morris, T. \& Wolf, A. (2009) Chapter 4: Recommended Soil Nitrate Tests. Recommended Soil Testing Procedures for the Northeastern United States (eds D. Agricultural Experiment Stations of Connecticut, Maine,, M. Maryland, New Hampshire, New Jersey, New York, \& R.I. Pennsylvania, Vermont, and West Virginia.). The Northeast Coordinating Committee for Soil Testing.

Grüter, D., Schmid, B. \& Brandl, H. (2006) Influence of plant diversity and elevated atmospheric carbon dioxide levels on belowground bacterial diversity. BMC Microbiology, 6, 1-8.

Gryndler, M., Larsen, J., Hršelová, H., Řezáčová, V., Gryndlerová, H. \& Kubát, J. (2006) Organic and mineral fertilization, respectively, increase and decrease the development of external mycelium of arbuscular mycorrhizal fungi in a long-term field experiment. Mycorrhiza, 16, 159-166.

Gustafson, D.I. (2011) Climate change: a crop protection challenge for the twenty-first century. Pest Management Science, 67, 691-696.

Hale, B., Bale, J., Pritchard, J., Masters, G. \& Brown, V. (2003) Effects of host plant drought stress on the performance of the bird cherry-oat aphid, Rhopalosiphum padi (L.): a mechanistic analysis. Ecological Entomology, 28, 666-677.

Hallmann, C.A., Foppen, R.P.B., van Turnhout, C.A.M., de Kroon, H. \& Jongejans, E. (2014) Declines in insectivorous birds are associated with high neonicotinoid concentrations. Nature, 511, 341-343.

Hasken, K.H. \& Poehling, H.M. (1995) Effects of different intensities of fertilizers and pesticides on aphids and aphid predators in winter-wheat. Agriculture Ecosystems \& Environment, 52, 4550 .

He, P., Wan, S.-Z., Fang, X.-M., Wang, F.-C. \& Chen, F.-S. (2016) Exogenous nutrients and carbon resource change the responses of soil organic matter decomposition and nitrogen immobilization to nitrogen deposition. Scientific Reports, $\mathbf{6}$.

Helfrich, M., Ludwig, B., Thoms, C., Gleixner, G. \& Flessa, H. (2015) The role of soil fungi and bacteria in plant litter decomposition and macroaggregate formation determined using phospholipid fatty acids. Applied Soil Ecology, 96, 261-264.

Helgason, B.L., Walley, F.L. \& Germida, J.J. (2010) No-till soil management increases microbial biomass and alters community profiles in soil aggregates. Applied Soil Ecology, 46, 390-397.

Helgason, T., Daniell, T.J., Husband, R., Fitter, A.H. \& Young, J.P.W. (1998) Ploughing up the woodwide web? Nature, 394, 431-431.

Hendrix, P.F., Coleman, D.C. \& Crossley, D.A. (1992) Using knowledge of soil nutrient cycling processes to design sustainable agriculture. Journal of Sustainable Agriculture, 2, 63-82.

Hewitt, E.J. (1966) Sand and water culture methods used in the study of plant nutrition. C.A.B., Farnham Royal.

Hijbeek, R., van Ittersum, M.K., ten Berge, H.F.M., Gort, G., Spiegel, H. \& Whitmore, A.P. (2016) Do organic inputs matter - a meta-analysis of additional yield effects for arable crops in Europe. Plant and Soil, 1-11.

Honek, A. (1991) Nitrogen-fertilization and abundance of the cereal aphids Metopolophium dirhodum and Sitobion avenae. Zeitschrift Fur Pflanzenkrankheiten Und Pflanzenschutz-Journal of Plant Diseases and Protection, 98, 655-660. 
Huang, J.K., Pray, C. \& Rozelle, S. (2002) Enhancing the crops to feed the poor. Nature, 418, 678684.

Huberty, A.F. \& Denno, R.F. (2004) Plant water stress and its consequences for herbivorous insects: a new synthesis. Ecology, 85, 1383-1398.

Hudewenz, A., Pufal, G., Bögeholz, A.L. \& Klein, A.M. (2014) Cross-pollination benefits differ among oilseed rape varieties. The Journal of Agricultural Science, 152, 770-778.

Hudson, B.D. (1994) Soil organic matter and available water capacity. Journal of Soil and Water Conservation, 49, 189-194.

Huesken, A. \& Dietz-Pfeilstetter, A. (2007) Pollen-mediated intraspecific gene flow from herbicide resistant oilseed rape (Brassica napus L.). Transgenic Research, 16, 557-569.

Janzen, H.H. (2006) The soil carbon dilemma: Shall we hoard it or use it? Soil Biology and Biochemistry, 38, 419-424.

Jennersten, O. (1984) Flower visitation and pollination efficiency of some North European butterflies. Oecologia, 63, 80-89.

Johnson, S.N., Clark, K.E., Hartley, S.E., Jones, T.H., McKenzie, S.W. \& Koricheva, J. (2012) Aboveground-belowground herbivore interactions: a meta-analysis. Ecology, 93, 2208-2215.

Johnson, S.N., Staley, J.T., McLeod, F.A. \& Hartley, S.E. (2011) Plant-mediated effects of soil invertebrates and summer drought on above-ground multitrophic interactions. Journal of Ecology, 99, 57-65.

Jung, S.C., Martinez-Medina, A., Lopez-Raez, J.A. \& Pozo, M.J. (2012) Mycorrhiza-Induced Resistance and Priming of Plant Defenses. Journal of Chemical Ecology, 38, 651-664.

Kaiser, M., Ellerbrock, R.H. \& Gerke, H.H. (2007) Long-term effects of crop rotation and fertilization on soil organic matter composition. European Journal of Soil Science, 58, 1460-1470.

Karban, R. \& Baldwin, I.T. (1997) Induced responses to herbivory. University of Chicago Press, Chicago [etc.].

Kardol, P., Bezemer, T.M., van der Wal, A. \& van der Putten, W.H. (2005) Successional trajectories of soil nematode and plant communities in a chronosequence of ex-arable lands. Biological Conservation, 126, 317-327.

Ke, X. \& Scheu, S. (2008) Earthworms, Collembola and residue management change wheat (Triticum aestivum) and herbivore pest performance (Aphidina: Rhophalosiphum padi). Oecologia, 157, 603-617.

Kempel, A., Schmidt, A.K., Brandl, R. \& Schädler, M. (2010) Support from the underground: Induced plant resistance depends on arbuscular mycorrhizal fungi. Functional Ecology, 24, 293-300.

Kennedy, C.M., Lonsdorf, E., Neel, M.C., Williams, N.M., Ricketts, T.H., Winfree, R., Bommarco, R., Brittain, C., Burley, A.L., Cariveau, D., Carvalheiro, L.G., Chacoff, N.P., Cunningham, S.A., Danforth, B.N., Dudenhoffer, J.H., Elle, E., Gaines, H.R., Garibaldi, L.A., Gratton, C., Holzschuh, A., Isaacs, R., Javorek, S.K., Jha, S., Klein, A.M., Krewenka, K., Mandelik, Y., Mayfield, M.M., Morandin, L., Neame, L.A., Otieno, M., Park, M., Potts, S.G., Rundlof, M., Saez, A., Steffan-Dewenter, I., Taki, H., Viana, B.F., Westphal, C., Wilson, J.K., Greenleaf, S.S. \& Kremen, C. (2013) A global quantitative synthesis of local and landscape effects on wild bee pollinators in agroecosystems. Ecology Letters, 16, 584-599.

Kessler, A. \& Baldwin, I.T. (2002) Plant responses to insect herbivory: The emerging molecular analysis. Annual Review of Plant Biology, 53, 299-328.

Khan, M. \& Port, G. (2008) Performance of clones and morphs of two cereal aphids on wheat plants with high and low nitrogen content. Entomological science, 11, 159-165.

Kjøller, R. \& Rosendahl, S. (2000) Effects of fungicides on arbuscular mycorrhizal fungi: differential responses in alkaline phosphatase activity of external and internal hyphae. Biology and Fertility of Soils, 31, 361-365.

Klatt, B.K., Burmeister, C., Westphal, C., Tscharntke, T. \& von Fragstein, M. (2013) Flower Volatiles, Crop Varieties and Bee Responses. Plos One, 8.

Klein, A.-M., Vaissiere, B.E., Cane, J.H., Steffan-Dewenter, I., Cunningham, S.A., Kremen, C. \& Tscharntke, T. (2007) Importance of pollinators in changing landscapes for world crops. Proceedings of the Royal Society B-Biological Sciences, 274, 303-313. 


\section{References}

Korthals, G.W., Thoden, T.C., van den Berg, W. \& Visser, J.H.M. (2014) Long-term effects of eight soil health treatments to control plant-parasitic nematodes and Verticillium dahliae in agroecosystems. Applied Soil Ecology, 76, 112-123.

Kos, M., Tuijl, M.A.B., de Roo, J., Mulder, P.P.J. \& Bezemer, T.M. (2015) Plant-soil feedback effects on plant quality and performance of an aboveground herbivore interact with fertilisation. Oikos, 124, 658-667.

Kostenko, O., Mulder, P.P.J., Courbois, M. \& Bezemer, T.M. (2016) Effects of plant diversity on the concentration of secondary plant metabolites and the density of arthropods on focal plants in the field. Journal of Ecology, n/a-n/a.

Kostenko, O., van de Voorde, T.F.J., Mulder, P.P.J., van der Putten, W.H. \& Martijn Bezemer, T. (2012) Legacy effects of aboveground-belowground interactions. Ecology Letters, 15, 813821.

Lal, R. (2004a) Soil Carbon Sequestration Impacts on Global Climate Change and Food Security. Science, 304, 1623-1627.

Lal, R. (2004b) Soil carbon sequestration to mitigate climate change. Geoderma, 123, 1-22.

Lal, R. (2006) Enhancing crop yields in the developing countries through restoration of the soil organic carbon pool in agricultural lands. Land Degradation \& Development, 17, 197-209.

Lal, R. (2016) Beyond COP 21: Potential and challenges of the "4 per Thousand" initiative. Journal of Soil and Water Conservation, 71, 20A-25A.

Lancashire, P.D., Bleiholder, H., Boom, T.V.D., LangelÜDdeke, P., Stauss, R., Weber, E. \& Witzenberger, A. (1991) A uniform decimal code for growth stages of crops and weeds. Annals of Applied Biology, 119, 561-601.

Landis, D.A., Wratten, S.D. \& Gurr, G.M. (2000) Habitat management to conserve natural enemies of arthropod pests in agriculture. Annual Review of Entomology, 45, 175-201.

Larsson, H. (2005) A crop loss model and economic thresholds for the grain aphid, Sitobion avenae (F.), in winter wheat in southern Sweden. Crop Protection, 24, 397-405.

Lau, T.C. \& Stephenson, A.G. (1993) Effects of soil-nitrogen on pollen production, pollen grain-size, and pollen performance in Cucurbita-Pepo (Cucurbitaceae). American Journal of Botany, 80, 763-768.

Lazcano, C., Gómez-Brandón, M., Revilla, P. \& Domínguez, J. (2013) Short-term effects of organic and inorganic fertilizers on soil microbial community structure and function. Biology and Fertility of Soils, 49, 723-733.

Lazebnik, J., Frago, E., Dicke, M. \& van Loon, J.A. (2014) Phytohormone Mediation of Interactions Between Herbivores and Plant Pathogens. Journal of Chemical Ecology, 40, 730-741.

Leirós, M.C., Trasar-Cepeda, C., Seoane, S. \& Gil-Sotres, F. (1999) Dependence of mineralization of soil organic matter on temperature and moisture. Soil Biology and Biochemistry, 31, 327-335.

Liao, N., Li, Q., Zhang, W., Zhou, G., Ma, L., Min, W., Ye, J. \& Hou, Z. (2016) Effects of biochar on soil microbial community composition and activity in drip-irrigated desert soil. European Journal of Soil Biology, 72, 27-34.

Lo, C.-C. (2010) Effect of pesticides on soil microbial community. Journal of Environmental Science and Health Part B, 45, 348-359.

Lobell, D.B., Schlenker, W. \& Costa-Roberts, J. (2011) Climate trends and global crop production since 1980. Science, 333, 616-620.

Losey, J.E. \& Vaughan, M. (2006) The economic value of ecological services provided by insects. BioScience, 56, 311-323.

Loveland, P. \& Webb, J. (2003) Is there a critical level of organic matter in the agricultural soils of temperate regions: a review. Soil and Tillage Research, 70, 1-18.

Lundin, O., Smith, H., Rundlöf, M. \& Bommarco, R. (2013) When ecosystem services interact: crop pollination benefits depend on the level of pest control. Proceedings. Biological sciences / The Royal Society, 280, 20122243.

Mäder, P., Fliessbach, A., Dubois, D., Gunst, L., Fried, P. \& Niggli, U. (2002) Soil fertility and biodiversity in organic farming. Science, 296, 1694-1697.

Maeder, P., Fliessbach, A., Dubois, D., Gunst, L., Fried, P. \& Niggli, U. (2002) Soil Fertility and Biodiversity in Organic Farming. Science, 296, 1694. 
Magdoff, F. \& Weil, R.R. (2004) Soil organic matter in sustainable agriculture. CRC, Boca Raton, Fla [etc.].

Majumder, B. \& Kuzyakov, Y. (2010) Effect of fertilization on decomposition of 14C labelled plant residues and their incorporation into soil aggregates. Soil and Tillage Research, 109, 94-102.

Makandar, R., Nalam, V.J., Lee, H., Trick, H.N., Dong, Y. \& Shah, J. (2012) Salicylic acid regulates basal resistance to Fusarium head blight in wheat. Molecular Plant-Microbe Interactions, 25, 431-439.

Makino, T.T., Ohashi, K. \& Sakai, S. (2007) How do floral display size and the density of surrounding flowers influence the likelihood of bumble bee revisitation to a plant? Functional Ecology, 21, 87-95.

Mamo, M., Molina, J.A.E., Rosen, C.J. \& Halbach, T.R. (1999) Nitrogen and carbon mineralization in soil amended with municipal solid waste compost. Canadian Journal of Soil Science, 79, 535542.

Marini, L., Tamburini, G., Petrucco-Toffolo, E., Lindström, S.A.M., Zanetti, F., Mosca, G. \& Bommarco, R. (2015) Crop management modifies the benefits of insect pollination in oilseed rape. Agriculture, Ecosystems \& Environment, 207, 61-66.

Marriott, E.E. \& Wander, M.M. (2006) Total and labile soil organic matter in organic and conventional farming systems. Soil Science Society of America Journal, 70, 950-959.

Martin, E.A., Reineking, B., Seo, B. \& Steffan-Dewenter, I. (2015) Pest control of aphids depends on landscape complexity and natural enemy interactions. PeerJ, 3, e1095.

Matson, P.A., Parton, W.J., Power, A. \& Swift, M. (1997) Agricultural intensification and ecosystem properties. Science, 277, 504-509.

Mattson, W.J. (1980) Herbivory in relation to plant nitrogen-content. Annual Review of Ecology and Systematics, 11, 119-161.

Matus, F. \& Rodríguez, J. (1994) A simple model for estimating the contribution of nitrogen mineralization to the nitrogen supply of crops from a stabilized pool of soil organic matter and recent organic input. Plant and Soil, 162, 259-271.

Maxmen, A. (2013) Crop pests: under attack. Nature, 501, S15-S17.

Mazzola, M. (2002) Mechanisms of natural soil suppressiveness to soilborne diseases. Antonie Van Leeuwenhoek International Journal of General and Molecular Microbiology, 81, 557-564.

Memmott, J., Cadotte, M., Hulme, P.E., Kerby, G., Milner-Gulland, E. \& Whittingham, M.J. (2010) Putting applied ecology into practice. Journal of Applied Ecology, 47, 1-4.

Meyer, G.A. (2000) Interactive effects of soil fertility and herbivory on Brassica nigra. Oikos, 88, 433441.

Minasny, B., Malone, B.P., McBratney, A.B., Angers, D.A., Arrouays, D., Chambers, A., Chaplot, V., Chen, Z.-S., Cheng, K. \& Das, B.S. (2017) Soil carbon 4 per mille. Geoderma, 292, 59-86.

Mohase, L. \& van der Westhuizen, A.J. (2002) Salicylic acid is involved in resistance responses in the Russian wheat aphid-wheat interaction. Journal of Plant Physiology, 159, 585-590.

Moran, P.J. \& Thompson, G.A. (2001) Molecular responses to aphid feeding in Arabidopsis in relation to plant defense pathways. Plant Physiology, 125, 1074-1085.

Morgan, S., Cole, H.P., Struttmann, T. \& Piercy, L. (2002) Stories or statistics? Farmers' attitudes toward messages in an agricultural safety campaign. Journal of agricultural safety and health, 8, 225-239.

Morriën, E., Hannula, S.E., Snoek, L.B., Helmsing, N.R., Zweers, H., De Hollander, M., Soto, R.L., Bouffaud, M.-L., Buée, M. \& Dimmers, W. (2017) Soil networks become more connected and take up more carbon as nature restoration progresses. Nature communications, 8, 14349.

Motzke, I., Tscharntke, T., Wanger, T.C. \& Klein, A.-M. (2015) Pollination mitigates cucumber yield gaps more than pesticide and fertilizer use in tropical smallholder gardens. Journal of Applied Ecology, 52, 261-269.

Muus, T.S.T. (2014) Microlepidoptera - aangebrande valkmot Evergestis extimalis (Scopoli, 1763) Microlepidoptera.nl (ed. S. Corver). Beetsterzwaag, the Netherlands.

Nevo, E. \& Coll, M. (2001) Effect of nitrogen fertilization on Aphis gossypii (Homoptera: Aphididae): variation in size, color, and reproduction. Journal of Economic Entomology, 94, 27-32. 


\section{References}

Nkem, J.N., Wall, D.H., Virginia, R.A., Barrett, J.E., Broos, E.J., Porazinska, D.L. \& Adams, B.J. (2006) Wind dispersal of soil invertebrates in the McMurdo Dry Valleys, Antarctica. Polar Biology, 29, 346-352.

Nowak, H. \& Komor, E. (2010) How aphids decide what is good for them: experiments to test aphid feeding behaviour on Tanacetum vulgare (L.) using different nitrogen regimes. Oecologia, 163, 973-984.

Ohashi, K. \& Yahara, T. (1998) Effects of variation in flower number on pollinator visits in Cirsium purpuratum (Asteraceae). American Journal of Botany, 85, 219-224.

Olsen, S.R., Cole, C.V. \& Watanabe, F.S. (1954) Estimation of available phosphorus in soils by extraction with sodium bicarbonate. USDA, Washington.

Orrell, P. \& Bennett, A. (2013) How can we exploit above-belowground interactions to assist in addressing the challenges of food security? Frontiers in Plant Science, 4.

Otieno, M., Woodcock, B.A., Wilby, A., Vogiatzakis, I.N., Mauchline, A.L., Gikungu, M.W. \& Potts, S.G. (2011) Local management and landscape drivers of pollination and biological control services in a Kenyan agro-ecosystem. Biological Conservation, 144, 2424-2431.

Pangesti, N., Pineda, A., Dicke, M. \& van Loon, J.J.A. (2015) Variation in plant-mediated interactions between rhizobacteria and caterpillars: potential role of soil composition. Plant Biology, 17, 474-483.

Pescod, K.V., Quick, W.P. \& Douglas, A.E. (2007) Aphid responses to plants with genetically manipulated phloem nutrient levels. Physiological Entomology, 32, 253-258.

Philippot, L., Raaijmakers, J.M., Lemanceau, P. \& van der Putten, W.H. (2013) Going back to the roots: the microbial ecology of the rhizosphere. Nat Rev Micro, 11, 789-799.

Pieterse, C.M.J., Poelman, E.H., Van Wees, S.C.M. \& Dicke, M. (2013) Induced plant responses to microbes and insects. Frontiers in Plant Science, 4.

Pimentel, D., Hepperly, P., Hanson, J., Douds, D. \& Seidel, R. (2005) Environmental, Energetic, and Economic Comparisons of Organic and Conventional Farming Systems. BioScience, 55, 573582.

Pineda, A., Dicke, M., Pieterse, C.M.J. \& Pozo, M.J. (2013a) Beneficial microbes in a changing environment: are they always helping plants to deal with insects? Functional Ecology, 27, 574-586.

Pineda, A., Pangesti, N., Soler, R., van Dam, N.M., van Loon, J.J.A. \& Dicke, M. (2016) Negative impact of drought stress on a generalist leaf chewer and a phloem feeder is associated with, but not explained by an increase in herbivore-induced indole glucosinolates. Environmental and Experimental Botany, 123, 88-97.

Pineda, A., Soler, R., Weldegergis, B.T., Shimwela, M.M., Van Loon, J.J.A. \& Dicke, M. (2013b) Non-pathogenic rhizobacteria interfere with the attraction of parasitoids to aphid-induced plant volatiles via jasmonic acid signalling. Plant, Cell and Environment, 36, 393-404.

Pinheiro, J., Bates, D., DebRoy, S., Sarkar, D. \& Team, R.C. (2014) nlme: Linear and Nonlinear Mixed Effects Models. R package version 3.1-117.

Post, W.M. \& Kwon, K.C. (2000) Soil carbon sequestration and land-use change: processes and potential. Global Change Biology, 6, 317-327.

Poveda, K., Steffan-Dewenter, I., Scheu, S. \& Tscharntke, T. (2003) Effects of below- and aboveground herbivores on plant growth, flower visitation and seed set. Oecologia, 135, 601-605.

Poveda, K., Steffan-Dewenter, I., Scheu, S. \& Tscharntke, T. (2005) Effects of Decomposers and Herbivores on Plant Performance and Aboveground Plant-Insect Interactions. Oikos, 108, 503-510.

Prescott, C.E. (2010) Litter decomposition: what controls it and how can we alter it to sequester more carbon in forest soils? Biogeochemistry, 101, 133-149.

Pulleman, M.M., Bouma, J., van Essen, E.A. \& Meijles, E.W. (2000) Soil Organic Matter Content as a Function of Different Land Use History. Soil Science Society of America Journal, 64, 689693.

R Core Team (2015) R: A language and environment for statistical computing. R Foundation for Statistical Computing, Vienna, Austria.

Ray, D.K., Mueller, N.D., West, P.C. \& Foley, J.A. (2013) Yield Trends Are Insufficient to Double Global Crop Production by 2050. Plos One, 8, e66428. 
Ray, D.K., Ramankutty, N., Mueller, N.D., West, P.C. \& Foley, J.A. (2012) Recent patterns of crop yield growth and stagnation. Nature communications, 3, 1293.

Reeves, D.W. (1997) The role of soil organic matter in maintaining soil quality in continuous cropping systems. Soil and Tillage Research, 43, 131-167.

Reganold, J.P. \& Wachter, J.M. (2016) Organic agriculture in the twenty-first century. Nature Plants, 2, 15221 .

Riedell, W.E., Beckendorf, E.A. \& Catangui, M.A. (2013) Relationships between soybean shoot nitrogen components and soybean aphid populations. Arthropod-Plant Interactions, 7, 667676.

Rinnan, R. \& Bååth, E. (2009) Differential utilization of carbon substrates by bacteria and fungi in tundra soil. Applied and Environmental Microbiology, 75, 3611-3620.

Robert-Seilaniantz, A., Grant, M. \& Jones, J.D. (2011) Hormone crosstalk in plant disease and defense: more than just jasmonate-salicylate antagonism. Annual Review of Phytopathology, 49, 317-343.

Rusch, A., Bommarco, R., Jonsson, M., Smith, H.G. \& Ekbom, B. (2013) Flow and stability of natural pest control services depend on complexity and crop rotation at the landscape scale. Journal of Applied Ecology, 50, 345-354.

Rusch, A., Valantin-Morison, M., Sarthou, J.-P. \& Roger-Estrade, J. (2010) Biological control of insect pests in agroecosystems: effects of crop management, farming systems, and seminatural habitats at the landscape scale: a review. Advances in Agronomy, Vol 109 (ed. D.L. Sparks), pp. 219-259.

Säle, V., Aguilera, P., Laczko, E., Mäder, P., Berner, A., Zihlmann, U., van der Heijden, M.G. \& Oehl, F. (2015) Impact of conservation tillage and organic farming on the diversity of arbuscular mycorrhizal fungi. Soil Biology and Biochemistry, 84, 38-52.

Sánchez, A.M., Rodríguez, M., Albert, M.J. \& Escudero, A. (2017) Effects of season and population size on pollination and reproductive output in a Mediterranean shrub. Plant Biology, n/a-n/a.

Sarthou, J.-P., Badoz, A., Vaissiere, B., Chevallier, A. \& Rusch, A. (2014) Local more than landscape parameters structure natural enemy communities during their overwintering in semi-natural habitats. Agriculture Ecosystems \& Environment, 194, 17-28.

Sauge, M.H., Grechi, I. \& Poëssel, J.L. (2010) Nitrogen fertilization effects on Myzus persicae aphid dynamics on peach: vegetative growth allocation or chemical defence? Entomologia Experimentalis et Applicata, 136, 123-133.

Schellhorn, N.A., Gagic, V. \& Bommarco, R. (2015) Time will tell: resource continuity bolsters ecosystem services. Trends in Ecology \& Evolution, 30, 524-530.

Schellhorn, N.A., Macfadyen, S., Bianchi, F.J.J.A., Williams, D.G. \& Zalucki, M.P. (2008) Managing ecosystem services in broadacre landscapes: what are the appropriate spatial scales? Australian Journal of Experimental Agriculture, 48, 1549-1559.

Scheper, J., Bommarco, R., Holzschuh, A., Potts, S.G., Riedinger, V., Roberts, S.P.M., Rundlöf, M., Smith, H.G., Steffan-Dewenter, I., Wickens, J.B., Wickens, V.J. \& Kleijn, D. (2015) Local and landscape-level floral resources explain effects of wildflower strips on wild bees across four European countries. Journal of Applied Ecology, 52, 1165-1175.

Scheper, J., Holzschuh, A., Kuussaari, M., Potts, S.G., Rundlof, M., Smith, H.G. \& Kleijn, D. (2013) Environmental factors driving the effectiveness of European agri-environmental measures in mitigating pollinator loss - a meta-analysis. Ecology Letters, 16, 912-920.

Scheu, S. (2001) Plants and generalist predators as links between the below-ground and above-ground system. Basic and Applied Ecology, 2, 3-13.

Schimel, J. \& Schaeffer, S. (2012) Microbial control over carbon cycling in soil. Frontiers in Microbiology, 3.

Schjønning, P., McBride, R.A., Keller, T. \& Obour, P.B. (2017) Predicting soil particle density from clay and soil organic matter contents. Geoderma, 286, 83-87.

Schmidt, M.W., Torn, M.S., Abiven, S., Dittmar, T., Guggenberger, G., Janssens, I.A., Kleber, M., Kögel-Knabner, I., Lehmann, J. \& Manning, D.A. (2011) Persistence of soil organic matter as an ecosystem property. Nature, 478, 49-56. 


\section{References}

Schröter, D., Cramer, W., Leemans, R., Prentice, I.C., Araújo, M.B., Arnell, N.W., Bondeau, A., Bugmann, H., Carter, T.R. \& Gracia, C.A. (2005) Ecosystem service supply and vulnerability to global change in Europe. Science, 310, 1333-1337.

Schütz, K., Bonkowski, M. \& Scheu, S. (2008) Effects of Collembola and fertilizers on plant performance (Triticum aestivum) and aphid reproduction (Rhopalosiphum padi). Basic and Applied Ecology, 9, 182-188.

Sebilo, M., Mayer, B., Nicolardot, B., Pinay, G. \& Mariotti, A. (2013) Long-term fate of nitrate fertilizer in agricultural soils. Proceedings of the National Academy of Sciences, 110, 1818518189.

Seppelt, R., Dormann, C.F., Eppink, F.V., Lautenbach, S. \& Schmidt, S. (2011) A quantitative review of ecosystem service studies: approaches, shortcomings and the road ahead. Journal of Applied Ecology, 48, 630-636.

Setälä, H., Bardgett, R.D., Birkhofer, K., Brady, M., Byrne, L., de Ruiter, P.C., de Vries, F.T., Gardi, C., Hedlund, K., Hemerik, L., Hotes, S., Liiri, M., Mortimer, S.R., Pavao-Zuckerman, M., Pouyat, R., Tsiafouli, M. \& van der Putten, W.H. (2014) Urban and agricultural soils: conflicts and trade-offs in the optimization of ecosystem services. Urban Ecosystems, 17, 239-253.

Seufert, V., Ramankutty, N. \& Foley, J.A. (2012) Comparing the yields of organic and conventional agriculture. Nature, 485, 229-232.

Shannon, C.E. (1948) A Mathematical Theory of Communication. Bell System Technical Journal, 27, 623-656.

Six, J., Bossuyt, H., Degryze, S. \& Denef, K. (2004) A history of research on the link between (micro)aggregates, soil biota, and soil organic matter dynamics. Soil and Tillage Research, 79, 7-31.

Six, J., Elliott, E.T. \& Paustian, K. (2000) Soil macroaggregate turnover and microaggregate formation: a mechanism for C sequestration under no-tillage agriculture. Soil Biology \& Biochemistry, 32, 2099-2103.

Smith, C.R., Blair, P.L., Boyd, C., Cody, B., Hazel, A., Hedrick, A., Kathuria, H., Khurana, P., Kramer, B., Muterspaw, K., Peck, C., Sells, E., Skinner, J., Tegeler, C. \& Wolfe, Z. (2016) Microbial community responses to soil tillage and crop rotation in a corn/soybean agroecosystem. Ecology and Evolution, 6, 8075-8084.

Smith, J.D., Kidwell, K.K., Evans, M.A., Cook, R.J. \& Smiley, R.W. (2003) Assessment of spring wheat genotypes for disease reaction to Rhizoctonia solani AG-8 in controlled environment and direct-seeded field evaluations. Crop Science, 43, 694-700.

Soler, R., Bezemer, T.M., Van der Putten, W.H., Vet, L.E.M. \& Harvey, J.A. (2005) Root herbivore effects on above-ground herbivore, parasitoid and hyperparasitoid performance via changes in plant quality. Journal of Animal Ecology, 74, 1121-1130.

Soler, R., Putten, W.H., Harvey, J.A., Vet, L.E.M., Dicke, M. \& Bezemer, T.M. (2012) Root Herbivore Effects on Aboveground Multitrophic Interactions: Patterns, Processes and Mechanisms. Journal of Chemical Ecology, 38, 755-767.

Solomon, S. (2007) Climate change 2007-the physical science basis: Working group I contribution to the fourth assessment report of the IPCC. Cambridge University Press.

Song, Y.Y., Ye, M., Li, C.Y., Wang, R.L., Wei, X.C., Luo, S.M. \& Zeng, R.S. (2013) Priming of Anti-Herbivore Defense in Tomato by Arbuscular Mycorrhizal Fungus and Involvement of the Jasmonate Pathway. Journal of Chemical Ecology, 39, 1036-1044.

Soon, Y.K. \& Arshad, M.A. (1996) Effects of cropping systems on nitrogen, phosphorus and potassium forms and soil organic carbon in a Gray Luvisol. Biology and Fertility of Soils, 22, 184-190.

Stagnari, F., Perpetuini, G., Tofalo, R., Campanelli, G., Leteo, F., Della Vella, U., Schirone, M., Suzzi, G. \& Pisante, M. (2014) Long-term impact of farm management and crops on soil microorganisms assessed by combined DGGE and PLFA analyses. Frontiers in Microbiology, 5,644 .

Steffan-Dewenter, I., Munzenberg, U., Burger, C., Thies, C. \& Tscharntke, T. (2002) Scale-dependent effects of landscape context on three pollinator guilds. Ecology, 83, 1421-1432.

Steffan-Dewenter, I. \& Tscharntke, T. (1999) Effects of habitat isolation on pollinator communities and seed set. Oecologia, 121, 432-440. 
Steiner, C., Teixeira, W.G., Lehmann, J., Nehls, T., de Macêdo, J.L.V., Blum, W.E.H. \& Zech, W. (2007) Long term effects of manure, charcoal and mineral fertilization on crop production and fertility on a highly weathered Central Amazonian upland soil. Plant and Soil, 291, 275-290.

Stockdale, E.A., Shepherd, M.A., Fortune, S. \& Cuttle, S.P. (2002) Soil fertility in organic farming systems - fundamentally different? Soil Use and Management, 18, 301-308.

Stockfisch, N., Forstreuter, T. \& Ehlers, W. (1999) Ploughing effects on soil organic matter after twenty years of conservation tillage in Lower Saxony, Germany. Soil \& Tillage Research, 52, 91-101.

Sumner, L., Eikenbary, R. \& Johnson, R. (1986) Survival and reproduction of Rhopalosiphum maidis (Fitch)(Homoptera: Aphididae) on winter wheat during simulated drought stress. Journal of the Kansas Entomological Society, 561-563.

Syswerda, S., Corbin, A., Mokma, D., Kravchenko, A. \& Robertson, G. (2011) Agricultural management and soil carbon storage in surface vs. deep layers. Soil Science Society of America Journal, 75, 92-101.

Tamburini, G., Berti, A., Morari, F. \& Marini, L. (2015) Degradation of soil fertility can cancel pollination benefits in sunflower. Oecologia, 1-7.

Tamburini, G., De Simone, S., Sigura, M., Boscutti, F. \& Marini, L. (2016) Soil management shapes ecosystem service provision and trade-offs in agricultural landscapes. Proceedings of the Royal Society B: Biological Sciences, 283.

Tariq, M., Wright, D.J., Rossiter, J.T. \& Staley, J.T. (2012) Aphids in a changing world: testing the plant stress, plant vigour and pulsed stress hypotheses. Agricultural and Forest Entomology, 14, 177-185.

Thaler, J.S., Humphrey, P.T. \& Whiteman, N.K. (2012) Evolution of jasmonate and salicylate signal crosstalk. Trends in Plant Science, 17, 260-270.

Thies, C., Roschewitz, I. \& Tscharntke, T. (2005) The landscape context of cereal aphid-parasitoid interactions. Proceedings of the Royal Society B-Biological Sciences, 272, 203-210.

Thies, C., Steffan-Dewenter, I. \& Tscharntke, T. (2003) Effects of landscape context on herbivory and parasitism at different spatial scales. Oikos, 101, 18-25.

Thies, C. \& Tscharntke, T. (1999) Landscape structure and biological control in agroecosystems. Science, 285, 893-895.

Tilman, D., Fargione, J., Wolff, B., D'Antonio, C., Dobson, A., Howarth, R., Schindler, D., Schlesinger, W.H., Simberloff, D. \& Swackhamer, D. (2001) Forecasting agriculturally driven global environmental change. Science, 292, 281-284.

Tonitto, C., Goodale, C.L., Weiss, M.S., Frey, S.D. \& Ollinger, S.V. (2014) The effect of nitrogen addition on soil organic matter dynamics: a model analysis of the Harvard Forest Chronic Nitrogen Amendment Study and soil carbon response to anthropogenic N deposition. Biogeochemistry, 117, 431-454.

Tscharntke, T., Klein, A.M., Kruess, A., Steffan-Dewenter, I. \& Thies, C. (2005a) Landscape perspectives on agricultural intensification and biodiversity - ecosystem service management. Ecology Letters, 8.

Tscharntke, T., Klein, A.M., Kruess, A., Steffan-Dewenter, I. \& Thies, C. (2005b) Landscape perspectives on agricultural intensification and biodiversity-ecosystem service management. Ecology Letters, 8, 857-874.

Tscharntke, T., Tylianakis, J., Rand, T., Didham, R., Fahrig, L., Batáry, P., Bengtsson, J., Clough, Y., Crist, T., Dormann, C., Ewers, R., Fründ, J., Holt, R., Holzschuh, A., Klein, A., Kleijn, D., Kremen, C., Landis, D., Laurance, W., Lindenmayer, D., Scherber, C., Sodhi, N., SteffanDewenter, I., Thies, C., van der Putten, W. \& Westphal, C. (2012) Landscape moderation of biodiversity patterns and processes - eight hypotheses. Biological reviews of the Cambridge Philosophical Society, 87, 661-685.

Tsiafouli, M.A., Thebault, E., Sgardelis, S.P., de Ruiter, P.C., van der Putten, W.H., Birkhofer, K., Hemerik, L., de Vries, F.T., Bardgett, R.D., Brady, M.V., Bjornlund, L., Jorgensen, H.B., Christensen, S., D' Hertefeldt, T., Hotes, S., Hol, W.H.G., Frouz, J., Liiri, M., Mortimer, S.R., Setala, H., Tzanopoulos, J., Uteseny, K., Pizl, V., Stary, J., Wolters, V. \& Hedlund, K. (2015) Intensive agriculture reduces soil biodiversity across Europe. Global Change Biology, 21, 973-985. 


\section{References}

Valantin-Morison, M., Meynard, J.M. \& Dore, T. (2007) Effects of crop management and surrounding field environment on insect incidence in organic winter oilseed rape (Brassica napus L.). Crop Protection, 26, 1108-1120.

van der Putten, W., Vet, L. \& Harvey, J. (2001) Linking above-and belowground multitrophic interactions of plants, herbivores, pathogens, and their antagonists. Trends in Ecology \& Evolution.

van der Wal, A., van Veen, J.A., Smant, W., Boschker, H.T., Bloem, J., Kardol, P., van der Putten, W.H. \& de Boer, W. (2006) Fungal biomass development in a chronosequence of land abandonment. Soil Biology and Biochemistry, 38, 51-60.

van Diepeningen, A.D., de Vos, O.J., Korthals, G.W. \& van Bruggen, A.H.C. (2006) Effects of organic versus conventional management on chemical and biological parameters in agricultural soils. Applied Soil Ecology, 31, 120-135.

van Eekeren, N., de Boer, H., Hanegraaf, M., Bokhorst, J., Nierop, D., Bloem, J., Schouten, T., de Goede, R. \& Brussaard, L. (2010) Ecosystem services in grassland associated with biotic and abiotic soil parameters. Soil Biology \& Biochemistry, 42, 1491-1504.

Van Geem, M., Harvey, J.A., Cortesero, A.M., Raaijmakers, C.E. \& Gols, R. (2015) Interactions Between a Belowground Herbivore and Primary and Secondary Root Metabolites in Wild Cabbage. Journal of Chemical Ecology, 41, 696-707.

van Gils, S., van der Putten, W.H. \& Kleijn, D. (2016) Data from: Can above-ground ecosystem services compensate for reduced fertilizer input and soil organic matter in annual crops? Dryad Digital Repository, http://dx.doi.org/10.5061/dryad.s08f7.

van Grunsven, R.H. \& Liefting, M. (2015) How to Maintain Ecological Relevance in Ecology. Trends in Ecology \& Evolution, 30, 563-564.

van Ittersum, M.K. \& Rabbinge, R. (1997) Concepts in production ecology for analysis and quantification of agricultural input-output combinations. Field Crops Research, 52, 197-208.

Veres, A., Petit, S., Conord, C. \& Lavigne, C. (2013) Does landscape composition affect pest abundance and their control by natural enemies? A review. Agriculture Ecosystems \& Environment, 166, 110-117.

Verhoog, A.D. (2002) Oilseed production in the EU. Statistics in Focus. Eurostat, European Communities.

Vermeulen, S.J., Campbell, B.M. \& Ingram, J.S. (2012) Climate change and food systems. Annual Review of Environment and Resources, 37, 195-222.

Viik, E., Maend, M., Karise, R., Laeaeniste, P., Williams, I.H. \& Luik, A. (2012) The impact of foliar fertilization on the number of bees (Apoidea) on spring oilseed rape. Zemdirbyste-Agriculture, 99, 41-46.

Vleeshouwers, L.M. \& Verhagen, A. (2002) Carbon emission and sequestration by agricultural land use: a model study for Europe. Global Change Biology, 8, 519-530.

Wall, P.C., Neate, S.M., Graham, R.D., Reuter, D.J. \& Rovira, A.D. (1994) The effect of Rhizoctonia root disease and applied nitrogen on growth, nitrogen uptake and nutrient concentrations in spring wheat. Plant and Soil, 163, 111-120.

Wardle, D.A. (2002) Communities and ecosystems: linking the aboveground and belowground components. Princeton University Press.

Wardle, D.A., Bardgett, R.D., Klironomos, J.N., Setälä, H., van der Putten, W.H. \& Wall, D.H. (2004) Ecological Linkages Between Aboveground and Belowground Biota. Science, 304, 16291633.

Wardle, D.A., Bellingham, P.J., Kardol, P., Giesler, R. \& Tanner, E.V. (2015) Coordination of aboveground and belowground responses to local-scale soil fertility differences between two contrasting Jamaican rain forest types. Oikos, 124, 285-297.

Welch, K.D. \& Harwood, J.D. (2014) Temporal dynamics of natural enemy-pest interactions in a changing environment. Biological Control, 75, 18-27.

Whitaker, J., Ostle, N., McNamara, N.P., Nottingham, A.T., Stott, A.W., Bardgett, R.D., Salinas, N., Ccahuana, A.J. \& Meir, P. (2014) Microbial carbon mineralization in tropical lowland and montane forest soils of Peru. Frontiers in Microbiology, 5, 720. 
Whitman, T., Pepe-Ranney, C., Enders, A., Koechli, C., Campbell, A., Buckley, D.H. \& Lehmann, J. (2016) Dynamics of microbial community composition and soil organic carbon mineralization in soil following addition of pyrogenic and fresh organic matter. ISME J.

Williams, A., Birkhofer, K. \& Hedlund, K. (2014) Above-and below-ground interactions with agricultural management: Effects of soil microbial communities on barley and aphids. Pedobiologia, 57, 67-74.

Wondafrash, M., Van Dam, N.M. \& Tytgat, T.O.G. (2013) Plant systemic induced responses mediate interactions between root parasitic nematodes and aboveground herbivorous insects. Frontiers in Plant Science, 4.

Wood, S.A., Sokol, N., Bell, C.W., Bradford, M.A., Naeem, S., Wallenstein, M.D. \& Palm, C.A. (2016) Opposing effects of different soil organic matter fractions on crop yields. Ecological Applications, n/a-n/a.

Woodcock, B.A., Harrower, C., Redhead, J., Edwards, M., Vanbergen, A.J., Heard, M.S., Roy, D.B. \& Pywell, R.F. (2014) National patterns of functional diversity and redundancy in predatory ground beetles and bees associated with key UK arable crops. Journal of Applied Ecology, 51, 142-151.

Wretenberg, J., Lindstrom, A., Svensson, S., Thierfelder, T. \& Part, T. (2006) Population trends of farmland birds in Sweden and England: similar trends but different patterns of agricultural intensification. Journal of Applied Ecology, 43, 1110-1120.

Wurst, S., Langel, R., Reineking, A., Bonkowski, M. \& Scheu, S. (2003) Effects of earthworms and organic litter distribution on plant performance and aphid reproduction. Oecologia, 137, 9096.

Zaller, J.G., Moser, D., Drapela, T., Schmoeger, C. \& Frank, T. (2008) Insect pests in winter oilseed rape affected by field and landscape characteristics. Basic and Applied Ecology, 9, 682-690.

Zehnder, G., Gurr, G.M., Kühne, S., Wade, M.R., Wratten, S.D. \& Wyss, E. (2007) Arthropod pest management in organic crops. Annu. Rev. Entomol., 52, 57-80.

Zelles, L. (1999) Fatty acid patterns of phospholipids and lipopolysaccharides in the characterisation of microbial communities in soil: a review. Biology and Fertility of Soils, 29, 111-129.

Zhang, J.B., Zhu, T.B., Cai, Z.C., Qin, S.W. \& Mueller, C. (2012) Effects of long-term repeated mineral and organic fertilizer applications on soil nitrogen transformations. European Journal of Soil Science, 63, 75-85.

Zhong, W., Gu, T., Wang, W., Zhang, B., Lin, X., Huang, Q. \& Shen, W. (2009) The effects of mineral fertilizer and organic manure on soil microbial community and diversity. Plant and Soil, 326, 511-522.

Zhou, G., Zhang, J., Zhang, C., Feng, Y., Chen, L., Yu, Z., Xin, X. \& Zhao, B. (2016) Effects of changes in straw chemical properties and alkaline soils on bacterial communities engaged in straw decomposition at different temperatures. Scientific Reports, 6.

Zuur, A., Ieno, E.N., Walker, N., Saveliev, A.A. \& Smith, G.M. (2009) Mixed effects models and extensions in ecology with $R$. Springer Science \& Business Media. 


\section{Summary}

Crop yield is influenced by various ecosystem services that operate aboveground and belowground, such as pollination by bees and hoverflies, and soil mineralization by soil organisms that decompose organic matter in the soil. However, it is not well known how these multiple ecosystem services interact while influencing crop yield. In this thesis, I assessed how soil organic matter content alters the effects of various aboveground ecosystem services, especially pollination and control of aboveground plant-feeding insects, with and without external inputs of mineral fertilizer, on crop yield.

A crop plant interacts with aboveground and belowground factors that enhance or inhibit yield. There is increasing awareness that aboveground factors, such as pollination, herbivory, and herbivore control, and belowground factors, such as nutrient provisioning by organic matter, are interlinked. For instance, enhanced levels of soil nutrients alter chemistry of aboveground plant tissues, which alters performance of aboveground herbivores. Also biotic processes, such as an association between crop plant and arbuscular mycorrhiza fungi or herbivory, can alter the plant chemistry and therefore the performance of aboveground herbivores. Understanding how aboveground-belowground interactions work in agricultural systems, can help optimizing yield.

Soil organic matter is crucial as it not only provides nutrients for crop growth, when mineralized, but also may influence plant-insect interactions. Normally, about half of the soil organic matter consists of carbon, meaning that enhancing soil organic matter content also means that carbon dioxide $\left(\mathrm{CO}_{2}\right)$ emissions are being counteracted. In addition, soil organic matter contains nutrients, such as nitrogen, phosphorous and potassium, which are essential for plant growth. By providing nutrients, soil organic matter also changes the plant chemistry and thereby plant attraction to aboveground pests. Moreover, soil organic matter provides soil structure, which promotes growth conditions for plant roots, it enhances the water holding capacity, and influences disease suppression. In other words soil organic matter influences crop yields in various ways, many of these have an effect belowground, whereas others have an influence on aboveground processes. In my thesis, I performed various experiments to unravel how soil organic matter content alters aboveground-belowground interactions. 
Using a greenhouse experiment (Chapter 2) I studied whether soil organic matter content influences the effect of mineral fertilizer supply and introduction of the pathogenic root fungus Rhizoctonia solani. I studied how these factors influenced the biomass of spring wheat (Triticum avenae) and the aphids (Sitobion avenae) on these plants. Moreover, I added some extra pots with high and low soil organic matter content that were sterilized in order to test whether the effects of soil organic matter originated from the microbial community. I found that $R$. solani indeed influenced wheat and aphid performance, but that this influence depended on the presence of a soil microbiome, on soil organic matter content, and on fertilizer supply. These results imply that soil organic matter conditions should be considered in studies on aboveground-belowground interactions.

In another greenhouse experiment (Chapter 3), I tested whether mineral fertilizer supply and soil organic matter content affect the effect of drought on aphid biomass on spring wheat. I found that mineral fertilizer supply positively influenced aphid biomass, but that these effects were stronger if the soil organic matter content was higher or when the wheat plants received ample water. This experiment also showed that the relative effect of drought stress might be smaller than expected if plants are infested by aphids.

Both experiments in chapters 2 and 3 were performed under controlled conditions and in pots. In order to test effects of soil organic matter content under field conditions, in Chapter 4 I selected pairs of wheat fields with contrasting (relatively low vs high) soil organic matter content. In each field I established two subplots, one with mineral fertilizer, and the other not. I studied how these factors influenced nitrogen, phosphorous and potassium mineralization, aphid and enemy performance and wheat yield. Under these realistic conditions, soil organic matter content appeared to have a very small effect on aphids and wheat yield. There was an overall positive relation between soil organic matter content and nitrogen mineralization. However, in a factorial analysis fields with a relatively high soil organic matter content did not show a higher mineralization rate, than neighbouring fields that had lower soil organic matter content. Moreover, a higher nitrogen mineralization rate related to a decreased yield benefit from mineral fertilizer supply. Insects on wheat plants were barely influenced by soil organic matter content. A higher soil organic matter content tended to result in fewer aphids if 


\section{Summary}

mineral fertilizer was supplied, but it did not affect parasitism rate or the abundance of grounddwelling beetles that prey on wheat herbivores. Therefore, I conclude that under field conditions in real farmers' fields, the effect of soil organic matter content on various ecosystem services that contribute to crop yield might be smaller than suggested in literature.

Not all ecosystem services that influence crop yield are operating at the same spatial scales. Population dynamics of wild bees, hoverflies and pest insects, are expected to largely depend on the landscape around the crop field, whereas interactions involving the soil community, such as mineralization of soil organic matter, depend on local soil conditions, and not so much on soils in the surrounding landscape. Using a semi-field experiment (Chapter 5) I studied whether soil organic matter content and mineral fertilizer supply have a different effect on yield of oilseed rape (Brassica napus), if pollinator visitation rates or pest levels are different. To test this, I grew plants in containers with soil with low or high soil organic matter content with or with fertilizer supply. I placed the plants and containers in various landscapes with contrasting pollinator visitation rates and pest pressure rates and found that both pollinator visitation rate and pest pressure had an important effect on yield of oilseed rape. Mineral fertilizer supply also strongly affected oil seed rape yield, but soil organic matter content had no effect. Moreover, the soil conditions did not change the effect of pollinator visitation rate and pest pressure on yield. From this experiment I conclude that ecosystem processes that operate at a landscape scale (pollination and pest pressure) do not necessarily affect the effects of soil conditions (soil organic matter content and mineral fertilizer supply) on crop yield.

Apart from the spatial processes, also temporal processes could influence crop yield. Effects of soil organic matter for instance might become stronger if the soil has been under increased duration of organic management. In Chapter 6, I collected soils from conventional fields and from fields that had been managed organically for increasing lengths of time. I found that long-term organic management did not result in an increased soil organic matter content, but that the PLFA-based fungal biomass was higher in organically managed than in paired conventionally managed fields. The duration of organic management did not have any effect. In a separate greenhouse experiment with these soils I looked how (duration of) organic management affected wheat biomass and the abundance of aphids (Sitobion 
avenae) that grow on wheat. I found that soils with a higher soil organic matter content also had more plant biomass. However, wheat biomass was higher in soils that were managed conventionally, whereas aphids performed better on plants in soil collected from organically managed fields. Again, there was no effect of duration of organic management.

Across the different experiments I observed sometimes a positive effect of soil organic matter on the biomass of crops, but this effect was not consistent. Therefore, my $\mathrm{PhD}$ study does not provide strong evidence that higher soil organic matter content is necessarily important for enhancing nutrient availability or other ecosystem services, such as pest control. In addition, processes that happen at the temporal and spatial scale also did not change the effects of soil organic matter. In my study, I have mainly focussed on effects of different amounts of soil organic matter, whereas I did not study the quality of soil organic matter in detail. Therefore, it is still an open question whether the quality of soil organic matter or the context under which it operates, can improve the benefits of soil organic matter on ecosystem services and yield. 


\section{Nederlandstalige samenvatting}

De oogst in de landbouw wordt beïnvloed door verschillende ecosysteemdiensten. Die ecosysteemdiensten zijn er bovengronds, zoals bestuiving door bijen en zweefvliegen, maar ook ondergronds, zoals mineralisatie door bodemorganismen die organische stof afbreken. Het is nog onduidelijk hoe deze ecosysteemdiensten elkaars invloed op de oogst beïnvloeden. In dit proefschrift onderzoek ik hoe organische stof in de bodem invloed heeft op het effect van verschillende bovengrondse ecosysteemdiensten. Ik heb gekeken of organische stof het effect van bestuiving en natuurlijke bestrijding van bovengrondse plantenetende insecten op de oogst beïnvloedt en of dit effect verandert wanneer er kunstmest wordt gebruikt.

Er is een wisselwerking tussen gewassen en verschillende boven- en ondergrondse factoren die de oogst sturen. De laatste jaren is steeds duidelijke geworden dat bovengrondse factoren - zoals bestuiving, vraat door insecten en predatie van die insecten - en ondergrondse factoren - zoals het beschikbaar komen van voedingsstoffen uit organische stof - met elkaar samenhangen. Meer voedingsstoffen in de bodem zorgen bijvoorbeeld voor een andere chemische samenstelling in de stengels en bladeren van het gewas, wat vervolgens weer mede bepaalt hoe goed plantenetende insecten het bovengronds doen. Ook biotische processen, zoals een infectie met arbusculaire mycorrhizaschimmels of vraat aan wortels kunnen de chemie van het gewas en daarmee de performance van bovengrondse herbivoren beïnvloeden. Als we begrijpen hoe deze interacties tussen de boven- en de ondergrond precies werken in agrarische systemen, kunnen we deze kennis gebruiken om de oogst op duurzame wijze te vergroten.

Organische stof is belangrijk in de landbouw. Bijvoorbeeld omdat bodemorganismen het kunnen mineraliseren tot voedingsstoffen die door de plant kunnen worden opgenomen, maar ook omdat het interacties tussen de planten en insecten kan beïnvloeden. Voedingsstoffen in organische stof, zoals stikstof, fosfor en kalium, zijn namelijk essentieel voor de groei van planten. Maar met het beschikbaar komen van extra voedingsstoffen, verandert ook de chemie van de plant en als gevolg daarvan de aantrekkingsdracht op bovengrondse plaaginsecten. Omdat ongeveer de helft van de organische stof in de bodem uit koolstof bestaat, zorgt het vergroten van het gehalte organische stof 
ook voor minder koolstofdioxide $\left(\mathrm{CO}_{2}\right)$ in de lucht. Verder zorgt meer organische stof voor een betere bodemstructuur, waardoor plantenwortels beter kunnen groeien en de bodem meer vocht vast kan houden. Ook kan meer organische stof de onderdrukking van ziekten in de bodem bevorderen. Tijdens mijn promotietraject heb ik verschillende experimenten uitgevoerd om na te gaan hoe organische stof in de bodem de interacties tussen de boven- en ondergrond beïnvloedt.

Met een kasexperiment (Hoofdstuk 2) heb ik gekeken of organische stof in de bodem invloed heeft op het effect van kunstmest en de introductie van de ziektenverwekkende bodemschimmel Rhizoctonia solani. Ik onderzocht of deze factoren invloed hebben op de biomassa van zomertarwe (Triticum avenae) en op de grote graanluis (Sitobion avenae) die we op deze planten hebben gekweekt. Daarnaast had ik een aantal extra potten met veel of weinig organische stof gesteriliseerd en daarin al of niet de pathogene bodemschimmel geïntroduceerd. Ik kon hierdoor testen of het effect van organische stof afhangt van de aanwezigheid van bodemorganismen. Ik ontdekte dat $R$. solani inderdaad een invloed heeft op de biomassa van tarwe en bladluizen, maar dat dit effect afhangt van de aanwezigheid van andere bodemorganismen, de hoeveelheid organische stof in de bodem en het al of niet toedienen van kunstmest. Deze resultaten laten zien dat organische stof in de bodem een rol kan spelen in interacties tussen de boven- en de ondergrond.

In een ander kasexperiment (Hoofdstuk 3) heb ik getest of het toedienen van kunstmest en de hoeveelheid organische stof in de bodem invloed heeft op het effect van droogtestress op de biomassa van de grote graanluis op zomertarwe. Ik ontdekte dat het toedienen van kunstmest de biomassa van bladluizen positief beïnvloedt, maar dat deze effecten sterker waren wanneer het gehalte organische stof hoger was of wanneer de planten voldoende water kregen. De resultaten van dit experiment suggereren verder dat de relatieve effecten van droogtestress kleiner zijn als een plant geïnfecteerd is met bladluizen.

Beide experimenten uit de hoofdstukken 2 en 3 werden uitgevoerd onder gecontroleerde omstandigheden, in potten en in een kas. Om na te gaan wat organische stof doet onder veldomstandigheden, heb ik in Hoofdstuk 4 paren van tarwepercelen gezocht die contrasteren in hun hoeveelheid organische stof. Ik zocht dus steeds een perceel met een hoog gehalte organische stof en 


\section{Nederlandtalige samenvatting}

een ander perceel dat vergelijkbaar was in andere bodemcondities, maar een lager gehalte organische stof had. In al deze percelen maakte ik twee proefvlakken: één met kunstmest en één zonder. Ik bekeek hoe deze factoren invloed hadden op de mineralisatie van stikstof, fosfor en kalium, op de performance van bladluizen en hun vijanden en op de tarweoogst. Onder deze realistische omstandigheden bleek het dat organische stof een heel klein effect had op de tarweoogst. Verder was er een overall positieve relatie tussen organische stof en stikstofmineralisatie. Maar als ik de gepaarde percelen met elkaar vergeleek in een factoriële analyse, dan bleek dat percelen met een relatief hoog gehalte organische stof niet meer stikstofmineralisatie hadden dan vergelijkbare percelen met een laag gehalte organische stof. Verder bleek dat een hogere stikstofmineralisatie gerelateerd is aan een kleiner positief effect van kunstmest op de tarweoogst. Insecten op de tarwe werden nauwelijks beïnvloed door het gehalte organische stof. Een hoger gehalte organische stof leek samen te hangen met minder bladluizen indien kunstmest was toegediend, maar er was geen effect op de parasitismegraad van deze bladluizen of op de aantallen loopkevers die bladluizen eten. Ik concludeer daarom dat onder veldomstandigheden het effect van organische stof misschien veel kleiner is dan wordt gesuggereerd in de literatuur.

Niet alle ecosysteemdienten die de gewasoogst beïnvloeden opereren op dezelfde ruimtelijke schaal. De populatiedynamiek van wilde bijen, zweefvliegen en plaaginsecten, worden bijvoorbeeld voor een groot gedeelte beïnvloed door het landschap rondom een landbouwperceel. Interacties in de bodem, zoals het mineraliseren van organische stof, zijn echter afhankelijk van lokale bodemcondities en niet echt door het landschap eromheen. Met een semi-veldexperiment (Hoofdstuk 5) heb ik gekeken of het gehalte organische stof en het toedienen van kunstmest

een ander effect heeft op de oogst van koolzaad (Brassica napus), als de plaagdruk of het aantal bestuivers in het landschap anders is. Om dit te testen, heb ik planten laten groeien in grote potten met grond met een hoog of een laag gehalte organische stof en met kunstmest en zonder kunstmest. Ik plaatste deze planten in verschillende landschappen die varieerden in het aantal bloembezoeken en de druk aan plaaginsecten. Ik ontdekte dat bestuiving en plagen een groot effect hadden op de oogst van koolzaad. Ook het toedienen van kunstmest had een groot effect, maar er was geen effect van de 
verschillende hoeveelheden organische stof in de bodem. Verder zag ik dat de bodemomstandigheden het effect van bestuiving en plaagdruk op de oogst niet veranderen. Uit dit experiment concludeer ik dat processen die plaatsvinden op landschapsschaal (bestuiving en plaagdruk) niet noodzakelijkerwijs het effect van bodemcondities (organische stof in de bodem of kunstmest) op de oogst beïnvloeden.

Naast ruimtelijke processen, kunnen ook temporele processen de oogst beïnvloeden. Het effect van organische stof bijvoorbeeld zou sterker kunnen worden naar mate de bodem langer biologische wordt beheerd zonder chemische pesticiden en kunstmest. In Hoofdstuk 6 heb ik grond verzameld van gangbaar beheerde percelen en van percelen die korter of langer biologisch beheerd werden. Ik ontdekte dat biologisch beheer niet zorgde voor meer organische stof en dat de microbiële gemeenschap nauwelijks anders was dan in de bodem van gangbaar beheerde percelen. De duur van dat biologische beheer had geen enkel effect op de bodemgemeenschap. In een kasexperiment met deze grond keek ik vervolgens of (de duur van) biologisch beheer invloed heeft op de biomassa van tarwe en het aantal grote graanluizen op deze planten. Ik ontdekte dat bodems met een hoger percentage organische stof ook meer biomassa aan tarwe produceerden. Maar tarwebiomassa was hoger op bodems die gangbaar beheerd werden, terwijl bladluizen het juist beter deden op biologisch beheerde bodem. Ook hier kon ik geen effect zien van de duur van dit biologische beheer.

Deze verschillende experimenten lieten mij zien dat er soms een positief effect van organische stof op de biomassa van gewassen te zien is, maar dat dit effect niet consistent is. Mijn proefschrift levert daarom geen sterk bewijs dat een hoger gehalte organische stof onontbeerlijk is voor het verbeteren van nutriëntenbeschikbaarheid en andere ecosysteemdiensten zoals bovengrondse plaagbestrijding. Daarnaast zag ik dat processen die plaatsvinden op een andere temporele of ruimtelijke schaal de effecten van organische stof niet veranderen. In mijn proefschrift heb ik vooral gefocust op verschillende hoeveelheden organische stof, maar ik heb niet in detail gekeken naar de kwaliteit van die organische stof. Het is daarom nog een open vraag of de kwaliteit van de organische stof of de context waaronder organische stof wordt verhoogd, ecosysteemdiensten en oogst kan verbeteren. 


\section{Acknowledgements}

When I first entered the Netherlands Institute of Ecology (NIOO), I could not believe I would ever work there. For my master program, I could do a 'few day internship', and after my visit at NIOO I was highly impressed. Such an impressive and sustainable building, such an impressive track record of scientific publications, such a wonderful atmosphere. I remember that I, even on paper, described NIOO as "too perfect, not suitable for me".

However, there are no certainties in life and perspectives and opportunities may rapidly change. On a late evening, I noticed a job offer I could not ignore and even though I noticed that I was too late to apply, I wrote an email. To my surprise, a bit later, I was invited for an interview at the fabulous NIOO.

This interview went terribly wrong. I had a radically different understanding of the project and after 15 minutes of failure Wim van der Putten said: "I think we know enough, do you still have a question?". Well, this was my very last chance to improve my impression and I asked as much as I could. The interview continued for another 20 minutes. Afterwards I felt demolished. Although these 20 minutes were a bit better, I was even more sure that the NIOO was too perfect and not suitable for me.

Now I am looking back on a four years $\mathrm{PhD}$ trajectory at $\mathrm{NIOO}$, the prestigious institute belonging to the Royal Netherlands Academy for Arts and Science (KNAW). I met many great friends and I was extremely proud to be part of such an amazing community with people from all over the word. It was, without a doubt, the best time of my life.

Well, for two years...

After that, I started to doubt my own research approaches and the usefulness of my work. I gradually discovered that academia does not suit me and that it is an environment I wanted to leave as quickly as possible. In the mornings, I started my computer in a hopeless mood without any energy. In the evening, I closed my computer, knowing that my $\mathrm{PhD}$ would take at least two years more. 
These two years after were hard and difficult. Without the support and patience of the people around me I would not have been able to defend and I am more than grateful for this support.

First of all, I would like to thank all the farmers (and in some cases terrain managers) I worked with. With some I had nice and long conversations about agriculture, natural processes and science. I would like to thank you all (as I often worked with whole families, I only mention the family name):

Siepel, van Vilsteren, Kroon, van Woerkom, Wall, van den Hoven, van Balen, Visser, Bongers, Breunissen, van de Westeringh, van der Woerd, Quist, Rozendaal, van Boxmeer, Roessink, Melgers, van de Bool, van Lierop, Tielen, Huiberts, Visser, Santing, Hamelink, Vos, MarisSchreuders, Zeelenberg, van Doorn, Nieuwelink, Vos, Dibbits, Meersma-Antonis, Huijs, de Krom, Peeters-Meertens, Kramer, van Zelderen, Vredevoogd, van de Bool, van de Groes.

My apologies for the people I forget to mention here. I also would like to thank a farmer of whom I do not know his name. My apologies for accidently using your land and thanks for still giving me permission to use your land.

Then, I want to thank Wim van der Putten and David Kleijn, my supervisors. They provided valuable feedback and allocated time for me when needed even though they are both incredibly busy. David, I would like to thank you for the meetings we had. I am impressed by the way you are able to keep complicated things simple and how you extract clear conclusions from field data. I learned a lot from our meetings. I also want to thank you for your patient help when I wrote my first paper. I found (find) scientific writing extremely difficult and your feedback definitely helped me a lot. Wim, thanks for sharing your insights and vision. It gave me a better understanding in how the world functions and I think it makes me more effective.

The working style of Wim and David had always been different. To put it in absurd extremes: David does not care about mechanisms or concepts, but he cares about the relevance of a finding under realworld conditions, whereas Wim's approach is the other way around. These different visions were both frustrating as well as insightful. Looking back on it, it was especially insightful. Thanks. 


\section{Acknowledgements}

Subsequently, I would like to thank Minggang Wang, with whom I shared an office throughout my whole PhD. Minggang, you are incredibly sharp. And you are able to provide critical feedback in the form of funny comments that have an excellent sense of humour which puts everything in perspective. Throughout the difficult moments of my PhD you made that I kept enjoying the NIOO. To be honest, your jokes even became part of my own identity. I never told you, but I found my previous girlfriend, just by repeating the conversations I had with you. Okay, this relationship was not entirely successful - "I also think it must be very hard to maintain a relationship with you", you said when it ended - but it shows the power of your humour and personality. I hope you will always keep your spontaneous and disarming attitude and I wish you all the best for the rest of your life.

Then, thanks to my paranymps: Eke Hengeveld and Ruth Schmidt. Eke, I do not know anyone who is more kind and helpful than you. Even before I had a practical problem with experiments, you came already with a clever and original solution end emotionally you were always of support. Ruth, thanks for our friendship and all the conversations we had. You made that I understand myself better and your trust in me, makes that I trust myself a bit more.

Moreover, there are many more friends from NIOO that I would like to thank:

Lysanne, the way you care about the world and nature, makes that I always feel inspired when I talk with you. Thanks for that. I wish you a dynamic but peaceful future.

Jasper, thanks for sharing doubt both in life and work. You are extremely clever, combined with a strong vision.

Minghui, you are a strong personality. Thanks for being a friend and for your trust. I wish you all the best, both in work and career.

Jeff, thanks for your discussions about context dependency and ecological realism. Sometimes it takes a bit too much time, but it is a pleasure to listen to you and to learn from you view on the world. 
Louise, thanks for involving me in the communication of NIOO and your clear vision on sustainability. It still inspires me and I hope I can use your vision in my further career. I was nice to work with you.

Maarten, thanks for your help in the first phase of my experiment. You are for quite a bit the type of person I want to become.

Roeland, thanks for the poems and for sharing your ability to enjoy life. I also want to become a bit like you.

Gerard, thanks for the collaboration and the discussions about applied research near the coffee machine.

Marta Manrubia, thanks for the good conversations we had. You are honest and caring, and you have a convincing way of being happy.

Marta Alirangues, I like your vision on the world and I hope the world becomes a bit closer to your vision.

Olga, it was an honour to work in the field with you. Thanks for your help with statistics and your caring personality.

Olaf, thanks for the help with the Rhizoctonia experiment. And for the conversations in which you were always correct and friendly. It is a pleasure to talk with you.

Maaike, thanks for all the conversations you had and for your creativity. And thanks for your help with the Rhizoctonia experiment.

Paolo, thanks for your humour and for being my housemate. Also, thanks for the nice dishes you cooked, with or without Sui.

Sui, thanks for the nice food and your almost dark humour.

Sam, thanks for your enthusiasm and care.

Lucille, it is an honour to know you. 


\section{Acknowledgements}

Joost, actually I do not even know you well. But when I talk with you I have the feeling you immediately understand me. Thanks!

Haikun and Sigrid, thanks for being a nice office mate and for your help with experiments.

Moreover, I want to thank: Ana, Arjen, Basten, Carolin, Ciska Raaijmakers, Ciska Veen, Cong, Elly, Feng, Freddy, Gera, Kadri, Kelly, Koen, Lucia, Martijn, Martine Huberty, Martine Kos, Pella, Robin, Roel, Roxina, Rutger, Sabrina, Stefan, Tanja, Viola and all other nice colleagues from Terrestrial Ecology I am (hopefully not) forgetting.

From Aquatic Ecology, Animal Ecology, Microbial Ecology, and Facilities I also would like to thank:

Ellen, Wolf, Lisette, Dedmer, Michiel, Bart, Tania, Antica, Luuk, Sven, Thijs, Jan, Antonella, Laura, Mandy, Peiyu, Wei, Libin, Kimberly, Nico, Erik, Wietse, Paolina, Annelies, Kristin, Sytske, Kay, Thiago, Femke, Marlies, Iris, Roos, Davide, Thoma, Rascha, Jip, Marylou, Martijn, Peter, Susanne, Marjolein, Gerda, Els, Ed, Hans, Gerben, Roy, Victor, Marianne, Froukje, Brechje, Monique, Perro, Ninke, Elly, Dick, Gerrie, Wim, Gregor, Gilles and Jeroen. Maybe I forget some people here as well.

I also would like to thank the students that I could supervise. Christian, it was great to work with you. You did a good job and I hope your work at NIOO helps a bit with your further career. Jorge, without you, I would never have been able to finish the field work. You were honest, hard-working and a nice person to work with. Martina, thanks for writing your thesis with me. You did an awesome job and I wish you all the best with the rest of your career.

In addition I would also like to thank the 'one day internship' students from plant sciences and forest and nature conservation of Wageningen University. I enjoyed a lot to have you around for one day. Also thanks to my students in the course Ecology 1: thanks for your enthusiasm. Teaching to you was one of the nicest aspects of my $\mathrm{PhD}$.

Moreover, I would like to thank a few collaborators from outside NIOO: 
Arjen, thanks for the discussions about applied and science with societal impact. And thanks for the collaboration in joint experiments.

Wim, Dennis and Ruud, thanks for the collaboration in the field. And thanks for showing the high efficiency one (not me) could reach in performing field experiments.

Giovanni, it was a pleasure to work with you. I always enjoyed our discussions, also when it got almost fanatic.

Nacho, thanks for your enthusiasm and inspiration. It was an honour to visit your lab in Seville.

I also want to thank all other collaborators in the EU Seventh Frame Liberation project, that funded my PhD, including: Riccardo, Ingolf, Sarah, Mark, Lorenzo, Audrey, Erika, and Samuel.

Gerlinde, thanks for you humour and the good conversations we had.

There are also a few people from outside academia I would like to acknowledge.

I got a lot of support from the editors of Resource, the magazine for student and employees of Wageningen U\&R. I am not sure, but maybe I would not have finished my PhD if I would not have had my column in Resource to complain from time to time my PhD. I especially would like to thank Albert. On a rainy evening (at a moment I did not had jacket with me) he offered me a beer. Half an hour later I had (again) a column in Resource. I also want to thank Lieke. She is the nicest editor I ever had and I learned a lot from her. And Edwin, for sharing his thoughts. Thanks Henk, for designing the cover.

I also would like to thank Robbert Wijers. It was always relaxing to run with you in the weekends. You gave me energy and helped me to put everything into perspective. Your advices for my next steps are also very important. Thanks for convincing me to run a marathon. It convinced me to finish a $\mathrm{PhD}$ as well.

Arthur, you helped me a lot with simple conversations and you are always able to show me what really counts in live. I feel sorry that I had such a limited amount of time for you. 


\section{Acknowledgements}

Arjen Boerman, sometimes I feel a bit lost. I started with practical education and ended up in academic research. I sometimes feel unrooted from the connections I had with the practical world, while not fully rooted in the academic world. However, when I talk with you I still feel the connection with the more practical level. Thanks for that.

Huub Smits, you are probably the most important teacher I had. Not just for the lessons you gave, but even more because of the trust you had in me. Thanks to you

And then, there are many more people I have to acknowledge. Journalists I work with, such as Alexandra Branderhorst and Reinout Burgers. People from places where I worked before, such as Brabants Landschap. Thanks a lot for getting me where I am now.

Anna, thanks for showing me the world with different eyes. For showing me the beauty of different colours of the sky, the flowers, paintings and anything else.

Finally, I want to thank my family for the unlimited support they gave. Thanks to my brother, Freek, for checking the endless amount of poorly written English. Thanks to my sister, Maud, for your support and care. Thanks to my father, Peter, for being able to just be happy with what you have. Thanks to my mother, Yvonne, for taking care of everything, but please, please also take care of yourself. 


\section{Affliation of co-authors}

Giovanni Tamburini

DAFNAE-Entomology, University of Padova, Padova, Italy

Lorenzo Marini

DAFNAE-Entomology, University of Padova, Padova, Italy

Arjen Biere

Department of Terrestrial Ecology, Netherlands Institute of Ecology (NIOO-KNAW), Wageningen, The Netherlands

Maaike van Agtmaal

Department of Microbial Ecology, Netherlands Institute of Ecology (NIOO-KNAW), Wageningen, The Netherlands

Department of Life Sciences (Silwood Park), Imperial College London, London, United Kingdom

Olaf Tyc

Department of Microbial Ecology, Netherlands Institute of Ecology (NIOO-KNAW), Wageningen, The Netherlands

\section{Martine Kos}

Department of Terrestrial Ecology, Netherlands Institute of Ecology (NIOO-KNAW), Wageningen, The Netherlands

\section{David Kleijn}

Plant Ecology and Nature Conservation Group, Wageningen University and Research, Wageningen, The Netherlands

Animal Ecology Team, Alterra - Wageningen University and Research, Wageningen, The

Netherlands

Resource Ecology Group, Wageningen University and Research, Wageningen, The Netherlands

Wim H. van der Putten

Department of Terrestrial Ecology, Netherlands Institute of Ecology (NIOO-KNAW), Wageningen, The Netherlands

Laboratory of Nematology, Wageningen University and Research, Wageningen, The Netherlands

Jorge Martín Rodríguez

Department of Terrestrial Ecology, Netherlands Institute of Ecology (NIOO-KNAW), Wageningen, The Netherlands

Sarah Redlich

Department of Animal Ecology and Tropical Biology, University of Würzburg, Würzburg, Germany

Michael P. D. Garratt

Centre for Agri-Environment Research - School of Agriculture, Policy and Development, University of Reading, Reading, United Kingdom

\section{Zoltán Elek}

Lendület Ecosystem Services Research Group, MTA Centre for Ecological Research, Vácrátót, Hungary

MTA-ELTE-MTM Ecology Research Group, Eötvös Loránd University, Budapest, Hungary

\section{Gergely Boros}

Lendület Ecosystem Services Research Group, MTA Centre for Ecological Research, Vácrátót, Hungary 
Affiliation of co-authors

\section{András Báldi}

Lendület Ecosystem Services Research Group, MTA Centre for Ecological Research, Vácrátót, Hungary

\section{Emily A. Martin}

Department of Animal Ecology and Tropical Biology, University of Würzburg, Würzburg, Germany

\section{Ingolf Steffan-Dewenter}

Department of Animal Ecology and Tropical Biology, University of Würzburg, Würzburg, Germany

\section{Simon G. Potts}

Centre for Agri-Environment Research - School of Agriculture, Policy and Development, University of Reading, Reading, United Kingdom

\section{Vesna Gagic}

Department of Ecology, Swedish University of Agricultural Sciences, Uppsala, Sweden

\section{Arjen de Groot}

Animal Ecology Team, Alterra - Wageningen University and Research, Wageningen, The Netherlands

\section{Gerard W. Korthals}

Department of Terrestrial Ecology, Netherlands Institute of Ecology (NIOO-KNAW), Wageningen, The Netherlands

Wageningen Plant Research, Wageningen University and Research, Wageningen, The Netherlands

Wietse de Boer

Department of Microbial Ecology, Netherlands Institute of Ecology (NIOO-KNAW), Wageningen, The Netherlands

Department of Soil Quality, Wageningen University and Research, Wageningen, The Netherlands 


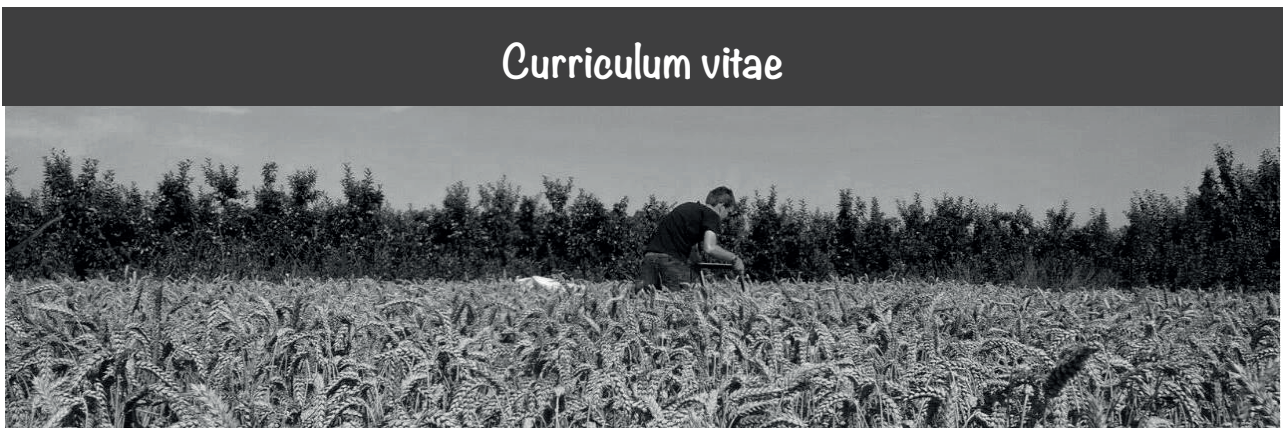

Stijn van Gils was born in Breda at April the $13^{\text {th }} 1987$ and moved afterwards to Waddinxveen and Uden. At school he performed poorly and the expectation was that he would never be able to finish any type of high school. Nevertheless, he had one goal: becoming a forest keeper.

After attending primary school and high school (vmbo) he went to the practical forestry school (Helicon MBCS Velp) where he learned how to drive tractors, how to cut a tree and how to manage nature areas and forests. Although he knew pretty well, how the practical work could work in theory, he lacked the practical skills to do so. As a result he continued with his studies with an applied bachelor at Van Hall Larenstein University of Applied Sciences, which was part of Wageningen University \& Research Centre (WUR) at that time.

During his bachelor he became a columnist and later journalist for the WUR magazine Resource. Gradually he expanded his freelance writing work. Due to his work for the WUR magazine, he also got to know Wageningen University itself. He noticed that people at a university were not that different, and decided to do a master in forest and nature conservation.

After his master he shortly worked at the regional nature conservation organization Brabants Landschap combined with freelance work, but he missed an international environment. In 2013 he found a PhD in agro-ecology at the Netherlands Institute of Ecology. Here, he missed having shortterm projects and to work on topics with a direct societal impact.

Now he is self-employed. He is expanding his writing work and he tries to deliver work that is constructive and critical and of a contribution to a sustainable society.

See www.stijnvangils.nl for more information and publications. 


\section{PE\&RC Training and Education Statement}

With the training and education activities listed below the PhD candidate has complied with the requirements set by the C.T. de Wit Graduate School for Production Ecology and Resource Conservation (PE\&RC) which comprises of a minimum total of 32 ECTS ( $=22$ weeks of activities)

\section{Review of literature (5 ECTS)}

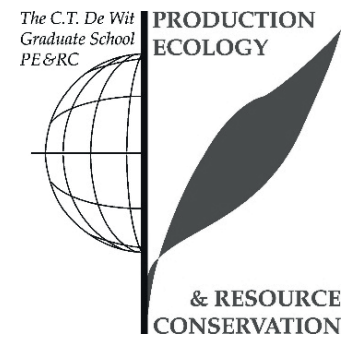

- Trade-offs between interacting services for major European crops

- Er zíjn grenzen: naar een circulaire economie: afkijken van de natuur; wetenschappers willen schimmellandbouw; wel of geen pesticiden, het ligt genuanceerd; eten uit een speculatielandschap

\section{Post-graduate courses (3.6 ECTS)}

Mixed Linear Models (2014)

Bugs at your service (2015)

Soil Ecology and the Planetary Boundaries (2016)

\section{Laboratory training and working visits ( 2 ECTS)}

- Visit to EBD-CSIC; Doñana Biological Station, Seville (2016)

\section{Invited review of (unpublished) journal manuscript (3 ECTS)}

- Journal of Ecology: nectar robbers and aphids (2015)

- Perspectives in Plant Science: root signals (2016)

- Nature Ecology \& Evolution: cascading impacts of land use change (2016-2017)

\section{Deficiency, refresh, brush-up courses (3 ECTS)}

Identification of terrestrial and freshwater nematodes for ecologists / environmentalists (2013)

\section{Competence strengthening / skills courses (3.4 ECTS)}

- Competence assessment; WGS (2013)

- $\quad$ Course on data management; WGS (2014)

- $\quad$ Ethics and Philosophy in Life Sciences (E\&P LS) (2015)

- Techniques for Writing and Presenting a Scientific Paper (TWP) (2015)

\section{PE\&RC Annual meetings, seminars and the PE\&RC weekend (1.5 ECTS)}

- $\quad$ PE\&RC Day (2014-2015)

- PE\&RC Midterm weekend (2016)

\section{Discussion groups / local seminars / other scientific meetings (7 ECTS)}


International symposia, workshops and conferences (8.5 ECTS)

- Netherlands Annual Ecology Meeting; oral presentation 2014 and 2017; Lunteren, the Netherlands

(2013-2017)

- EcoSummit; Montpellier, France (2016)

- $\quad$ BES Meeting; Liverpool, United Kingdom (2016)

\section{Lecturing / supervision of practicals / tutorials (3 ECTS)}

- $\quad$ Assisting in an ecology course related to Terrestrial Ecology (NIOO) or REG (2014-2016)

\section{Supervision of a MSc student}

- Effects of organic soil management and root herbivory on pollinator visitation rate and seed production in Sinapis alba 
The research described in this thesis was carried out at the Department of

Terrestrial Ecology of the Netherlands Institute of Ecology (NIOO-KNAW) in

Wageningen. The project was funded by the European Community Seventh Framework Program (grant no. 311781), LIBERATION (www.fp7liberation.eu).

Cover illustration: Henk van Ruitenbeek | www.henkvanruitenbeek.nl

Design: Tim Jacobs - Identim | www.identim.nl

Printing: Digiforce | www.proefschriftmaken.nl

This is NIOO thesis number 141. 